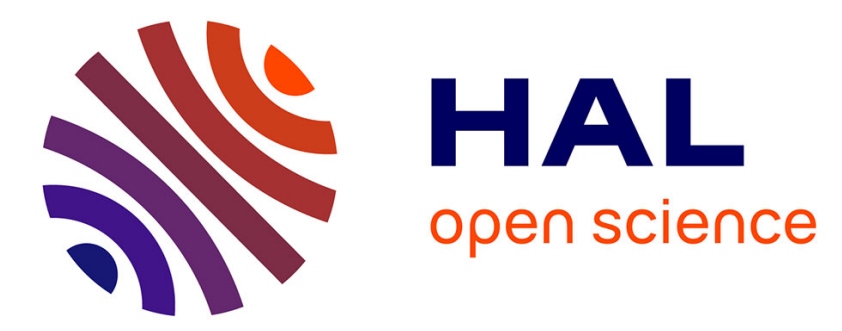

\title{
Femmes de Sasaguri: au fond du religieux et à l'ubac du séculier
}

\author{
Yoriko Kanda, Masako Tanigawa, Anne Bouchy
}

\section{To cite this version:}

Yoriko Kanda, Masako Tanigawa, Anne Bouchy. Femmes de Sasaguri: au fond du religieux et à l'ubac du séculier. Cahiers d'Extrême-Asie, 2013, no. 22, p. 547-606. 10.3406/asie.2013.1425. halshs-03134733

\section{HAL Id: halshs-03134733 \\ https://shs.hal.science/halshs-03134733}

Submitted on 8 Feb 2021

HAL is a multi-disciplinary open access archive for the deposit and dissemination of scientific research documents, whether they are published or not. The documents may come from teaching and research institutions in France or abroad, or from public or private research centers.
L'archive ouverte pluridisciplinaire HAL, est destinée au dépôt et à la diffusion de documents scientifiques de niveau recherche, publiés ou non, émanant des établissements d'enseignement et de recherche français ou étrangers, des laboratoires publics ou privés. 


\title{
Femmes de Sasaguri : au fond du religieux et à l'ubac du séculier Yoriko Kanda, Masako Tanigawa, Anne Bouchy
}

\begin{abstract}
The present article analyzes the narratives by women who are not shown on the center stage of history. Though they are the living witness of the age and the locality, and support the traditions, are not recorded in written documents.

In Sasaguri, there are women who come from the outside, attracted by the religious pole of the sacred places, and obtain there religious powers. Those who come to visit them are not only pilgrims, but also their personal believers. The supreme authority in Sasaguri, the abbot of Nanzō-in, is supported by his wife. She pulled him out to the secular position of "husband", while he remains the religious authority. Another woman born and raised in Sasaguri, the wife of the abbot of Chizuru-ji, is a secular person in supporting her religious husband, but at the same time, being the daughter of parents, both charismatic religious persons, who came to Sasaguri from the outside, she fully inherited their subtle power, and is on the point of making her religious power bloom inside her native town.

Women who lived and worked in the coal mines of Meiji Takata Industry until the beginning of the 1960s were at the same time female workers who had came there from the outside, and central beings of the inside, since they were wives of workers' families. There were also prostitutes who worked there. They constituted the inside of the secular world needed by mine workers, but also the outside of the outside, as discriminated women.

Through the eyes and actions of these women, the article attempts to describe the complex interactions of dynamics between outside and inside, and sacred and secular.
\end{abstract}

\section{Citer ce document / Cite this document :}

Kanda Yoriko, Tanigawa Masako, Bouchy Anne. Femmes de Sasaguri : au fond du religieux et à l'ubac du séculier. In: Cahiers d'Extrême-Asie, vol. 22, 2013. Le vivre ensemble à Sasaguri, une communauté de Kyūshū. Dans l'entrelacs des dynamiques du dedans et du dehors. pp. 547-606;

doi : https://doi.org/10.3406/asie.2013.1425

https://www.persee.fr/doc/asie_0766-1177_2013_num_22_1_1425

Fichier pdf généré le 06/02/2019 


\title{
Femmes de Sasaguri : AU FOND DU RELIGIEUX ET À L'UBAC DU SÉCULIER
}

\author{
KANDA Yoriko 神田より子
}

\begin{abstract}
The present article analyzes the narratives by women who are not shown on the center stage of history. Though they are the living witness of the age and the locality, and support the traditions, are not recorded in written documents.

In Sasaguri, there are women who come from the outside, attracted by the religious pole of the sacred places, and obtain there religious powers. Those who come to visit them are not only pilgrims, but also their personal believers. The supreme authority in Sasaguri, the abbot of Nanzo-in 南藏院, is supported by bis wife. She pulled bim out to the secular position of "busband," while be remains the religious authority. Another woman born and raised in Sasaguri, the wife of the abbot of Cbizuru-ji 千鶴寺, is a secular person in supporting ber religious busband, but at the same time, being the daughter of parents, both charismatic religious persons, who came to Sasaguri from the outside, she fully inberited their subtle power, and is on the point of making ber religious power bloom inside ber native town.

Women who lived and worked in the coal mines of Meiji Takata Industry 明治高田工業所 until the beginning of the 1960 s were at the same time female workers who bad came there from the outside, and central beings of the inside, since they were wives of workers' families. There were also prostitutes who worked there. They constituted the inside of the secular world needed by mine workers, but also the outside of the outside, as discriminated women.

Through the eyes and actions of these women, the article attempts to describe the complex interactions of dynamics between outside and inside, and sacred and secular.
\end{abstract}

Partant de l'approche de deux faces de la vie de Sasaguri 䉒栗, petite commune du nord de Kyūshū, la présente contribution se propose d'examiner la façon dont les femmes ont participé à la vie de la société japonaise moderne. Il s'agit, d'une part, de la relation des femmes au Nouveau pèlerinage de Shikoku à Sasaguri (Sasaguri shin Shikoku Reijo 篠栗新四国霊場), qui tient une place essentielle dans l'histoire et l'économie de Sasaguri, et, d'autre part, du rôle des femmes dans les mines de charbon qui furent l'un des pôles majeurs de l'industrie japonaise entre la fin du XIX ${ }^{e}$ siècle et les années 1950. Après avoir donné un aperçu de l'histoire du nord de Kyūshū, dont fait partie Sasaguri, nous envisagerons le statut de la femme dans le contexte de la société locale.

Sasaguri est aujourd'hui regardé comme un quartier résidentiel, commode et calme, auquel accèdent en 20 minutes de train tous ceux qui y résident et travaillent à Hakata 博多, principale grande ville du nord de Kyūshū. Pour éclairer l'histoire de cette région, je situerai dans un premier temps les données de terrain actuelles 
par rapport au continent asiatique voisin. Cette proximité avec l'Asie peut être facilement perçue lorsqu'on monte jusqu'au sommet du mont de Kome domine Sasaguri. De là, on a sous les yeux la baie de Hakata 博多湾 et la mer de Genkai 玄界灘, toutes proches. Cette situation particulière, à l'origine d'un certain nombre d'éléments marquants de l'histoire locale, a contribué à forger la mentalité de la population du nord de Kyūshū.

Cette relation de proximité avec l'Asie remonte à l'Antiquité et s'est établie par le biais de la baie de Hakata. C'est ce qu'attestent des bronzes coréens, ainsi que le sceau du bloc en or du « Roi du pays japonais de Na des Han » (Kan no Na no Wa no Kokuō 漢倭奴国王), mis à jour par des fouilles au nord de Kyūshū. Les bronzes furent fabriqués vers 450-400 avant notre ère. Le sceau fut donné en 57 par l'empereur Guangwu-di (Kōbu tei 光武帝) à l'envoyé du pays de $\mathrm{Na}$, nom du Japon d'alors. Cet envoyé apportait des présents à Luoyang (Rakuyō 洛陽), capitale des Han postérieurs (Gokan 後漢). Au début du viII ' siècle, avec l'établissement des codes (ritsuryō 律令) sur le modèle chinois, le gouvernement fit construire au nord de Kyūshū un centre diplomatique, Dazai-fu 大萃府. Du viII au XII ${ }^{\mathrm{e}}$ siècle, c'est de la baie de Hakata que partirent tous les envoyés du Japon vers les monarques des Sui (Zui 隋), des Tang (Tō 唐) et de Silla (Shiragi 新羅). Hakata devint ainsi la porte d'entrée de la culture asiatique. Au XIII' siècle, la Mongolie, empire mondial, tenta par deux fois d'envahir Hakata. Mais à la fin du XVI ${ }^{e}$ siècle, Toyotomi Hideyoshi 豊臣秀吉 (I537-I598), alors à la tête du Japon, déclara la guerre aux pays voisins, l'archipel des Ryūkyù 琉球, les Indes, les Philippines. Il leva une armée de dizaines de milliers de soldats et voulut soumettre la Corée, en vue d'envahir par la suite la Chine des Ming. Au XVII ${ }^{e}$ siècle, les paysans de Nagasaki 長崎 se révoltèrent contre leur lourd impôt et contre l'interdiction du christianisme imposée par le bakufu 幕府 des Tokugawa 徳川 : c'est ce qu'on appelle la Révolte de Shimabara (Shimabara no ran 島原の乱, I637-I638), après quoi le commerce avec les pays étrangers fut strictement interdit au Japon. Il ne fut autorisé que dans l'île de Dejima 出島 rattachée à Nagasaki, et ce, uniquement avec les Pays-Bas et la Chine. Â partir du XIX siècle, l'apparition de navires étrangers près des côtes du Japon, ainsi que la défaite de la Chine face à l'Angleterre dans la guerre de l'Opium (I840-1842), suscitèrent l'émergence du discours sur l'importance de la défense nationale. Mais lorsque le bakufu des Tokugawa en I868 fut renversé, et que fut mis en place le nouveau gouvernement de Meiji 明治 (1868-1912), les échanges avec l'étranger furent rétablis ${ }^{1}$.

Le nord de Kyūshū a donc été et reste une région ouverte sur le debors, c'està-dire sur l'autre côté de l'espace maritime. Aussi y règne-t-il un climat favorisant l'accueil des gens venant d'ailleurs, dont nous avons nous-mêmes pu bénéficier au cours de notre travail. Au sein d'un tel environnement, les hommes n'ont cessé, tout au long de l'histoire, de traverser la mer dans les deux sens. Mais qu'en a-t-il été pour les femmes?

Selon Gary P. Leupp, « de l'année 1619 à l'année 1655, on a enregistré à Batavia 17 cas de mariages entre des Européens et des femmes japonaises ou ayant du sang

I. Kawazoe Shōji 川添昭二 et al., éd., Fukuoka ken no rekishi 福粡県の整史 (Histoire du département de Fukuoka), 1997, p. 12-100, 121-136, 175-178, 197-201, 251-266. 
japonais ${ }^{2}$ ». En effet, à la suite de la fermeture du pays décrétée par le bakufu, « en 1636, les Portugais reçurent l'ordre de quitter le Japon, et en 1639 les Hollandais partirent également en emmenant avec eux leurs femmes japonaises et leurs enfants ${ }^{3}$ ». On pense que tous vivaient alors dans les quartiers japonais des villes, comme celui d'Ayutthaya en Thaïlande.

Mais il a aussi existé pour les femmes d'autres formes de traversées de la mer. De l'époque d'Edo jusqu'à la seconde guerre mondiale, les femmes de la région d'Amakusa 天草 de Kumamoto 熊本 que l'on appelait Karayuki san 唐行きさん (《celles qui partent pour la Chine ») traversaient la mer pour aller pratiquer la prostitution sur le continent, en tant que travail saisonnier. Selon Morikuri Shigekazu 森栗茂一-4, ces femmes n'étaient pas des «malheureuses » qui, par pauvreté ou manque de terres, étaient forcées de quitter leur village pour se livrer à la prostitution à l'étranger. En effet, dit-il, « le travail saisonnier hors du pays (dekasegi 出稼ぎ) était une pratique courante à l'époque d'Edo, avec un pourcentage de $2 \mathrm{I}, 4 \%$ pour les hommes et de $19,2 \%$ pour les femmes, pratique qui, dans le cadre de la politique moderne, puis à partir de Meiji avec l'industrialisation et la généralisation de l'économie monétaire, se développa notamment dans cette région d'Amakusa et de Shimabara où le travail saisonnier hors du pays était l'une des formes de travail de subsistance ». Morikuri a ainsi attiré l'attention sur le fait que le travail saisonnier à l'étranger était devenu un système local, et que seules les femmes qui s'en trouvaient exclues n'avaient d'autre choix que de devenir des Karayuki san pour qui la prostitution était l'unique forme possible de travail à l'étranger. Dans cette région de Kyūshū, la prostitution était donc elle aussi l'une des formes de dekasegi.

Le point important signalé ici est l'existence du travail des femmes à l'extérieur de chez elles. J'ai relu « Relation des pratiques coutumières des femmes ${ }^{5}$ » en me rappelant les paroles de son auteur, Miyamoto Tsune.ichi 宮本常- (1907-I98I), appelé l'« ethnologue qui marche »: " les femmes partaient en voyage pour connaître le monde ». Ce qui m'intéresse dans ce livre, c'est le lien entre le voyage des femmes et le travail saisonnier à l'extérieur. De la côte ouest de Kyūshū aux îles de la mer Intérieure (Seto nai-kai 瀬戸内海), les femmes des maisons d'agriculteurs dont les terres ne produisaient pas de riz avaient coutume de partir pour un travail saisonnier dans les régions rizicoles, d'où elles rapportaient du riz comme salaire. Elles

2. Gary P. Leupp ゲイリー・P・ループ, « 1543 nen kara I868 nen no Nihon ni okeru ijinshukan kankei ni tsuite 》一五四三年から一八六八年の日本における異人種間関係について (Les relations inter-raciales au Japon entre 1543 et 1868), dans Wakita Haruko 脇田春子 et S. B. Hanley S · B ハンレー, éd., Jendā no Nibon shi, jō. Shūkyō to minzoku : shintai to seiai ジェンダーの日本史・上、 宗教と民俗;身体と性愛 (Histoire du genre au Japon, vol. I, Religion et fait coutumier : corps et sexualité), I994, P. 340-341.

3. Gary P. Leupp, op. cit., p. 335-336.

4. Morikuri Shigekazu 森栗茂-., «Baibaishun rōdōsha no hassei. Amakusa mono no furusato kara 》売買春労働者の発生一一天草者のふるさとから (L'émergence des travailleurs de la prostitution : du pays d'Amakusa), dans Wakita Haruko et S. B. Hanley, éd., Jendã no Nibon shi, jō. Shükyō to minzoku : shintai to seiai, 1999, p. 493-521.

5. Miyamoto Tsune.ichi 宮本常--, Onna no minzokushi 女の民俗誌 (Ethnographie des femmes), 200I, p. 89-II6. 
allaient par groupes de trois ou cinq, et l'on disait qu'elles prenaient « un emploi pour rapporter les céréales (koku yose bōkō 款寄せ奉公) 》 ou qu'elles partaient pour «le service d'automne» (akishi 秋仕).

En outre, il n'était pas rare que les femmes se rendent en pèlerinage. Elles partaient ainsi à plusieurs, en groupe, pour faire le circuit des Quatre-vingt-huit lieux de Shikoku (Shikoku Hachijū bakkasho 四国八十八ヶ所) ou des Trente-trois lieux de l'Ouest du pays (Saigoku Sanjü sankasho 西国三十三力所). Selon Miyamoto, elles quittaient généralement la maison sans prévenir leurs parents, mais étant donné qu'elles étaient nombreuses à être parties, leur départ était compris et accepté comme un pèlerinage au sanctuaire d'Ise 伊势神宮. Car le voyage était alors regardé comme faisant partie de l'apprentissage des jeunes filles. De même, lorsqu'elles étaient employées au service d'autres maisons, les filles ne le disaient pas toujours à leurs parents. Il existait des « marchés de l'emploi » (bōkō ichi $i$ 奉公市) où les accords étaient conclus entre maîtres et serviteurs/servantes, après quoi ceux-ci travaillaient pour une durée d'un à six mois. Ces périodes de travail chez des maîtres étaient également pour les jeunes filles l'occasion d'apprendre les bienséances et les façons de se conduire dans la société. Pour Miyamoto, «voir le monde ", objectif reconnu à ces voyages et à ces emplois, était envisagé, non seulement comme la possibilité de rapporter des produits alimentaires, mais aussi de faire l'apprentissage de la vie.

Un tel point de vue differe de celui de l'ethnologie traditionnelle. Fondée par Yanagita Kunio 柳田国男 dans les années 1930, l'ethnologie du Japon est l'une des rares disciplines qui, dès ses débuts, a pris les femmes pour objet d'étude. Dans son ouvrage, Kura.ishi Atsuko 倉石あつ子 ${ }^{6}$ montre l'importance des travaux de Yanagita en ce domaine : ce dernier fut le premier homme appartenant au milieu scientifique à s'intéresser à leur vie quotidienne et à hautement valoriser le rôle social des femmes du peuple, qui jusque-là n'avait pas laissé de trace écrite. L'attention de Yanagita avait en effet été attirée par leur rôle essentiel dans la transmission des traditions, au sein d'une société où, à l'arrière-plan des hommes qui agissent dans l'espace publique, ce sont elles qui travaillent à la conservation des maisons et des coutumes orales. Cette position originale a donc été celle des tenants de cette discipline, dont le domaine de recherche était précisément l'environnement de la vie quotidienne. Kura.ishi fait également remarquer qu’à la suite de Yanagita, les femmes ethnologues ont eu tendance à axer principalement leurs recherches sur l'activité et le rôle déterminants des femmes dans la vie quotidienne, tandis que les hommes se sont plutôt intéressés à leur rôle dans l'univers du religieux et des pratiques oraculaires associées à l'usage de pouvoirs. Elle conclut en soulignant la multiplicité et la complexité des problèmes que rencontrent les femmes dans notre société moderne, expliquant que, de ce fait, les méthodes d'approche en sont encore à l'état d'ébauche : il est donc nécessaire, dit-elle, de réexaminer les données accumulées jusqu'à présent pour trouver un nouveau point de vue qui croisera les difficultés propres à la condition des femmes et à celle des hommes.

6. Kura.ishi Atsuko 倉石あつ子, Josei minzoku shiron 女性民俗試論 (Essai d'ethnologie des femmes), 2009, p. 9-20. 
Or d'après Kura.ishi, il est impossible de trouver des solutions aux problèmes que rencontrent les femmes, sans avoir saisi au préalable quels sont leurs divers modes de vie contemporains et la conscience qu'elles en ont. Néanmoins, en réalité, elle limite elle-même son champ d'investigation au cadre des fonctions féminines définies par le genre - fonction de maîtresse de maison, travaux domestiques, aide aux personnes dépendantes, etc. - , ce qui l'empêche de développer un argumentaire ouvert et neuf sur la question des femmes.

Pour dépasser ce type de point de vue, Miyamoto, dans le chapitre « Chroniques de la vie quotidienne ${ }^{7}$ » de l'ouvrage cité précédemment, note quantité d'activités et de positions féminines qui ne peuven du rôle de la maîtresse de maison : les emplois au-dehors en couple, les activités des plongeuses et des ouvrières, le voyage pour le travail à l'extérieur, l'apprentissage, le régime successoral des femmes, la condition des femmes après la seconde guerre mondiale, etc. Par cette approche souple dépassant les cadres du genre, Miyamoto nous donne des clefs pour trouver de nouvelles approches. On peut espérer que son point de vue permette de reconstruire une autre histoire des femmes japonaises et de donner naissance à de riches études locales. Dans ce sillage, d'importants travaux de recherche ont vu le jour à partir des années 1980 où prospérèrent des études sur le genre, comme les ouvrages collectifs Histoire du genre au Japon dirigé par Wakita Haruko 脇田春子 et Susan B. Hanley, ou L'espace-temps des femmes et des hommes. Repenser l'bistoire des femmes au Japon édité par Kōno Nobuko 河野信子 et al. ${ }^{8}$.

C'est en tenant compte de cet arrière-plan que je m'intéresserai ici au développement de Sasaguri à partir de Meiji. Le Japon moderne fut fondé en 1868 , première année de l'ère Meiji. Le charbon produit dans la région nord de Kyūshū joua un rôle important dans ce processus de modernisation. À la suite du décret de libre accès aux ressourccs minières de 1869 , l'exploitation des houillères, aussi bien sous gestion nationale que sous celle du grand capital, connut un développement sans précédent. En outre, avec la révolution industrielle qui suivit la guerre sino-japonaise (1894-1895) et l'instauration du capitalisme avant la guerre russo-japonaise (1904I905), on assista à la brusque modernisation du pays ${ }^{9}$. Dans ce contexte, pour les ouvriers des mines, tout comme pour les femmes qui travaillaient dans les quartiers les plus animés des villes et des cités minières du nord de Kyūshū, le pèlerinage de Shikoku à Sasaguri et son temple principal, le Nanzō-in 南蔵院 ${ }^{\mathbf{1 0}}$, furent l'un des pôles de support moral.

7. Miyamoto Tsune.ichi, «Seikatsu no kiroku »生活の記録 (Chronique de la vie quotidienne), dans Onna no minzokushi, p. 44-20I.

8. Wakita Haruko et S. B. Hanley, éd., Jendā no Nibon shi, op. cit., 1994 et 1995. Kōno Nobuko 河野信子 et al., Onna to otoko no jikū. Nibon joseishi saikō 女と男の時空:日本女性史再考 (L'espace-temps des femmes et des hommes. Repenser l'histoire des femmes au Japon), 1995-2001.

9. Sasaguri-chō bunkazai senmon-iinkai 䇥栗町文化財専門委貝会, éd., Sasaguri chōshi. Rekishiben 篗栗町范:歴史編 (I Iistoriographie de Sasaguri. Histoire), 1982, p. 258-275.

Io. Sur le Nanzō-in et son histoire, voir dans le présent volume l'article de Suzuki Masataka 鈴木正崇, “Modernisation des temples bouddhiques et société locale : le Nanzō-in de Sasaguri », p. $35 \mathbf{I}^{-421}$. (N.D.T.) 
La présente contribution ne porte pas sur la vie quotidienne des femmes. Elle se propose d'examiner les modalités de leur action à différentes époques, dans le cadre de ce pèlerinage considéré comme champ d'attraction religieux d'une part, et, d'autre part, dans celui de l'exploitation des mines qui fut lié au développement de la Marine japonaise. Le pèlerinage dépend à la fois des spécialistes religieux, de l'entourage de ceux-ci, qui le gère, et des pèlerins. Mon analyse portera sur les différentes façons dont les femmes établissent des liens avec le champ d'attraction religieux de Sasaguri et vivent en ce lieu ; sur ce que l'on peut appeler cet intérieur du pèlerinage qu'est la vie des familles et des gardiennes des temples et oratoires de ses 88 étapes, appelées "lieux des vignettes "(fudasho 札所) ${ }^{11}$; ainsi que sur les activités des femmes dans les temples dits " hors numérotation » ou « surnuméraires » (bangai 番外), car situés sur ce circuit de pèlerinage mais non comptés dans les 88 étapes de celui-ci.

Quant au travail dans les mines, en 1931, les femmes en furent exclues en 1931, par un décret leur interdisant d'y entrer ${ }^{12}$, à l'exception de quelques petites et moyennes houillères : de sorte que le travail des femmes y fut limité à celui du tri du charbon, et qu'ainsi la mine devint un monde d'hommes. Deux catégories de femmes soutenaient le travail des mineurs : les unes participaient à l'extraction de la houille dans les houillères de petite et moyenne envergure, et avec le durcissement de la situation de guerre à partir de 1942, et jusqu'à l'après-guerre, elles travaillèrent même à l'intérieur, avec des hommes originaires d'autres pays asiatiques. Les autres sont celles qui remplirent un rôle similaire aux «femmes de réconfort 》 (ianfu 慰安婦) de l'armée, et qui travaillaient comme prostituées dans les « centres de réconfort » (ianjo 慰安所) des mines. Les houillères de Sasaguri fermèrent en 1960 : elles font aujourd'hui partie de l'histoire, dont il ne subsiste que des archives. En me focalisant sur ces femmes qui travaillaient dans les houillères, je ferai porter mon analyse sur cette dimension de l'ubac des mines.

Pour éclairer les réalités du pèlerinage et des mines - ces deux aspects particuliers de Sasaguri qui relèvent respectivement du champ du religieux et de celui du séculier - j'ai choisi un certain nombre d'axes d'approche.

Concernant les femmes qui sont au cœur de l'existence de ce pèlerinage, j'examinerai d'abord le discours que l'épouse du défunt supérieur du Nanzō-in, centre du circuit, tient sur ce temple lui-même. Mais il y a d'autres femmes que celles qui viennent en pèlerinage : aussi me pencherai-je ensuite sur le cas de celles qui, attirées par ces lieux cultuels, sont devenues des maitres de ces lieux saints. Enfin, abordant les temples et oratoires « hors numérotation » (bangai), qui sont des espaces de culte où quantité de réponses sont dispensées aux multiples afflictions exprimées par les visiteurs, j'étudierai la situation des femmes qui vivent en ces lieux en tant que spécialistes du religieux. Ces spécialistes rassemblent des fidèles qui ont recours à leurs pouvoirs et qui sont plus que de simples pèlerins de passage.

II. Abréviation de «lieux (où l'on dépose les) vignettes" (fuda [wo osameru] tokoro 札[を納 める]所). (N.D.T.)

12. Joshi nyūkōo kinshirei 处子入坑禁止令. 
Une autre partie de l'étude est consacrée aux femmes des houillères. Les mines du nord de Kyūshū, dont le charbon était un combustible indispensable aux navires de guerre, furent désignées en 1888 comme réserves minières pour la Marine. Selon les archives locales, avant la seconde guerre mondiale, les femmes pouvaient y travailler. La présente contribution s'intéresse d'une part aux ouvrières de la mine, et d'autre part aux femmes des «centres de réconfort » que les entreprises installaient pour les mineurs exploitant les houillères, c'est-à-dire à l'aspect occulté de cette histoire sociale. Je mettrai en regard cette étoile de la modernité de la région nord de Kyūshū que fut l'Entreprise minière de Meiji-Takata (Meiji Takada kōgyōsho 明治高田鉱 業所) parmi les houillères de Sasaguri, et la prostitution, qui en représente la face négative. L'analyse de ces diverses positions me permettra d'engager une réflexion sur la dynamique du dedans et du debors.

Comme instrument de cette approche, j'ai privilégié la parole des femmes du peuple, qui généralement n'apparaissent pas sur le devant de la scène de l'histoire ${ }^{13}$. Elles furent les témoins vivants de leur époque et de leur localité, et leurs paroles ont été le support de transmissions et de coutumes qui n'émergent jamais dans l'écriture. Il ne s'agit pas là de la seule différence des cadres méthodologiques et théoriques de ces deux disciplines que sont l'histoire, qui utilise principalement l'analyse des archives écrites, et de l'ethnologie, qui cherche à mettre en lumière les éléments traditionnels non écrits de la société par le biais d'entretiens. Je pense en effet qu'il est possible, par là, de proposer une nouvelle méthode d'analyse qui a échappé à Yanagita Kunio et à ses successeurs. Je veux parler de l'attitude et du regard qui furent ceux de Miyamoto Tsune.ichi. J'ai précédemment cité ses paroles : " les femmes partaient en voyage pour connaître le monde ${ }^{14}$ ». Mais, lui-même, l'« ethnologue qui marche », ne cessa de se rendre sur les lieux pour noter les paroles et les actes. Cela vaut bien sûr dans lc cas prćsent, cette enquête se déroulant dans l'espace de Sasaguri qui comprend un circuit de pèlerinage : les gens partent pour ce voyage qu'est le pèlerinage à Sasaguri ; c'est cet acte hors du cadre de l'ordinaire, le "voyage ", qui attire les gens en ces lieux.

En outre, l'attrait de Sasaguri ne concerne pas seulement les gens ordinaires. Les spécialistes religieux qui apparaissent dans cette contribution sont des personnes qui ont été sauvées de leurs propres maux par le biais de leurs activités dans le domaine religieux. Or, l'entretien direct est le seul moyen d'entrer en contact avec eux. C'est pourquoi j'ai essayé de rester aussi fidèle que possible à leurs paroles, que je suis allée écouter de nombreuses fois. L'empathie est ici nécessaire. Or les dires de chaque locuteur sont quasiment uniques. Chacun d'entre eux parle d'un univers qu'il est le seul à connaître. Aussi n'ai-je pas hésité à les nommer par leur nom réel et à analyser leurs paroles avec autant de précisions que possible.

13. Pour développer son propos, l'auteur a privilégié le fil de la parole des femmes, qui est ici soit citée intégralement, soit résumée. La transcription intćgralc de ces paroles fera partie de la base de données japonaises éditée sur le site de l'EFEO comme complément de la publication de ce numéro des CEA. (N.D.T.)

14. Miyamoto Tsune.ichi, Onna no minzokushi, p. 324. 


\section{Le pouvoir des femmes dans la formation du Nouveau pèlerinage de Shikoku à Sasaguri}

Nous nous intéresserons en premier lieu aux épouses des supérieurs, qui, vivant " au fond » des temples, n'ont généralement pas l'occasion d'apparaître sur le devant de la scène de l'histoire, alors même qu'elles n'ont cessé de soutenir, depuis leur position effacée, leurs maris, administrateurs du sacré. Mais tout d'abord, un mot sur l'origine du pèlerinage, où apparaît une femme qui eut un rôle déterminant pour celui-ci ${ }^{15}$. Dans « Le circuit des sites historiques », Hayashi Kakuga 林覚雅 (1925-1989), le second des supérieurs du Nanzō-in, présente en ces termes l'origine des Quatre-vingt-huit lieux saints du Nouveau pèlerinage de Shikoku à Sasaguri :

En 1835 (Tenpō 天保 6), le pèlerinage fut fondé par la nonne Jinin 慈忍, résidant à Meino-Hama 姪浜 (quartier ouest de l'actuel Fukuoka 福岡). Alors qu'elle était en route pour Shikoku où elle voulait faire le pèlerinage des quatre-vingt-huit temples, elle passa par Sasaguri où sévissait alors une épidémie. Elle s'y arrêta pour en demander l'arrêt en pratiquant sous la cascade et décida d'y créer un Nouveau pèlerinage de Shikoku. Elle s'engagea dans cette tâche, mais mourut avant de l'avoir achevée. À sa suite, un habitant de Sasaguri, Fujiki Tōsuke 藤木藤助, qui avait une grande dévotion pour le Grand Maître Kōbō à l'origine de ce pèlerinage de Shikoku, installa quatre-vingt huit statues de bouddhas sur tout le territoire villageois pour y réaliser ce circuit des Quatre-vingt-huit lieux du Nouveau Shikoku à Sasaguri (Sasaguri Shin Sbikoku Hacbijü bakkasho 策栗新四国八十八力所).

Mais avec la politique gouvernementale d'éradication du bouddhisme (baibutsu kishaku 廃仏毀釈) durant les premières années de Meiji, en 1886 le préfet de Fukuoka ordonna la suppression de ce pèlerinage de Sasaguri. Tō Ki.ichirō 藤产一郎, alors maire de Sasaguri, s'éleva contre cette décision et, avec le soutien d'un groupe de villageois, ayant cherché par tous les moyens à l'annuler, finit par obtenir du ministère de l'Intérieur l'autorisation de sa sauvegarde sous forme de temple. C'est ainsi que le Nanzō-in, situé alors sur le mont Kōya 高野ıl, fut installé à Sasaguri comme temple principal du pèlerinage, et que les 88 oratoires originels du pèlerinage et leurs enceintes furent transformés en « oratoires et enceintes en enclaves éloignées » du Nanzō-in, ce qui permit d'obtenir l'autorisation officielle en $1899^{16}$.

\section{L'épouse de Hayashi Kakuga, le second supérieur du Nanzō-in, pivot du pèlerinage de Sasaguri}

Née en 1926, Hayashi Toshie 林俊枝 (fig. I) est l'épouse du second supérieur du temple, Kakuga 党雅, et la mère du supérieur actuel, Kakujō 覚乗 (lui-même né en 1953). Venue de l'extérieur de Sasaguri au moment de son mariage, elle se souvient qu'à cette époque, le Nanzō-in était dans un état de grande indigence. Ses paroles, qui témoignent du regard féminin sur le temple, permettent de mieux comprendre la façon de vivre des second et troisième supérieurs, ainsi que de leur héritier qui en sera le quatrième.

15. Sur l'historique du pèlerinage et la nonne Jinin 慈忍, voir dans ce même volume la contribution de Nakayama Kazuhisa I业和久, "La dynamique de création, réplication et déclin des lieux de pèlerinage : le nouveau pèlerinage de Shikoku à Sasaguri ", p. 269-350. (N.D.T.)

16. Shiseki meguri 史跡巡り, cité dans Sasaguri-chō bunkazai senmon-iinkai, éd., Sasaguri chōshi. Rekishi-hen, p. 243-245. 


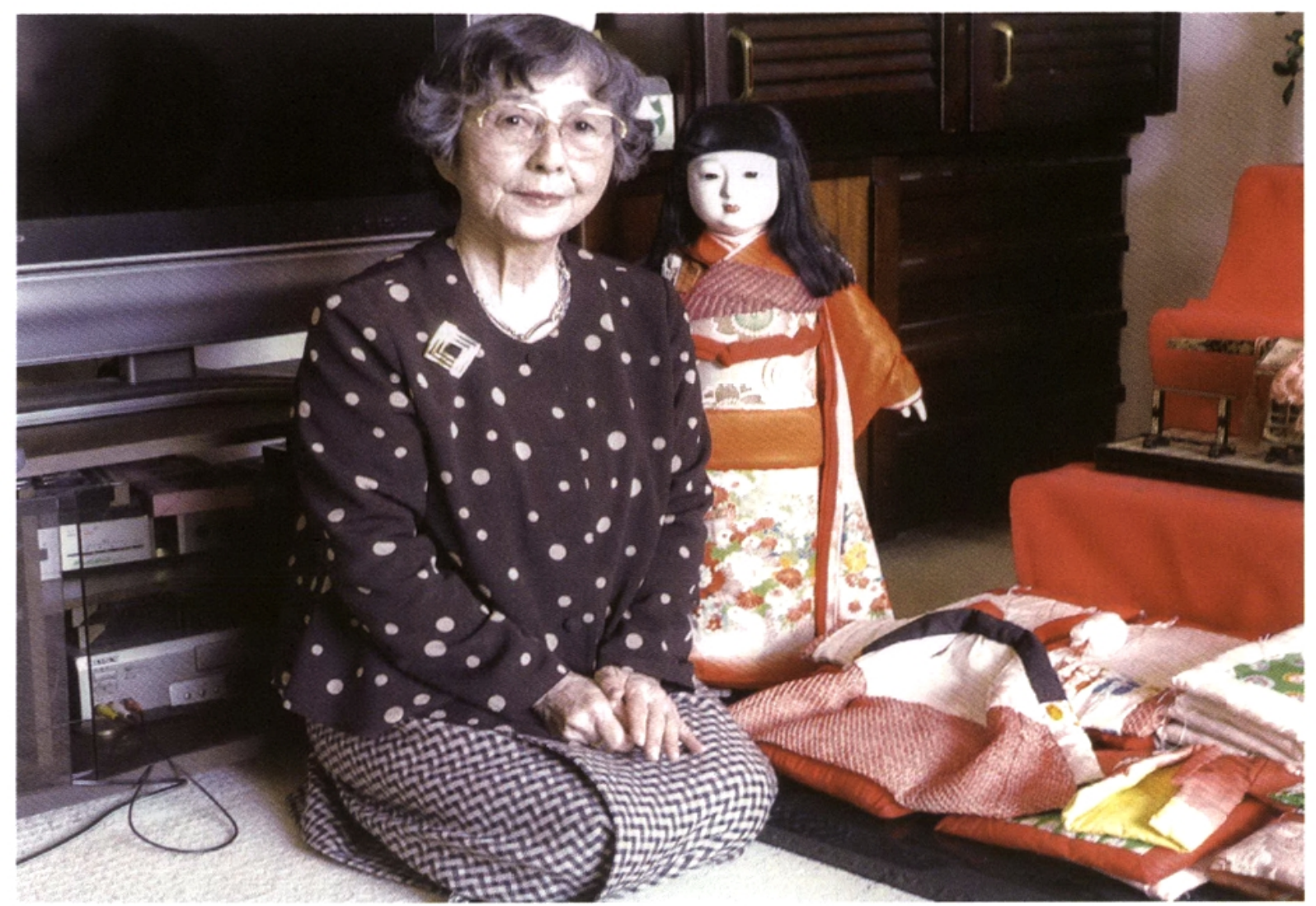

Fig. I : Hayashi Toshie 林俊江, épouse du second supérieur du Nanzō-in.

Le premier d'entre eux, Hayashi Kaku.un 林覚雲 (1875-1945), vint du mont Kōya en 1902 et il est regardé comme le " patriarche restaurateur » (chükō no so 中興の祖) du temple. Né en 1875 , il est mort à l'âge de 70 ans, en juin 1945. Dans l'enceinte du temple se dresse la statue de pierre de ce " patriarche restaurateur du temple Nanzō-in, grand recteur Kaku.un 》南蔵院中興の祖, 覚雲大僧正, qui porte l'inscription : « Pour la commémoration du centième anniversaire de l'implantation du Nanzō-in à Sasaguri. À la mémoire de celui qui se consacra au pèlerinage de Shikoku à Sasaguri. Mai $1998^{17}$ ".

LE PREMIER SUPÉRIEUR ET SA FEMME, BELLE-MÈre DE TOSHIE. - Kaku.un, le beau-père de Toshie, fut le premier supérieur du Nanzō-in à Sasaguri. Il doit son nom au Hongaku-in 本覚院, le temple du mont Koya d'où il fut envoyé à Sasaguri pour sauver le pèlerinage. Il avait alors une vingtaine d'années. Il construisit un petit oratoire de 4 tatami et demi (environ $8 \mathrm{~m}^{2}$ ), qui lui servit de base pour ses activités de prédication religieuse. Selon Toshie, "il se considérait comme exilé à Sasaguri, car ses deux autres condisciples avaient été envoyés l'un, aux États-Unis et l'autre, en Corée ». On peut imaginer quels étaient ses sentiments lorsqu'il se comparait à

17. 平成十年五月、南荿院招致百周年記念篠栗四国霊場永年功学者の碑. 
ses collègues qui déployaient leurs activités à l'étranger, alors que lui seul avait été affecté à Sasaguri, c'est-à-dire au fin fond de la campagne japonaise, à un endroit dont il n'avait jamais entendu parler. C'est peut-être pour cette raison qu'en mémoire de son grand-père, l'actuel supérieur - qui est donc le troisième - a choisi de commencer à Hawaï ses activités de diffusion religieuse.

Hayashi Toshie, épouse du second supérieur et belle-fille de Kaku.un, évoque ainsi ses beaux-parents. Sa belle-mère, dont la famille tenait une maison de thé, avait tout de la commerçante et était une maitresse femme, habile en toutes choses. Quant à son beau-père, après son installation en 1902, il n'avait presque pas de paroissiens (danka 橿家) ; aussi commença-t-il ses activitćs en pratiquant les rites (kitō 祈螦) sur demande. "Mon beau-père se rendait aux mines à bicyclette pour transmettre l'enseignement bouddhique. Et quand il construisit le bâtiment principal du temple, les mineurs sont venus apporter leur aide avec leurs pioches. " Comme en témoigne cet épisode, le lien entre le Nanzō-in et les mines était extrêmement fort, au point qu'on l'appelait le « temple des mines » (tankō-dera 炭坑寺). Outre ses activités auprès des mineurs, Kaku.un s'occupait aussi des " geishas-terreurs 》 (bazoku geisha 馬賊芸者 $)^{18}$. C'est pourquoi parmi les pèlerins, les femmes travaillant dans les bars et les cabarets étaient particulièrement nombreuses. Tous ces gens ont été les soutiens de la première époque du Nanzō-in. Aussi le supérieur et son épouse les ont-ils toujours accueillis chaleureusement. "Notre temple dépend des fidèles. Si nous ne prenons pas soin d'eux, ils nous quitteront », disait sa belle-mère à Toshie. Et de fait, le Nanzō-in a été le support moral de tous les mineurs.

SON ÉPOUXX ET SES FRÈRES. — Kakuga avait trois frères aînés. Or c'est lui, le dernier des quatre fils, qui succéda à son père, ce qui est rare. Après avoir été soldat de l'armée de l'air pendant la seconde guerre mondiale, et porté disparu durant 3 ans, il réapparut en 1948, et entra à l'université au mont Kōya. Selon Toshie, si les trois aînés ne reprirent pas le temple après leur père, c'est probablement parce que celui-ci était dans un état misérable à la fin de la guerre et que l'héritage ne représentait aucune valeur. Durant les 3 ans qui s'écoulèrent entre la mort de Kaku.un et le retour du front de Kakuga, le temple, alors sans supérieur, faillit être accaparé par un moine de Fukuoka, qui assurait l'intérim au Nanzō-in. La belle-mère de Toshie parlait de cet épisode avec fougue ; elle aurait dit alors : "Jamais je ne le cèderai, je porterai plainte au mont Kōya ! », exprimant ainsi sa forte détermination à protéger le temple. C'est dans ce contexte historique et situationnel que Toshie entra au temple pour épouser Kakuga.

AprÈs SON MARIAGE. - Toshie venait de Yame 八女, du département de Fukuoka. À son mariage en 1948, elle ne savait pas comment elle allait se débrouiller pour vivre. Sa famille avait une entreprise de bougies. Lorsque fut décidé son mariage avec le fils du Nanzō-in, par des relations de sa mère qui était une femme d'une grande dévotion,

18. Tel était le nom donné aux geishas de Hakata, réputées pour leur force de caractère. Littéralement "brigand à cheval ", bazoku a été utilisé pour désigner les bandes armées qui sévirent en Mandchourie de la fin du XIX siècle jusqu'aux années 1940. Des aventuriers japonais intégrèrent ces bandes de bazoku; certains en devinrent même des chefs importants. Les bazoku étaient connus pour leur bravoure et représentaient un certain idéal romantique pour les Japonais de la première moitié du $\mathrm{xx}^{e}$ siècle. (N.D.T.) 
elle dit s'être sentie "punie ", tant elle détestait tout ce qui avait rapport aux temples. De plus, à la suite de l'échec en affaires d'un frère de son mari, sur tous les meubles de la maison étaient collées les vignettes rouges de saisie mobilière. Dans cette situation d'indigence totale, l'humour de son mari sauvait tout. Ainsi, au début de son mariage, Toshie faisait souvent des rêves en couleur. On lui avait dit que c'était là une maladie mentale. Pourtant, lorsqu'elle ne racontait à personne leur contenu, ce qu'elle avait vu se réalisait. Son mari lui dit alors : "Je vais te mettre comme fondatrice de religion, tu délivreras des oracles et moi je vivrai à tes crochets sans rien faire ! " Toshie pensa toutefois que cette plaisanterie était déplacée et ne lui en parla plus.

LA viE AVEC KaKUGA. - Après la guerre, son mari fut un certain temps instituteur de l'école primaire de Sasaguri, parce que les revenus du temple n'étaient pas suffisants pour vivre. Comme il enseignait dans le temple même où était ouverte une annexe de l'école, lorsqu'il avait des services à célébrer, il laissait jouer les élèves. Il continua à entretenir les liens que son père avait noués avec les mineurs. Durant l'après-guerre où la nourriture manquait, il rapportait souvent ce qu'il avait reçu des gens des mines, chez qui il y avait toujours quelque chose à partager. Car nombreux étaient les mineurs qui disaient que ceux qui portaient une amulette protectrice du Nanzō-in échappaient au danger et avaient la vie sauve. C'est probablement là ce qui unissait fortement au temple les travailleurs de la mine. À partir de 1955, Kakuga continua ses prédications, mais il fut aussi sollicité pour faire des conférences. Il avait un don pour la parole dont son fils a hérité. Comme le temple ne pouvait compter sur la présence de paroissiens, les prédications étaient pour lui un moyen de gagner sa vie. Pour ce faire, il voyagea dans toutes les régions de Kyūshū ; aussi peut-on imaginer facilement que ses multiples déplacements contribuèrent de façon décisive à rendre populaire le pèlerinage de Sasaguri.

Durant la seconde moitié de la vie de Toshie, le Nanzō-in s'est agrandi, la vic cst parvenue à un équilibre stable, et le temple a obtenu le titre de « temple principal de la branche du mont Kōya de l'École Shingon " (Kōyasan Shingon-shü bekkaku bonzan 高野山真言宗別格本山). Toshie a été reconnue comme veuve d'un homme célèbre et mère d'un autre homme célèbre. À l'écouter en parler, on voit qu'elle en est fière, mais ce qui rend l'entretien avec elle agréable, c'est qu'elle ne dit jamais du mal de personne et ne parle qu'en bien de sa belle-fille. En outre, c'est quelqu'un qui a du goût. Son mari aimait le parfum du bois de calambac ${ }^{19}$ et savait même deviner les prix des bâtonnets d'encens. C'est ainsi qu'elle a elle-même adhéré à une association d'encens.

LE SUPÉRIEUR ACTUEL. - Son fils, Kakujō 覚乗, le supérieur actuel, est né alors que se déroulait un rite du feu (goma kitō 護摩祈裙) et il reçut l'ordination bouddhique (tokudo 得度) ${ }^{20}$ à l'âge de 8 ans. Au cours de son enfance, c'était un garçon qui ne parlait pas du tout. Son père s'inquiétait de son avenir dans la fonction de moine : "Ce garçon est incapable de faire des prédications. On va lui apprendre à faire les rites. " Néanmoins, lorsqu'il partit pour Hawaï, à l'âge de 22 ans, pour y faire des prédications, il acquit la maîtrise de la parole. Il est difficile d'imaginer

19. Kyara 伽羅, c'est-à-dire jinkō 沈香 (Aquilaria crassna).

20. De nos jours, au Japon, ce rite d'entrée dans la voie bouddhique peut, mais pas nécessairement, ouvrir un parcours de spécialiste religieux affilié au bouddhisme. (N.D.T.) 
cela en voyant ce moine aujourd'hui éloquent et volubile, mais c'était alors ce qui préoccupait ses parents. Or ce troisième supérieur du Nanzō-in est un homme qui a de la chance. Quand il a hérité du temple, la gestion était en bonne route. Et au moment même où il envisageait une extension des activités du temple, avec la construction d'une maison de thé dans son enceinte et de la statue du Grand Bouddha couché, il a gagné par deux fois à la loterie. Il s'est marié avec une femme d'esprit, ancienne élève de l'université de jeunes filles de Seinan ${ }^{21}$, qui parle bien l'anglais, et qui reçut des cours particuliers d'une amie des Clinton, alors dans son université.

Le Nanzō-in a pour fidèles un grand nombre de femmes qui travaillent dans les bars et les cabarets. Ceci est à rattacher à ce que nous avons déjà mentionné en évoquant le premier supérieur " qui s'occupait des "geishas-terreurs" », mais aussi aux liens établis avec le monde du spectacle. Kakuga fut en effet invité à jouer dans un film. Sa femme Toshie, elle-même, était admiratrice d'un acteur de kabuki, Nakamura Kanzaburō 中村勘三郎, et fréquentait la comédienne Miyako Chōchō ミヤ コ蝶々. C'est ce qui fut sans doute à l'origine de l'entretien entre cette comédienne et Kakuga sur le sujet "Qu'est-ce que vivre heureux ?", publié dans le volume « Kyüshū. Voyage aux lieux saints de Sasaguri' ${ }^{22}$ ».

Le fUTUR SUPÉRIEUR. - Né en 1979, Kakuryū 覚龍, fils de Kakujō et petit-fils de Toshie, le futur supérieur, a fait son apprentissage de moine au mont Kōya. Son épouse est une femme d'une grande beauté qui a fait partie de l'opéra d'actrices de Takarazuka 宝场, où elle était dans la même promotion que la femme de l'acteur de kabuki, Onoe Shōroku 尾上松禄.

\section{Les pèlerins}

Selon la publication précédemment citée ${ }^{23}$, en 1986 , les pèlerins venant visiter Sasaguri étaient aux nombre d'un million. Mais peu après la guerre, il n'y en avait aucun. Il a fallu attendre que soit terminée la période de reconstruction de l'après-guerre pour voir arriver les premiers d'entre eux. C'est à partir des années 1950 qu'ils se mirent à affluer ; on vit surtout apparaître de nombreux guides (sendatsu 先達) qui venaient accompagnés de grands groupes de fidèles. On parle aujourd'hui encore, dans les auberges de pèlerins et dans les boutiques de souvenirs, d'un groupe appelé Kanbara 蒲原, et d'un autre appelé Onoda 小野田, venu d'Onoda à Yamaguchi 山口県. J'ajouterai ici aux paroles de Toshie ce que disent de ces groupes les femmes qui travaillaient alors dans les auberges.

Fujiki Nobuko 藤木信子, née en 1926, est entrée en 1948 dans l'auberge de pèlerins Kadoya 角屋 à Yamate 山手. Les clients étaient alors très nombreux. Comme il n'y avait pas de machine à laver, elle faisait la lessive dans la rivière. Au mois de novembre, elle allait dans la montagne ramasser le bois de chauffage pour l'hiver. Elle se souvient d'un

21. Seinan Jogakuin 西南女学院.

22. Yomiuri shinbun-sha 読䒧新聞社, éd., Kyūshū Sasaguri reijō no tabi. Kōbō Daishi no sekai 九州・篠栗篮場の旅——厸法大師の世界 (Kyūshū. Voyage aux lieux saints de Sasaguri : le monde du Grand Maître Köbō), 1986, p. 36-41.

23. Yomiuri shinbun-sha 読売新聞社, éd., op. cit. 
groupe de fidèles du mont Ishizuchi 石鎳山 qui venait de Kokura 小倉 (département de Fukuoka 福岡県), et dont il fallait répartir les 70 à 80 membres entre trois auberges. Ce groupe de pèlerins est encore aujourd'hui celui qui a le plus grand nombre de fidèles. A l'époque, on couchait Is personnes dans une même chambre de 8 tatami $\left(\mathrm{I}_{4} \mathrm{~m}^{2}\right)$.

Tō Yone 藤米, qui tient une boutique d'instruments cultuels, le Shinkō-dō 真弘堂, à Narubuchi 鳴淵, est née dans cette maison en 1927. Dans sa jeunesse, elle aidait sa grand-tante qui s'était mariée avec le fils de l'auberge Kameya 龟屋. Quand les clients de celle-ci dépassaient la centaine, la boutique Shinkō-dō accueillait ceux qui ne pouvaient être logés à l'auberge. Pour les coucher, on étendait des futon 布団 dans toutes les pièces et les pèlerins devaient dormir à deux sur un seul tatami $\left(2 \mathrm{~m}^{2}\right)$.

Okabe Kayo 岡部かよ, patronne de l'auberge Sannō-ya 山王屋 qui constitue la $9^{c}$ étape du pèlerinage, est née en 1929 à Kashii 香椎 (Fukuoka). Elle a été adoptée 3I jours après sa naissance par la maison Sannō-ya, dont elle est ainsi devenue l'héritière. Dans sa jeunesse, il n'y avait pas de voitures; aussi, nombreux étaient les clients qui passaient 3 ou 4 nuits de suite. Au cours de l'après-guerre, on recevait beaucoup de femmes dont les fils étaient morts au front ainsi que de nombreux pèlerins qui effectuaient le circuit de pèlerinage pour faire un vou. D'autre part, cette auberge a toujours pratiqué aussi l'agriculture et peut ainsi offrir aux repas les légumes et le riz qu'elle a cultivés, ce qui plaît beaucoup à ses clients, qui sont aujourd'hui bien plutôt des touristes que des pèlerins.

L'oratoire de Kannon 観音堂 $\left(\mathrm{n}^{\circ} 8 \mathrm{r}\right.$ du circuit) de la rivière Futase (Futase gawa 二瀬川) était aussi autrefois l'auberge Sakae-ya 栄屋. En 1954, Inoue Tomoko 井上 友子, née en 1935, y a fait la simple " pose du pied ${ }^{24}$ » et un échange de coupes de sake, avant que ne soit célébrée la cérémonie de son mariage en 1955. C'est à l'époque Meiji que cette maison a accepté de prendre en charge l'oratoire du pèlerinage, lorsque son fondateur quitta sa famille d'origine (maison souche, bonke 本家) pour fonder une maison séparée (bunke 分家). Tomoko en est ainsi la troisième maîtresse de maison. La maison d'origine des Inoue était le restaurant Yoshida dango-ya 吉田 団子屋 à Kido Nanzō-in Mae 城戸南蔵院前. La famille Inoue dirigeait, il y a 67 ans, l'entreprise de taxis Inoue, laquelle devint celle des taxis-Sasaguri après la mort du maître de maison de la seconde génération. De cette maison Inoue, qui gérait l'auberge Sakae-ya, est issu le fondateur de celle des Komeya 米谷, puis, de cette dernière, le fondateur de l'auberge Tsuru-ya (Tsuruya ryokan 鶴屋旅館). Tomoko a cependant fermé son auberge Sakae-ya lors de la révision de la loi en 1982, qui obligeait les auberges à rénover leur équipement contre les incendies. Les trois autres auberges de ce quartier ont alors fait de même.

LES PÈLERINS ET LA PRATIQUE DE LA CASCADE (takigyó 滝行). — L'une des caractéristiques du pèlerinage de Sasaguri est que de nombreux groupes de pèlerins étaient - et sont encore - guidés par des spécialistes religieux nommés ogamiya san 拝み屋さん, les « intercesseurs » ou « invocateurs », dont les pratiques sont fondées sur des formes fusionnelles du culte des dieux et des bouddhas (shinbutsu shügō 神仏習合). Dans les années 1950, notamment, il y avait des groupes de 200 personnes venues de Saga 佐賀

24. Asbi ire 足入れ, forme ancienne de mariage, par accord tacite et sans cérémonie, qui précédait parfois de plusieurs années le rite officiel du mariage. 


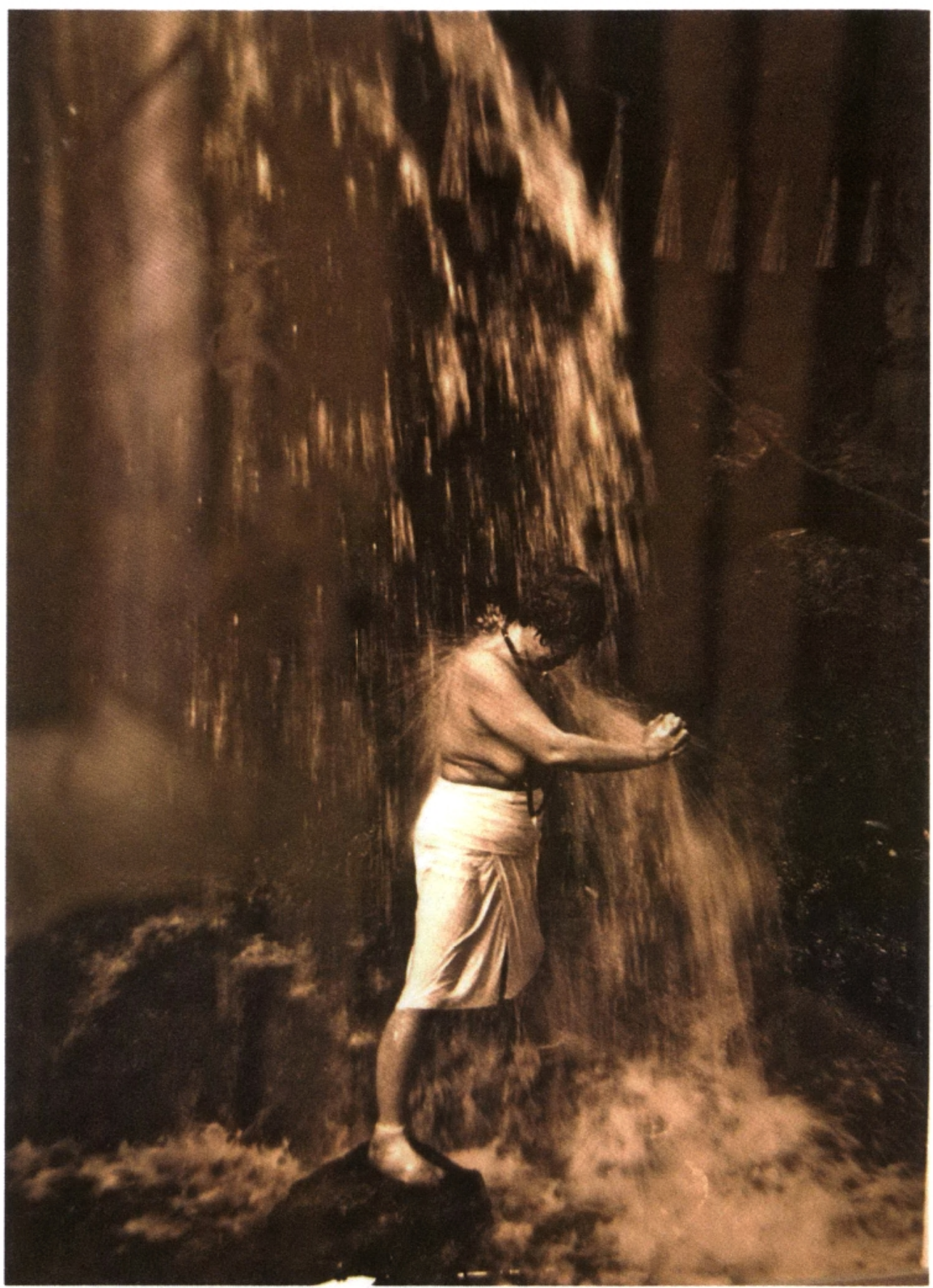

Fig. 2 : Femme sous la cascade à Sasaguri.

(Photographie d'avant-guerre. Centre de documents historiques et de matériaux ethnographiques de Sasaguri)

et de roo personnes venues de Shimonoseki 下関. Parmi eux étaient particulièrement célèbres celui de Kanbara 神原 du nouveau mont Narita 新成田山 de Saga et celui d'Onoda 小野田 mené par un guide appelé Matsuoka 松岡. Tous pratiquaient l'ascèse de la cascade sous la conduite de leurs responsables, qui en avaient reçu l'ordre par des oracles. Ils appelaient cela « la pratique/ascèse » (ogyō お行) ou la «pratique/ascèse de la cascade » (takigyō 滝行) (fig. 2). 
Aujourd'hui, avec le train, on accède à Sasaguri en 20 minutes depuis Hakata. Pourtant, malgré cette proximité de la mégalopole, cette commune est suffisamment montagneuse pour offrir un grand nombre de cascades où il est possible de pratiquer. Autrefois, ceux qui se mettaient sous la cascade étaient des membres de gangs (yakuza ヤクザ) des quartiers commerçants de Hakata et d'Iizuka 飯塚, ou encore des femmes que fréquentaient les mineurs. C'est là encore une caractéristique du Nanzō-in. Plusieurs geishas ou femmes travaillant dans les cabarets se firent nonnes à la suite de pratiques sous la cascade du Nanzō-in. Nous y reviendrons ci-après.

Tous étaient des gens dont les moyens d'existence étaient précaires et dépendaient largement de l'époque et de la situation sociale. Aussi ne se contentaient-ils pas de prier les dieux comme les autres : au contraire, ils le faisaient en mettant leur propre corps en jeu. Afin de répondre à leurs attentes, tous les supérieurs successifs du Nanzō-in se sont toujours rendus jusque chez eux pour leur parler des dieux et des bouddhas. Si ces pèlerins venaient, ce n'était donc pas seulement parce qu'il y avait une cascade, mais aussi parce qu'il y avait quelqu'un qui était prêt à les écouter.

Le NANZō-IN et SASAguri : Dedans et DeHoRs. - Confrontés, début Meiji, à l'interdiction du pèlerinage de Sasaguri sur ordonnance ministérielle, les habitants ont réussi à éviter sa disparition en faisant installer le Nanzō-in du mont Kōya, temple qui fut placé à la tête de tous les oratoires composant le circuit du pèlerinage. C'est ainsi que Kaku.un, le premier supérieur du Nanzō-in, vint à Sasaguri qu'il voyait comme une terre d'exil. Il réussit à vivre dans le minuscule oratoire qu'il avait construit grâce au soutien des mineurs et à l'aide de sa femme. Et c'est dans ce contexte d'indigence totale que, peu après la guerre, Toshie a épousé l'un de leurs fils, le deuxième supérieur Kakuga.

Les épouses de ces supérieurs du Nanzō-in, la "maîtresse femme » de Kaku. un, et Toshie, celle de Kakuga, ont été les supports de la vie du temple dans ces conditions extrêmes. En l'absence de leurs maris, qui allaient dans toutes les régions de Kyūshū pour étendre leurs activités religieuses, elles gardaient le temple qui était aussi leur maison. Afin que les supérieurs, dont l'existence relève du monde du "sacré ", puissent assurer leur fonction religieuse, ces femmes venues du dehors, et qui appartenaient au monde séculier, les soutenaient ainsi du dedans. Ces épouses, devenues êtres du dedans tout en conservant une existence séculière, ont gardé le " fond " (oku 奥) du sacré de Sasaguri. Par rapport à elles, l'épouse du supérieur actuel (troisième génération), cette femme d'esprit aux talents linguistiques avérés en anglais qui est sortie d'une université réputée de Kyūshū, est toujours à la réception générale du Nanzō-in. Cette troisième épouse, venue du debors, soutient donc en tant qu'être séculier, depuis le dedans, son mari qui travaille au premier plan dans le registre du sacré ; mais elle est également aux commandes de l'administration générale qui constitue le côté externe des affaires du temple. Elle travaille donc non seulement du côté intérieur, dans la partie privée du temple, mais elle assure aussi la direction du côté extérieur, dans la partie publique de celui-ci.

Quant à la quatrième jeune épouse du futur supérieur (quatrième génération), qui attire le regard par sa beauté, elle est venue elle aussi du dehors et qui plus est de l'opéra d'actrices de Takarazuka. Elle est de même toujours à la réception du temple, où elle retient l'attention des visiteurs. Au XXI ${ }^{\mathrm{e}}$ siècle, les femmes du Nanzō-in ne sont donc plus seulement des « femmes du fond » du religieux et du sacré (oku san 奥さん, 
« celle qui est au fond (de la maison) »), qui auraient la seule responsabilité d'un rôle interne. Elles ont à représenter la face extérieure séculière du temple, par rapport à la face extérieure sacrée que représente leur mari. À ce titre, on peut dire qu'elles sont la «figure » du Nanzō-in.

\section{Les femmes des autres temples et oratoires du circuit de pèlerinage}

D'autres femmes attirent également l'attention à Sasaguri. Ce sont celles qui, venues de l'extérieur pour y faire des pratiqucs, ont ćtć priscs dans lc champ d'attraction du pèlerinage et qui, par le biais de divers liens, se sont installées à Sasaguri où, s'étant lancées dans une activité religieuse, elles ont fini par devenir gardiennes de l'un ou l'autre des oratoires du circuit. Un grand nombre d'entre elles sont reconnues comme détentrices de pouvoirs, et c'est pour cette raison que des consultants ne cessent d'affluer vers elles. Ces visiteurs dépassent le cadre des seuls pèlerins et c'est en tant que fidèles qu'ils fréquentent assidûment Sasaguri. Ces femmes deviennent ainsi des gens des fudasho, c'est-à-dire de l'intérieur de Sasaguri, et en tant que charismatiques (reinōsha $a$ 霊能者, «qui ont des pouvoirs subtils »), conduisent leurs activités au fond de ces lieux saints.

\section{La supérieure $d u$ Dainichi-ji 大日寺 ( $n^{\circ} 28 d u$ pèlerinage)}

Shōzaki Ryōsei 庄崎良清 (fig. 3), aujourd'hui supérieure du Dainichi-ji, est née en I930 à Tachi.arai 大刀洗町 (Fukuoka). Comme le veut l'héritage historique de cette région, où depuis le XVII e siècle vécurent des "chrétiens cachés ${ }^{25}$ ", elle était catholique par sa famille. Mais à la suite d'une expérience de possession par une divinité en 1979, elle fit diverses pratiques dans les montagnes, puis reçut l'ordination bouddhique au Nanzō-in, en 198I. Son parcours est relaté en détail dans un livre où Fujita Shōichi 藤田庄市 rapporte ses paroles ${ }^{26}$. Nous examinerons ci-dessous ce que m'a raconté Ryōsei ainsi que les rituels dont j'ai été témoin au Dainichi-ji.

LE RITE DES MILLE LUMières (sentōmyō 千灯明) AU DAINICHI-JI. — Le 8 avril 2006, le rite des mille lumières commence au Dainichi-ji. Les huit fidèles qui ont aidé aux préparatifs se rassemblent devant la statue de Dainichi, le bouddha principal du temple. Mille bougies doivent être allumées par les participants dans toute l'enceinte du temple, de façon à ce qu'elles brûlent toutes ensemble. Si le vent en éteint, il faut donc sans cesse les rallumer. Une fois le rite terminé, tous vont entendre ce que Ryōsei appelle omikuji ${ }^{27}$, "la divination », c'est-à-dire les oracles qu'elle transmet. C'est ce qu'attendaient une grande partie de ceux qui participaient au rite. Pour

25. Kakure kirishitan 鲶れキリシタン.

26. Shōzaki Ryōsei 庄崎良清, Fujita Shōichi 藤田性市 (photos, entretiens), Omikuji. Shinbutsu no utsuwa to narite おみくじ——神仏の器となりて (Les oracles : en devenant le réceptacle des dieux et des bouddhas), 1993 (éd. augmentée, 2007), p. 28-59.

27. Expression que l'on rencontre dans cette région de Kyūshū pour désigner les oracles et qui dérive peut-être de l'emploi de ce terme utilisé plus généralement dans le sens de « divination ». (N.D.T.) 


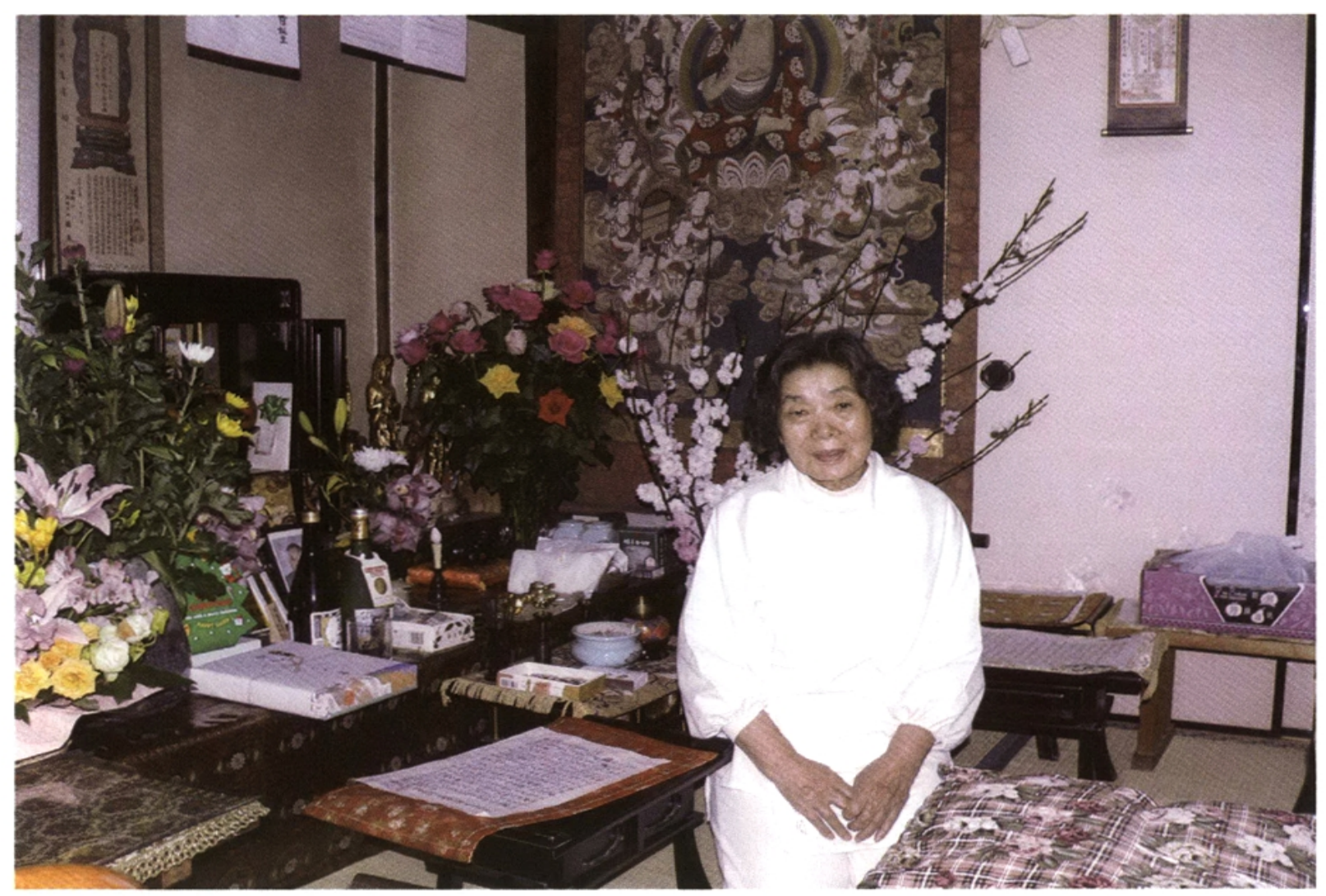

Fig. 3 : Shōzaki Ryōsei, supérieure du Dainichi-ji (nº 28 du pèlerinage).

cela, tous se réunissent devant la grande statue écarlate du roi des Enfers, le grand roi Enma 閻魔大王, où Ryōsei commence par faire des invocations pour les fidèles présents ; puis, frappant le dos de chacun avec son bâton à anneaux (shakujō 錫杖) en poussant un cri de force « eit ! », elle dit « tout va bien », ou « tout va s'arranger », "ça va guérir », " accouchement sans problème », " vœux exaucés », et ainsi de suite.

Il est ici demandé aux fidèles de participer activement aux rites. Il ne leur suffit de regarder Ryōsei et d'entendre ses paroles. Ils doivent lire les sütra à haute voix, allumer les mille bougies et compter cent allers et retours (obyakudo お百度) devant l'autel pour déposer leurs demandes. C'est alors que, frappés sur le dos par le bâton à anneaux, ils se sentent dégagés des chaînes de dépendance de leurs actes passés (innen 因縁) et peuvent entendre les oracles de Ryōsei. Le rite se déroule ainsi sans heurt : d'un côté, les paroles et les actes exécutés avec la plus grande assurance par Ryōsei, et de l'autre, le comportement empreint de confiance des fidèles.

Ryōsei laisse les autres participants assister à ses entretiens avec les fidèles les plus proches, à qui elle explique les liens particuliers qui existent entre elle et le grand roi Enma. Par ailleurs, elle prononce de nombreux oracles au cours même de cet échange, en s'écriant " voix d'Enma ", " voix des ancêtres ", "voix du foetus avorté », " paradis fleuri », et ainsi de suite.

Après le rite, Ryōsei déjeune avec tous ceux qui y ont pris part. Elle raconte alors combien ses oracles se sont bel et bien réalisés jusqu'à présent, et comment ils ont 
aidé les fidèles. Tous l'écoutent en approuvant. Elle répète de quelle façon les rites ont sauvé tous ceux qui sont venus lui demander de l'aide : tous les candidats ont été admis cette année aux écoles nationales ou départementales; des malades atteints de cancer ont guéri. Mais elle parle aussi de ce qui lui arrive. Les toilettes, le réseau d'égouts et la cuisine du Dainichi-ji viennent d'être refaits. Au moment où elle pensait devoir faire installer des toilettes, le roi Enma lui a dit : «Pas de souci. »Et, de fait, la femme du chef d'une entreprise de taffetas de soie, le Nisshō-dō 日商堂, est venue ce jour-là lui dire qu'elle voulait faire un don pour installer les toilettes. Quant à la cuisine, le dieu de l'eau a dit que «c'était bon ». Tous ceux qui sont là l'écoutent attentivement et semblent tout à fait acquiescer. C'est parce qu'ils ont été aidés par elle qu'ils sont devenus ses fidèles et l'entourent. "Elle a abandonné tout ce qui la concerne pour prendre sur elle les souffrances des autres », écrit Fujita Shōichi dans son livre. Et de fait, c'est une sorte de communauté centrée sur le religieux qui s'est créée autour de la personnalité de cette femme.

Cette communauté se différencie de celle des autres fudasho, lieux saints intérieurs à Sasaguri. Il s'agit là de relations établies entre la charismatique Ryōsei et le côté le plus profond de la face interne de ces lieux saints.

Les souvenirs du voyage en France et en Europe. - Ryōsei est née catholique. "J'ai trouvé une statue des chrétiens cachés dans le placard de la maison du père de ma mère. Il y avait aussi une photo d'un prêtre catholique que fréquentait ma grand-mère. C'était un Français. "Il y a quelque temps, elle avais émis le souhait : " Je voudrais me libérer de mon vœu et retourner à la vie ordinaire. » Comme Hayashi Kakujō, supérieur du Nanzō-in, devait à ce moment-là se rendre à Barcelone en Espagne pour y célébrer un office à la Sagrada familia, où avait travaillé l'un de ses camarades de collège, le sculpteur Soto.o Etsurō 外尾悦郎, il fut convenu que Ryōsei l'accompagnerait. Elle partit donc pour l'Europe avec l'intention d'arrêter ses activités religieuses. Mais, au Vatican, en Italie, sur la tombe de saint Pierre, puis à Lourdes, en France, elle reçut des messages divins. « Près du tombeau de saint Pierre, quelque chose de bien m'a été dit. Quand j'étais à Rome pour me libérer de mon vœu, j'ai soudain été totalement paralysée par une force non ordinaire (kanashibari 金縛り) alors que j'entendais ces mots : "Renonce à l'avidité et à la cupidité". »De sorte qu'une fois rentrée au Japon : «J'ai alors pris conscience que le fait de manger est de l'avidité, comme l'est aussi le fait d'élever des animaux de compagnie ${ }^{28}$. C'est pourquoi j'ai décidé de reprendre les choses depuis le début. Dès lors, tout s'est mis à aller bien. » Aussi a-t-elle finalement continué ses activités comme avant.

Dans la cuisine, il y a deux statues de Marie qu'elle a achetées à Lourdes, avec des offrandes de roses qu'elle aime. Elle en a aussi mis une autre dans la pièce où se trouve celle d'Amida et où elle dispense ses oracles.

Ryōsei, complètement épuisée par ses activités qui l'obligent à utiliser des pouvoirs subtils, était partie en voyage vers les lieux saints du catholicisme situés à l'extérieur du Japon mais qui n'en étaient pas moins le point de départ de sa propre démarche intérieure, en formulant au plus profond d'elle-même le souhait de mener une vie

28. Jusque-là Ryōsei avait de nombreux chiens. 
comme tout le monde. Mais ce qu'elle y a acquis, c'est en fait une nouvelle certitude religieuse. Suivant l'oracle « Renonce à l'avidité et à la cupidité », qui n'était autre qu'une voix intérieure, elle a pu reprendre, à son retour au Japon, sa vie de spécialiste religieuse telle qu'elle l'avait menée jusqu'alors.

Les PRATIQUes D'ASCÈSE. - Pour comprendre comment Ryōsei a gagné la confiance de ses disciples et fidèles, il importe de savoir comment, par des pratiques où sa vie était mise en jeu, elle a acquis sa certitude intérieure. Nous suivrons le déroulement de ses pratiques par le biais de ses paroles, recueillies par Fujita Shōichi.

"Je vais te sauver la vie, mais travaille à sauver les êtres. » C'est conduite par cette voix que Ryōsei s'est engagée dans le chemin de l'ascèse en commençant par une " pratique de cent jours » (byakunichi no gyō 百日の行). Durant cette période, le bouddha Dainichi, revêtu d'or et d'argent, se tenait toujours devant ses yeux. Puis, elle a effectué une «pratique de trois ans et trois mois » et s'est rendue dans toutes les montagnes et à toutes les cascades. C'est alors qu'au cours de pratiques face à Benzaiten 弁財天 du mont Seburi 背振山 (Fukuoka), elle a entendu ce message : "Reçois l'ordination devant le bouddha Shaka 积迦如来 du fudasho $n^{\circ}$ I du pèlerinage de Sasaguri. »C'est ainsi qu'elle s'est rendue au Nanzō-in et que naquit Shōzaki Ryōsei, disciple de Hayashi Kakujō. Après cela, alors qu'elle faisait un

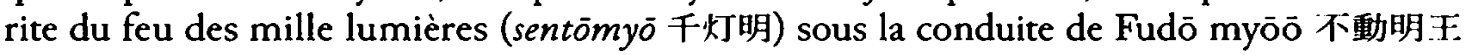
à la cascade Shiranami 白波の滝 du mont Abura 油山 (Fukuoka), elle a vu apparaître au milieu des flammes en caractères d'or «Plan du Diamant 》(Kongö-kai 金用界) et a obtenu la connaissance du rituel secret permettant de supprimer les enchaînements karmiques (innen) en ce monde. Puis, alors qu'elle faisait le rite du feu (goma 護摩) devant les statues des Seize Arhats (Jüroku rakan 十六羅漢) du mont Seburi, cette fois elle aperçut dans les flammes les caractères «Plan de la Matrice " (Taizō-kai 胎藏界). Grâce à ce rite du feu, elle est devenue capable de sauver les âmes qui, à cause d'enchaînements karmiques, ne peuvent atteindre la bouddhéité (jōbutsu 成仏).

Á la dernière étape de ses pratiques d'ascèse, quelqu'un est entré chez elle. Elle s'est aperçue que c'était la Vieille du bord du fleuve (Shözuka bāsan ショウズカ婆さん) que l'on traverse pour aller dans les Enfers, qui lui disait : «Viens vite. » Par la suite, Hayashi Kakujō du Nanzō-in lui a demandé de devenir la gardienne du Dainichi-ji, le $28^{e}$ fudasho. Or en s'y rendant, elle a vu que la statue principale de ce temple était Dainichi, le bouddha qui tournoyait autour d'elle au moment de la pratique des cent jours, et que devant la grande statue d'Enma, roi des Enfers, se tenait celle de la Vieille qui lui était apparue. Aussi, une fois terminée cette période de mille jours de pratiques et après avoir fait l'expérience en son corps de l'univers ésotérique Shingon, Ryōsei est-elle devenue supérieure du Dainichi-ji, le « temple de Dainichi », qui n'est autre que l'univers lui-même ${ }^{29}$.

Quand Ryōsei va prier dans des lieux saints extérieurs à Sasaguri, des oracles lui sont transmis par des personnages qui y sont liés. C'est aussi ce qui s'est passé lorsqu'elle s'est rendue sur les lieux saints du catholicisme, et il en a été de même à Kyōto. Alors qu'elle était assise devant les statues de Kannon du temple Sanjūsangen-dō 三十三間堂 de Kyōto, Kasuga no Tsubone 春挶 ${ }^{30}$ lui a dit : «Ce que tu as demandé lorsque tu étais sous la cascade a été entendu. Ton vœu sera exaucé. » Aussi retournet-elle y prier chaque année.

29. Shōzaki Ryōsei et Fujita Shōichi, Omikuji. Shinbutsu no utsuwa to narite, p. 38-82.

30. Kasuga no Tsubone (1579-1643) a été la nourrice du troisième shōgun 将軍 Tokugawa, Tokugawa Iemitsu 徳川家光 (1623-I651), et a eu une grande influence au début de l'époque Edo. (N.D.T.) 
Elle pratique souvent sous la cascade, surtout sous celle du Nanzō-in, où il est possible de bien percevoir le monde des âmes et des dieux. Et si elle a commencé à y aller, c'est parce que «cela le lui a été dit ». La première fois, elle s'est rendue à la cascade Yōrō 養老の滝, en dessous de l'Oku-no-in 奥の院 (《oratoire du fond») du mont Wakasugi 若杉山. C'était pour briser les enchaînements karmiques de quelqu'un appelé Hosu ホス : ainsi l'âme d'un ancêtre de cette personne apparut, et dit qu'elle ne s'éloignerait pas d'elle; les gens qui assistaient à cette scène crurent que Ryōsei elle-même était cette âme. Aussi se sont-ils tous mis à la frapper à la tête avec leur bâton à anneaux. Ce n'est qu'une fois sous la cascade du Nanzō-in qu'elle put guérir complètement de ces blessures. Cet épisode remonte à 1982, à l'époque où elle en était encore au début de ses pratiques, environ au centième jour de l'ascèse de mille jours. Il semble que la pratique de la cascade permette à Ryōsei de faire se manifester les pouvoirs qu'elle a en elle-même.

Lors de ces cent premiers jours, seul lui est apparu le monde des dieux et des bouddhas, sous la conduite de Fudō myōō. Elle passait alors la nuit dans des lieux propices à la retraite au plus profond de la montagne. Un jour, alors qu'elle était au mont Rai 雷山 (près du mont Seburi), comme il y avait trop de vent pour allumer des bougies, elle fit brûler ensemble de nombreux bâtonnets d'encens. Kannon lui dit alors : "Merci pour le parfum de l'encens. " Pour Ryōsei qui perçoit le monde subtil, communiquer avec les dieux et les bouddhas, êtres de ce monde subtil, se fait sans rupture, comme s'il s'agissait d'une conversation de la vie ordinaire.

Mais les affaires de ce monde ne s'en sont pas pour autant éloignées de Ryōsei. Durant la période d'ascèse de mille jours, alors qu'elle faisait ses pratiques dans la campagne et dans les montagnes, les fidèles qui venaient avec elle étaient tous des gens qui avaient fait faillite ou qui étaient malades. Aussi son mari lui dit-il de quitter la maison, ajoutant qu'il allait la placer à l'hôpital psychiatrique. Toutefois, sa deuxième fille Tomoko 知子 est toujours restée auprès d'elle. À cause des dettes contractées pendant cette période, son mari s'est montré très dur avec elle. Cependant sa mère défunte lui est apparue pour arranger la situation. Les dieux "règlent " aussi les dettes, lui a-t-elle dit. Et quand elle a construit le bâtiment principal du Dainichi-ji, le dieu qu'elle vénère comme protecteur lui a dit également : "Ça ira, car c'est moi qui travaille. »

Quand elle ne fit qu'un avec le bouddha Dainichi, elle se mit à briller si intensément qu'elle crut qu'elle était devenue chauve. Mais c'était cette divinité qui, volant dans le ciel, s'était unie à elle. À cette époque, au premier coup d'œil sur quelqu'un, elle voyait immédiatement tout ce qui le concernait. Aujourd'hui encore, quand elle fait la récitation des sütra, elle peut voir comme à la lumière d'une bougie. On lui a d'ailleurs répété les propos d'un astronaute, selon lequel que les bougies du Dainichi-ji se voyaient comme une seule et même lumière.

Les récits du monde réel et ceux du monde subtil s'enchâssent sans aucune rupture dans le fil de son discours. Alors qu'elle parle de ses pratiques les plus rigoureuses, elle introduit une réflexion sur les difficultés que lui causent ses dettes. Elle relate ensuite de quelle façon, grâce à l'aide des ancêtres et des dieux, elle a réussi à rembourser ces dettes, dont la somme était exorbitante. Ce sont ces expériences 
ainsi racontées par Ryōsei qui m’ont permis de saisir ce que signifiait son expression 《récipient des dieux et des bouddhas » (shinbutsu no utsuwa 神仏の器).

C'est à l'extérieur de Sasaguri que Ryōsei a commencé ses activités de spécialiste religieux charismatique. Puis sous la direction du supérieur du Nanzō-in, et par le biais de ses pratiques sous la cascade de ce temple, alors qu'elle était venue du dehors de Sasaguri, elle devint supérieure du Dainichi-ji, fudasho du dedans de Sasaguri. Tout en assurant sa fonction de supérieure, c'est-à-dire la face religieuse officielle dans le cadre de cet espace saint du pèlerinage, elle est devenue elle aussi un être du plus profond de l'intérieur de ce même espace pour tous ceux qui viennent vers elle en comptant sur ses pouvoirs.

Les PAROles De L'UNE de SES DISCIPLES. - Au Dainichi-ji, il y a toujours un certain nombre de disciples qui s'occupent de Ryōsei et du temple. Voici ce que m'a raconté l'une d'elles:

J'ai arrêté mon travail pour venir ici en 1986. À l'époque, les bâtiments ressemblaient plutôt à des fourrés. C'était aux alentours de la $2^{\mathrm{e}}$ année après l'arrivée de Shōzaki sensei (maître) ici. Elle allait en pèlerinage le mercredi à Sasaoka 筒, et le samedi à Nakagawa 中IIl. Pendant son absence, je rangeais sa maison pour l'aider. Le voisinage s'étonna bientôt des transformations du temple depuis le changement de supérieure. Shōzaki sensei était arrivée vers 1983. La maison d'habitation d'alors avait le plancher tout gondolé. Mais elle dit qu'elle voulait d'abord bâtir le bâtiment principal du temple. Dans les premiers temps de ma venue ici, elle disait vouloir construire le temple pour y vénérer le Bouddha principal. Mais les dons ne venaient pas et elle dut s'y adonner pleinement. Ensuite elle a aussi reconstruit l'oratoire du grand roi Enma, vers I983 ou 1989. Mais c'est seulement une fois achevée la reconstruction du bâtiment principal du temple qu'elle a enfin commencé à s'occuper de son lieu d'habitation.

Cette femme, l'une de ses disciples, a été le témoin des changements drastiques survenus au Dainichi-ji autrefois délabré. Ryōsei a la conviction que « les dons reçus de ceux qui sont venus [lui] demander conseil appartiennent aux dieux et aux bouddhas ». Et c'est avec ces dons qu'elle a reconstruit le temple et les oratoires. Aujourd'hui, si les gens disent que le Dainichi-ji est « le temple des fleurs », c'est parce qu'elle aime les fleurs, sous lesquelles sa maison et toute l'enceinte sont quasiment ensevelies.

LA LiGnÉE DES GARDIENnEs (dömori 堂守) DE L'oratoIRE DE DAINICHI. — «Ce lieu où j'exerce mes activités ", dit Ryōsei, "a été fondé par la nonne Hayashi Shinkō 林真光, la première supérieure. On a les photos de cette première supérieure, de la deuxième, Fuchigami Ryōon 淵上良音, et de la quatrième, Miyake Myōshū 三宅 妙秀, mais pas celle de la troisième, Okamoto 岡本. »Voici ce qu'elle dit de Miyake Myōshū :

J'ai 78 ans cette année (2007). La gardienne qui m'a précédée, Miyake Myōshū, m’a dit qu'elle avait vécu ici presque 30 ans. Elle habitait dans cette pièce. J'ai pris sa succession avant sa mort. Elle est morte quelques années après mon installation dans ce bâtiment. Comme je ne savais rien de ce qu'il fallait faire, je voulais habiter avec elle pour apprendre auprès d'elle. Mais nous n'avons pas vécu ensemble. Je suis arrivée ici vers I98I. J'ai entendu dire qu'elle avait reçu l'ordination au Nanzō-in ou à l'A kashi-dera 明石寺, le $43^{\circ}$ fudasho. 
Elle s'est retirée à la cascade de Chizuru 千鶴滰. Elle vivait de la pension de son mari. Il y avait les fidèles, mais ce temple était alors délabré.

\section{La première gardienne, Hayasbi Shinkō 林真光. - D'après Ryōsei :}

Hayashi Shinkō était fille d'une riche maison de Fushimi 伏見 à Kyōto. Toutefois, des circonstances ont fait qu'elle dut être vendue (comme prostituée). On lui banda les yeux et elle fut embarquée sur un bateau, puis débarquée à Hakata. Elle travaillait à Nakasu 中州 de Hakata. Il semble qu'elle ait été rachetée par Iwasaki Yatarō 岩崎弥太郎 de l'entreprise automobile de Mitsubishi 三菱自動車. À cause de sa beauté, deux hommes entrèrent en conflit, et moururent. C'est ce qui lui fit prendre la voie bouddhique. De son temps, ce temple connut une grande prospérité. C'est elle qui a planté le prunier du jardin. C'est par l'intermédiaire du Nanzō-in qu'elle serait venue ici.

Selon le livre de Yokota Toyoji 横田豊次 ${ }^{31}$, son vrai nom était Mitsu ミツ. Elle est née dans la banlieue de Kyōto à la fin du XIX ${ }^{e}$ siècle (au début de Meiji). L'entreprise de tissus de son père ayant fait faillite, elle fut vendue comme avance sur les remboursements de ses dettes, dans le quartier de Gion à Kyōto ; elle avait alors 14 ans. Après un an de sévère apprentissage, elle devint geisha à Hakata, sous le nom d'Ayame あやめ. Elle était d'une beauté exceptionnelle et à cause d'elle, deux jeunes gens se querellèrent. L'un tua l'autre et fut ensuite condamné à mort. Ainsi tous les deux moururent. Cette tragédie la décida à quitter le monde. Elle reçut l'ordination bouddhique du premier supérieur du Nanzō-in, Hayashi Kaku.un, et, en 1899 , fonda son propre temple au $28^{c}$ oratoire du pèlerinage de Shikoku à Sasaguri, sous le nom d'ermitage Shinkō-an du Dainichi-ji 大日寺真光庵. C'est ainsi que naquirent la nonne Shinkō et le Dainichi-ji. Elle mourut après la guerre, en I950, à l'âge de 79 ans.

La quatrième gardienne, Miyake Myōshū 三宅妙秀. 一 Shichijō Kinue 七条衣重 du Chizuru-ji 千鶴寺 que nous retrouverons dans la partie suivante, évoque Myōshū en ces termes :

Avant Shōzaki Ryōsei, c'est Miyake Myōshū qui vécut longtemps au Dainichi-ji. Elle y était quand mon père est venu ici vers 1961, après avoir pratiqué l'ascèse au mont Ishizuchi 石鎚山 et reçu l'ordination au Maegami-ji 前神寺, situé sur cette montagne. À l'époque de Miyake, j'accompagnais souvent mon père au Dainichi-ji. Pour moi, elle était comme ma grand-mère et prenait soin des affaires de notre temple et de nous. Ses fidèles s'occupaient des affaires de la maison. En 198I, nous l'avons accueillie au Chizuru-ji.

Le Dainichi-ji a toujours été géré par des supérieurs qui étaient des femmes. La première, Hayashi Shinkō, s'était faite nonne à cause de la mort de deux hommes attirés par sa beauté. Sur la deuxième et sur la troisième, je n'ai pu obtenir que peu d'informations. Quant à la quatrième, Miyake Myōshū, Ryōsei s'en souvient bien, de même que Kinue du Chizuru-ji qui en parle comme de sa grand-mère. Les parents de Kinue entretinrent avec elle des relations amicales tout au long des années qu'elle passa au Dainichi-ji. Et c'est finalement chez eux, au Chizuru-ji, qu'elle mourut. Ceci permet de penser qu'elle aussi faisait des pratiques d'ascèse (gyōja 行者), mais

31. Yokota Toyoji 横田豐次, Zange no Kuwa. Hayashi Shinkō-ni den 鐵侮の鍬——林真光尼伝 (La houe de repentance : biographie de la nonne Hayashi Shinkō), 1982, p. 5-193. 
on n'en sait guère davantage. La première supérieure et l'actuelle Ryōsei ayant reçu toutes deux l'ordination au Nanzō-in, il est clair qu'il s'est tissé des liens étroits entre ce temple et le Dainichi-ji au fil des générations de gardiennes.

La supérieure actuelle, Shōzaki Ryōsei, venue du debors, est devenue un être du dedans par sa fonction de supérieure du Dainichi-ji, et son activité religieuse en tant que « récipient des dieux » détenteur de pouvoirs fait d'elle un acteur religieux ancré au plus profond du religieux. Comme la plupart des disciples de Ryōsei, l'une d'entre eux est elle aussi venue du dehors, attirée par les pouvoirs de cette dernière. Pour entrer dans cet espace privé au fond du sacré, elle est allée jusqu'à quitter son travail. Et c'est en tant qu'être du monde profane qu'elle soutient de l'intérieur le rôle religieux de Ryōsei. Ses fonctions sont analogues à celles des épouses des hommes supérieurs de temple : ceux-ci remplissent leur rôle sacré au premier plan, tout en dépendant de leurs épouses, êtres du dedans. Ici, c'est une ancienne fidèle devenue disciple qui apporte son concours pour soutenir la vie quotidienne profane à l'intérieur du temple.

\section{Le Chizuru-ji 千鶴寺 de Gō no Haru 郷之原 ( $n^{\circ} 12$ du pèlerinage)}

Le Chizuru-ji se situe au fin fond de Gō no Haru. Selon la tradition, Chizuru (Mille grues), le nom de la cascade de cet endroit, viendrait de Miyake Chizuru 三宅千鶴, guerrier invité du fief Kuroda 黒田藩 (fief de Fukuoka à l'époque Edo), qui aurait pratiqué sous cette cascade alors qu'il s'entraînait à la maîtrise du sabre ${ }^{32}$. Les adeptes shugen 修験 des monts Hōman 宝満山 et Hiko 英彦山 (département de Fukuoka), dont le parcours rituel passait par cet endroit où ils pratiquaient l'ascèse de la cascade, auraient donné au lieu le nom de «Gyō no hara » 行の原, c'est-à-dire "Champ des pratiques », devenu par la suitc Gō no Haru. Quant à l'origine du temple, le premier supérieur, Shichijō Chizan 七條智山, qui était un yamabushi 山伏 adepte du shugendō 修験道, y a d'abord ouvert en 1952 le « lieu d'entraînement de la cascade de Chizuru » (shugen dōjō Chizuru no taki 修験道場千鶴の滝). Puis en 1960, ayant racheté les droits de propriété du $12^{e}$ fudasbo alors situé à Haginoo 萩尾, il a fait de son dōjō le nouveau $\mathrm{n}^{\circ}$ i2 du pèlerinage.

Shichijō Kinue 七條衣重 vit depuis longtemps dans ce temple avec ses parents qui l'ont fondé en 1954. Elle est née en I96i à Shimonoseki, où se trouvait la maison paternelle de sa mère. Ses parents, tels qu'en parle Kinue, semblent avoir été d'authentiques pratiquants de l'ascèse. Ses paroles expriment la fierté qu'elle éprouve à leur égard.

SON PÈre ChIzAN. - Chizan, son père, était adepte shugen du mont Ishizuchi (Shikoku) et a pratiqué l'ascèse au temple Maegami-ji. Sa fille rapporte les nombreuses anecdotes le concernant, selon lesquelles il guérissait les malades par ses pouvoirs (bōriki 法力). S’il n'avait rien à manger, il faisait des tournées pour recueillir

32. Kumamoto daigaku bungaku-bu chiikikagaku-ka minzoku kcnkyūshitsu 熊本大学文学. 部地域科学科民俗研究室, éd., Sasaguri Shikoku Hachijü bakkasho. Reijō to fudasho no genzai 筗栗 四国八十八力所一一霊場と札所の現在 (Les 88 lieux saints du nouveau Shikoku de Sasaguri : la situation actuelle des lieux saints et des stations de pèlerinage), 1988, p. 27-29. 
des dons (takubatsu 托鈄). Il se rendait souvent chez ses fidèles pour des rites de guérison ou des rituels du feu. C'était l'un de ces pratiquants de l'itinérance (jugyō 遊行) dont font partie les adeptes shugen, soufflant dans une conque, parcourant tout le pays pour faire des collectes et manifestant des pouvoirs, dont les effets sur les malades faisaient d'eux ses fidèles. Il célébrait les funérailles de ceux qui étaient trop pauvres pour en payer les frais. Le son de sa conque était si puissant qu'il était admiré de tous. Ses grandes connaissances lui valaient aussi le respect de tout le monde. Ce que l'on dit de lui au Nanzō-in, auquel il apportait souvent son aide pour le grand rite du feu shugen, atteste également la confiance que lui portait ce temple.

Lors de sa fondation par Chizan en 1952, le lieu d'entrainement shugen de la cascade de Chizuru était hors de la numérotation du pèlerinage (bangai 番外). S'il est devenu fudasho, c'est sans doute grâce aux liens que Chizan établit avec Kakujō, le supérieur du Nanzō-in à cette époque. Ce changement de statut de bangai à fudasho éclaire l'évolution des relations entre l'intérieur et l'extérieur de Sasaguri. Cet adepte du shugendō, venant du dehors de Sasaguri, y a trouvé un lieu qui lui est apparu comme le meilleur pour la pratique de la cascade et a décidé de s'y installer pour le restant de ses jours. Ainsi a-t-il commencé son activité religieuse dans ce lieu nommé «shugen dōjō de la cascade de Chizuru ». À cette époque, le Chizuruji était encore un temple hors numérotation, et Chizan était quelqu'un du dehors par rapport au dedans du pèlerinage de Sasaguri. Mais grâce aux échanges avec le Nanzō-in, lieu central et symbole même de l'autorité religieuse interne de Sasaguri, il a pu obtenir le titre de fudasho pour le Chizuru-ji, devenu le nouveau $\mathrm{n}^{\circ}$ i2 du circuit. Cela a permis à Chizan de devenir non seulement un spécialiste religieux du dedans, mais aussi un être du fond du sacré par ses pouvoirs.

Kinue désigne les pouvoirs reconnus à son père par le terme bōriki 法力, littéralement " pouvoirs de la Loi (bouddhique) ", notion qui fait partie des connaissances transmises par son père, adepte shugen. Ses explications sur ces pouvoirs témoignent de sa propre position et de son orientation comme spécialiste religieux.

SA MÈre TADAKO ただ子. — Tadako, la mère de Kinue, était elle aussi adepte du shugendō du mont Ishizuchi. Après la mort de son mari, elle prit la qualification religieuse minimale lui permettant d'exercer à sa place, mais elle pensait ne pas avoir suffisamment de légitimité, ce qui l'empêchait de participer aux cérémonies des autres temples. Pourtant, elle faisait des rites pour ceux qui venaient les lui demander, répondait aux consultants, délivrait des oracles. On comprend par là qu'elle avait réussi à gagner la confiance des visiteurs. Sans avoir entendu l'histoire des consultants, elle devinait exactement leur demande, simplement en regardant leur visage. Cette attitude dénote une solide conviction et de la confiance en soi. En outre, l'importance que revêtaient pour elle les activités religieuses transparaît dans ses propres mots : "Ce n'est pas en faisant une simple prière qu'on peut comprendre ", ou encore " $\mathrm{Si}$ vous ne pouvez assurer votre vie quotidienne, allez donc faire des collectes de dons."

Elle avait aussi de la largesse d'esprit, ce que l'on peut deviner dans ce qu'elle disait de la supćricurc du Jimyōhō-in 慈妙法院, Yamamoto Seien 山本聖圆, dont nous parlerons ci-après : "Tout abandonner pour prendre cette voie comme elle, c'est absolument extraordinaire. " Tadako savait reconnaître ceux qui mènent 
d'authentiques activités religieuses. C'est aussi ce qui fait dire à Kinue, sa fille, qui a su discerner la force intérieure de ses parents : « La concentration intérieure, il l'ont acquise par la pratique. Tous deux faisaient des pratiques d'ascèse que personne ne fait. » On peut imaginer que dans son enfance, Kinue ressentait quelque mécontentement lorsque sa mère ne pouvait lui promettre d'aller faire des courses avec elle ou qu'elle ne pouvait l'avoir pour elle seule. Néanmoins, on perçoit, dans les paroles de Kinue, la confiance qu'elle avait en la force religieuse de ses parents.

Tadako, née au-dehors, a pratiqué l'ascèse à l'extérieur, et était quelqu'un du dehors. En venant à Sasaguri avec son mari adepte du shugendō, et tout en s'occupant des aspects séculiers des activités religieuses de celui-ci, cette femme est devenue quelqu'un du dedans de cet espace religieux. Dans le même temps, elle n'a cessé de faire des pratiques d'ascèse, sur le mont Ishizuchi, puis sous la cascade à Sasaguri. Ainsi, en tant que charismatique manifestant des pouvoirs, elle était également un être du fond de ces lieux de pèlerinage, qui, après la mort de son mari, assura un rôle religieux de premier plan, comme supérieure du Chizuru-ji.

KinUE ET SON MARI. - Élevée par des parents liés tout d'abord au culte du mont Ishizuchi, qui étaient fiers de leur fonction religieuse et dont elle reconnait les pouvoirs et la force intérieure, Kinue se montre digne, par ses capacités, d'être l'héritière du talent charismatique maternel. Faisant sans cesse preuve de respect envers ses parents et pour leur attitude religieuse, au fil du dialogue, elle apparaît comme décidée à prendre leur relève. Elle souhaite également que ses enfants lui succèdent plus tard. Aussi les invite-t-elle à mots couverts à pratiquer sous la cascade. Son mari ne va pas au-delà de sa position et de sa fonction de moine et supérieur de ce temple Shingon. Elle semble donc attendre que ses enfants aillent au-delà.

Par ailleurs, en tant que fille du temple, elle tient une position difficile dans la localitć où il lui a fallu mener une vie réservée. Elle laisse aussi entrevoir une sorte de tristesse de n'avoir pu bénéficier comme elle l'aurait voulu de l'attention de sa mère qui était toujours trop prise pour s'occuper d'elle. Mais elle lui est reconnaissante de lui avoir permis d'aller travailler au Ninna-ji 仁和寺 de $\mathrm{Kyōto}^{33}$, où elle a pu échanger avec des condisciples qui partageaient cette même expérience de filles de temple. Elle a alors pu goûter une liberté qui aurait été impossible pour elle à Sasaguri. Et c'est avec un grand entrain qu'elle évoque ses souvenirs de Kyōto.

Ayant passé son enfance au Chizuru-ji, fudasho de Sasaguri, Kinue est une femme du dedans. Or, en tant que fille élevée par des parents charismatiques et adeptes du shugendō, et ayant eu sous les yeux de multiples aspects de leur activité religieuse, elle n'a pu ignorer les grandes espérances que manifestent à son égard les fidèles venus du dehors. C'est pourquoi, après une période d'interruption, elle a continué les pratiques sous la cascade : elle y fait déjà des invocations pour ceux qui sont en difficulté. Elle répond aussi aux fidèles, qu'elle a commencé à aider de ses conseils. Autrement dit, elle a déjà pris conscience de sa position de spécialiste charismatique en puissance. Et les fidèles de longue date lui ont dit : «Prends la relève ! » Ces soutiens la fortifient certainement dans la conscience qu'elle a de ce qu'elle doit

33. Temple Shingon de Kyōto. (N.D.T.) 
accomplir. Kinue, tout en étant femme du supérieur du temple, et, par là, dans la position de quelqu'un qui soutient de l'intérieur les fonctions religieuses officielles du temple face à l'extérieur, montre la conscience et le comportement de quelqu'un qui veut s'affirmer comme spécialiste religieux utilisant des pouvoirs. Ainsi l'on peut dire que si elle assure une fonction séculière de l'intérieur, elle assure aussi déjà ce rôle charismatique au plus profond du religieux, et différent de celui du supérieur qui, lui, a la charge des aspects officiels de premier plan.

\section{Les femmes des temples surnuméraires (bangai 番外)}

L'une des particularités du pèlerinage de Shikoku à Sasaguri est la présence d'un grand nombre de bangai 番外 : ces temples non inclus dans le comput des quatrevingt-huit temples du parcours n'accueillent pas seulement les pèlerins circulant d'un fudasbo à l'autre, mais disposent aussi de tout un éventail de réponses aux multiples afflictions qu'on vient confier à leurs responsables. Ici exercent ceux qui sont couramment appelés des « intercesseurs 》 (ogamiya san 拝み屋さん), ou 《invocateurs ». Ces derniers sont quasiment tous des gens venus de l'extérieur de Sasaguri : ils ont trouvé ici un lieu convenant à des pratiques qui leur sont propres, et ont ouvert sur place un espace rituel. Nous verrons comment ces « intercesseurs » ont découvert ce champ d'attraction qu'est Sasaguri, et comment ils s'y sont installés en devenant ainsi des êtres du dedans de ce périmètre religieux. Nous analyserons également le parcours d'une femme affiliée au Nichiren 日蓮宗, extérieure au pèlerinage de Sasaguri, qui assure la fonction de reidan-shi 霊断師 ${ }^{34}$. Cette femme est l'épouse d'un moine venu à Sasaguri pour y fonder son propre temple Nichiren, parce que c'est un haut lieu Shingon du culte du Grand Maître Kōbō, où n'existait aucun temple Nichiren.

À travers ces différents cas, nous questionnerons la position des spécialistes religieux à l'intérieur de la société locale de Sasaguri pour tenter de mettre en lumière les dynamiques du dedans et du dehors dans les rapports qu'entretiennent les fidèles venus du dehors.

\section{Le Jimyōhō-in 慈妙法院}

Yamamoto Seien 山本聖圆 conduit ses activités religieuses près de la gare Kido Nanzō-in mae 城戸南蔵院駅前. Elle est née en 1940 dans le quartier Sumiyoshi 住吉 à Ōsaka, où son père était forgeron de sabres. Ce dernier est ensuite venu à Kyūshū, où il est entré chez Mitsui 三井 en 194I pour forger les sabres de l'armée. Durant la guerre, il a fait don de trois sabres au sanctuaire de Fushimi Inari 伏見稲荷 à Kyōto, sabres dont Seien, au cours d'un voyage scolaire, a pu vérifier l'existence dans le catalogue. Elle a entendu dire que ses ancêtres étaient des guerriers. Sa mère était fille du chef du village (shōya 庄屋). À la suite de son père, Seien est elle aussi venue à Kyūshū en 194I, avec sa mère et ses quatre frères. Après la guerre, elle est retournée à Ōsaka

34. Voir la traduction et l'explication du terme note 40 , p. 577. 
où elle est entrée au lycée. Mais sa maison ayant été emportée vers 1959 par une inondation, elle est revenue à Kyūshũ sur le conseil de gens de Mitsui.

DEVENIR SUPÉRIEURE D'UN TEMPLE. - Lors de notre première rencontre, Seien a bien souligné que son temple est affilié au Daikaku-ji 大覚寺 de Kyōto ${ }^{35}$. Elle reconnaît à quel point il est important d'avoir reçu l'ordination de façon légitime, de même que son titre de supérieure, ceci à la fois pour avoir des disciples et pour mener des activités religieuses. Elle a donc suivi dans ce but un enseignement religieux au Raizan Sennyo-ji 雷山千如寺 d'Itoshima 系島 (dans le sud-ouest du département de Fukuoka), appelé aussi Raizan Kannon 雷山観音, où elle a reçu l'ordination. Quant à sa nomination au rang de supérieure, elle l'a obtenue au Daikaku-ji après avoir suivi l'entraînement du kegyō 加行 (pratique de l'ésotérisme bouddhique ; sk. prayoga) qui lui a permis d'acquérir le statut d'ajari 阿閣梨 (sk. ācārya) avec l'ondoiement de la transmission de la Loi (denbō kanjō 伝法櫵頂). Selon Seien, il est nécessaire d'avoir accompli cet entraînement des moines afin de pouvoir prier pour les autres, sans quoi l'on n'est rien d'autre qu'un ogamiya.

Son PROPRE TEMPLE. - Avant de venir à Sasaguri, elle habitait à Noma, dans le quartier sud de la ville de Fukuoka 福岡市南区野間. Elle vénérait une petite statue de Fudō myōō 不動明王 devant laquelle venaient prier les voisins. Mais il n'y avait même pas de boîte pour les offrandes.

C'est vers 1983 qu'elle a établi des liens avec Sasaguri, dans un premier temps avec le Chizuru-ji, ceci parce qu'elle s'est trouvée obligée de quitter son habitation de Fukuoka. Et si elle y a trouvé un lieu pour fonder un temple, c'est à la fois grâce au hasard et aux recherches de son mari. Mais elle avait «vu » les lieux : «C'était comme un paysage projeté sur un écran. Il y avait un terrain, des marches ; à l'est, une rivière en forme de $\mathrm{S}$, à droite profonde et à gauche peu profonde ; trois arbres. » Or c'est exactement le terrain qu'à trouvé son mari à Sasaguri. Elle dit pourtant qu'elle n'aimait pas Sasaguri « car il y a trop de temples et beaucoup de monde », et elle aspirait au calme pour se recueillir.

SES ACTIVITÉS EN TANT QUE SUPÉRIEURE. - Le 8 et le 9 avril, elle fait un rite du feu, de même que le 31 décembre, à partir de 23 heures 55 , où elle demande la santé pour ses fidèles au cours de l'année nouvelle. Suivant les requêtes de ceux-ci, elle fait aussi des rites du feu deux ou trois fois par mois pour demander la santé. Tout au long de l'année, elle continue à accomplir pour eux des rites du feu, mais sans aucune demande précise ; simplement, elle n'y fait plus qu'un avec le bouddha. Le deuxième dimanche du mois est le jour de la fête du temple, et les fidèles viennent. Le 3 février, pour la fête du setsubun 節分, elle fait un grand rite du feu shugen où elle brûle tout ce qui a été amassé au cours de l'année écoulée. Le premier samedi de juillet, Seien va avec ses fidèles et ses disciples jusqu'au mont Ishizuchi de Shikoku en prenant le bateau à Kokura. Ils se rendent ensuite au mont Kōya puis au sanctuaire Izumo d'Ōsaka (Izumo taisha Ōsaka bunshi 出雲大社大阪分京), avant de rentrer en avion depuis l'aéroport du Kansai. Ce voyage dure 5 jours.

35. Temple Shingon de Kyōto. (N.D.T.) 
Les rites du feu sont majoritaires dans les ritualités de Seien, car pour cette disciple de maîtres du Shingon et du Shugen, c'est le moyen le plus efficace de procurer de l'aide à autrui. Quant au pèlerinage annuel au mont Ishizuchi, il repose sur les liens qu'elle entretient avec le Chizuru-ji.

LES PRATIQUES D'ASCÈSE (shugyō 修行). - C'est parce que cela l'intéressait que Seien s'est, dit-elle, engagée dans cette voie. Le déclencheur a été le pèlerinage des Trente-trois Kannon de Kyūshū qu'elle a fait à l'âge de 38-39 ans ${ }^{36}$. Puis, dans la presqu'île de Kunisaki 国東半島, elle a pratiqué la suppression de la parole, celle du sommeil, celle de la nourriture cuite, et ainsi de suite une semaine pour chaque : se taire, c'est pour arriver à la concentration intérieure ; veiller, c'est pour l'emporter sur soi-même. C'est vers 1982 qu'elle a pensé devoir faire des pratiques d'ascèse, et elle les a commencées en 1983. En voyant les passants, elle laissait alors échapper : "Celui-là va mourir », ce qui mettait en colère ses voisins. Dès avant son ordination, en tout cas, elle adorait aller dans les temples. Elle rapporte ainsi son parcours :

À 23 ans, un moine rencontré dans la rue, alors qu'il recueillait des aumônes, m'a dit : "Vous aiderez les autres. » $\grave{A}_{33}$ ans, un autre m'a dit à nouveau : "Si vous ne vous mettez pas à aider les autres, à 50 ans vous serez dans un fauteuil roulant. » Toutefois, $\dot{a}$ ce moment-là, je n'ai pas pris leurs paroles au sérieux. En 1983, à Fukuoka, j'ai senti sur un côté des hanches comme si l'on m'enfonçait des baguettes de fer rougies au feu, et je ne pouvais plus marcher. Cela s'est reproduit deux fois, et chaque fois ce fut la même chose. J'en ai parlé ce soir-là à mon mari, qui m’a dit : "C'est un message. Il t'est arrivé ce que t'avait dit ce moine. "Néanmoins, comme je ne savais pas ce que je devais faire pour aider les autres, je suis partie pratiquer la marche dans la presqu'île de Kunisaki. C'est à cette époque que j'ai rencontré ce sensei du $12^{c}$ fudasho. J'étais allée à Sasaguri, sur le conseil de mon mari. Et m'étant perdue, je me suis retrouvée dans ce temple. C'est ainsi que j'ai rencontré maitre Tadako de la cascade Chizuru. C'était le jour de la fête du temple et plusieurs centaines de personnes étaient assises dans le bâtiment principal pour assister au rite du feu. Tous priaient dans la fumée, recouverts de sueur. À cettc vuc j'ai pensé que je voulais faire la même chose. Je fréquente toujours ce temple. Lorsqu'il a brûlé dans un incendie, j’y suis allée tout de suite. Avec la précédente supérieure, nous étions comme des sœurs. Elle est allée elle aussi au mont Ishizuchi. Un jour, elle m'a dit de prendre sa succession. Mais je ne voulais pas le temple de quelqu'un d'autre. Elle a une fille, que je considère comme la mienne. Je suis allée fréquemment à la cascade Chizuru et mon mari, lui aussi, est allé dans ce temple pour rendre service. À l'époque de maître Tadako, la cascade était puissante car la supérieure avait une grande force d'invocation. Aujourd'hui, la cascade est sans puissance. Après la mort de la supérieure Tadako, cette cascade m'est devenue déplaisante, je n'arrivais plus à y entrer. J'ai arrêté la pratique de la cascade parce que pour moi ce n'était plus nécessaire, et y entrer m'était devenu désagréable. Maître Tadako est née en 1927 et morte à l'âge de 66 ans ; jusqu'à sa mort, elle n'a cessé de pratiquer l'ascèse de la cascade, et moi aussi. J'ai la vision subtile, mais je n'entends pas de sons. Quand mon maître du temple de Raizan est mort, à ce moment même, je l'ai vu assis à côté de moi. J'étais alors à Ōsaka.

Seien a établi avec le Chizuru-ji des relations dont nous avons parlé précédemment. Tadako, la mère de Kinue, qui était la précédente supérieure, faisait donner

36. Il faut noter que dans la suite de son récit, les âges indiqués sont quelque peu contradictoires. Il y a sans doute une confusion dans sa mémoire. 
l'ordination en groupe à ses disciples par le supérieur du Maegami-ji, temple du mont Ishizuchi où elle-même avait suivi son entraînement. Mais Seien, n'étant pas convaincue par cette ordination collective, a préféré la demander et la recevoir au temple du Raizan. C'est ensuite au Daikaku-ji de Kyōto qu'elle a poursuivi sa formation dans le but de fonder son propre temple. Avant d'en arriver là, elle n'a cessé de faire des pèlerinages dans tout le pays et a inventé ses propres pratiques. L'événement qui l'a décidée à s'engager ainsi fut donc, comme elle le dit, cette annonce que deux moines itinérants lui ont faite chacun, alors qu'elle avait 23 et 33 ans, avec l'avertissement, la seconde fois, qu'elle serait victime d'un handicap physique si elle ne se conformait pas à cet avis. L'expérience qu'elle fit à 40 ans de l'impossibilité de bouger est ce qui l'a amenée au Chizuru-ji. Elle dit avoir atteint le sommet de ses pratiques d'ascèse vers l'âge de $37-38$ ans, au moment où elle est entrée en contact avec le temple Raizan.

On a l'impression que Tadako et Seien, qui ont pratiqué de la même façon et, par là, acquis des pouvoirs religieux similaires, se comprenaient mutuellement. Kinue l'atteste en disant que sa mère admirait la supérieure du Jimyōhō-in, qui a pratiqué au risque de sa vie pour entrer dans cette voie : Tadako soutenait, dit-elle, que celui qui va jusque-là peut tout obtenir du bouddha qu'il révère. Pourtant, Seien a éprouvé une certaine réticence à l'égard du fait que la mère de Kinue n'avait pas le titre permettant de conférer l'ordination à ses disciples. C'est certainement pour cette raison qu'elle souligne avoir elle-même obtenu au Daikaku-ji l'ondoiement de la transmission de la Loi nécessaire à sa légitimité.

PERCEPTION SUBTILE (reikan 霊感), POUVOIRS DE LA LOI (bōriki 法力) ET POUVOIRS OCTROYÉs (kuriki 功力). — Selon Seien :

Il est nécessaire d'avoir le pouvoir de vénérer l'entité au centre de ses pratiques cultuelles pour réaliser la fusion avec elle, c'est-à-dire " l'entrée en soi (du bouddha) et l'entrée de soi (dans le bouddha)» (nyüga ga.nyū 入我我入).

J'ai la perception subtile (reikan 霊感) de naissance. Elle est supérieure à tout. C'est par là que l'« on prend les oracles»(mikuji wo toru みくじをとる). C'est ce que m'a appris mon maître du mont Raizan. C'est différent des pouvoirs de la Loi (bōriki 法力) qui font prendre conscience de ce que l'on fait et qui s'acquièrent par la pratique rigoureuse. Les pouvoirs de la Loi sont obtenus par l'effort. Mon maître, lui, possédait ce que l'on appelle les «pouvoirs octroyés 》 (kuriki 功力), qui jaillissent spontanément et sont accordés par le bouddha. Ce monde est terrible et précieux à la fois. Je suis heureuse d'aider les autres... Lorsque je fais le rite du feu (goma 護摩), j’utilise les pouvoirs octroyés, pas ceux de la Loi.

Seien m'a ainsi expliqué de quelle manière distinguer la perception subtile, les pouvoirs de la Loi et les pouvoirs octroyés. Selon elle, il faut donc avoir le pouvoir d'invoquer le bouddha principal, et de fusionner avec lui. Mais elle dit en outre avoir la perception subtile de naissance, c'est-à-dire qu'elle reconnaît avoir la capacité de spécialiste des oracles (reinōsha 霊能者). Quant aux pouvoirs de la Loi, acquis par l'ascèse, et aux différents moyens de perception subtile, ils correspondent à son aptitude de pratiquant de l'ascèse (gyoja 行者), et elle les distingue des pouvoirs octroyés par le bouddha dont son maître du mont Raizan disposait de façon spontanée.

Seien est originaire d'Ōsaka. C'est pour des raisons relatives au travail de son père qu'elle est venue à Fukuoka et c'est à la suite d'un problème physique qu'elle s'est mise 
à pratiquer l'ascèse. Toutefois, elle dit avoir été avertie dès sa jeunesse par des moines de passage qu'elle aurait un avenir de spécialiste religieux. Aussi l'entrée « dans cette voie » a-t-elle été pour elle le moment où elle a « reconnu » que ce qui lui arrivait physiquement en était le «signe » annoncé. Elle souligne l'aide que lui a toujours apportée son mari. C'est lui qui l'a incitée tout d'abord à entrer dans la voie de l'ascèse, en l'incitant à reconnaitre dans son infirmité soudaine la réalisation de ce qui lui avait été annoncé. C'est lui qui a trouvé le terrain du temple actuel à Sasaguri. Seien et son mari sont venus de l'extérieur de Sasaguri ; mais à la différence des spécialistes religieux précédents, c'est l'époux qui est le soutien interne pour cette femme devenue spécialiste du religieux. Seien a pratiqué l'ascèse, a reçu l'ordination puis le statut d'ajari et le titre de supérieur, tout ceci grâce à l'aide de son mari, qui a assuré les aspects intérieurs profanes de leur vie, lui permettant ainsi d'assumer son rôle sacré au premier plan. On peut dire que c'est grâce à lui qu'elle a pu s'engager sans hésiter dans cette voie de spécialiste religieux.

Concernant la position de Seien, venue du dehors, comme celle-ci pratique ses activités religieuses à l'intérieur de l'espace du Nouveau pèlerinage de Shikoku à Sasaguri, on peut dire, à ce titre, que c'est quelqu'un du dedans. Mais dans le même temps, en tant que responsable d'un temple hors numérotation, c'est aussi quelqu'un d'extérieur par rapport à l'intérieur de cet espace du pèlerinage. En outre, comme spécialiste religieux faisant usage de pouvoirs, elle se situe également au plus profond du sacré. Ajoutons enfin qu'elle a conscience de sa propre légitimité religieuse en tant que supérieure d'un temple affilié légitimement à la branche du Daikaku-ji, qui est extérieure à Sasaguri.

\section{Le sanctuaire Beni-bime Inari 紅姫稲荷神社 et le Renshō-ji del'École Nichiren 日蓮宗蓮照寺}

À ro minutes à pied de la gare de Sasaguri, se dresse, sur une petite colline, le sanctuaire Beni-hime Inari 紅姫稲荷神社. L'histoire des origines du sanctuaire ${ }^{37}$ relate ainsi qui fut Beni-hime, "la princesse Pourpre" :

Beni-hime, fille de Sugawara no Michizane ${ }^{38}$, avait accompagné son père dans son exil à Dazai-fu. Après la mort de celui-ci, poursuivie par les partisans des Fujiwara, elle mourut à cet endroit, alors qu'elle était en route pour apporter une lettre de son père à son frère aîné qui se trouvait à Kōchi 高知 (Shikoku). Ayant pitié de sa mort, les habitants du lieu édifièrent un oratoire dédié à son âme qu'ils vénérèrent de génération en génération comme dieu Inari (Inari gami 稲荷神).

37. Beni-bime Inari-sha engi 紅姫稲荷社縁起 (texte du panneau explicatif à l'entrée du sanctuaire).

38. Sugawara no Michizane 菅原道真 (845-903), noble et lettré du début de l'époque de Heian, devenu ministre de droite sous l'empereur Daigo 醍醐天皇 : sur calomnie de Fujiwara no Tokihira 藤原時平, il fut exilé en 90 à Daizai-fu, où il mourut. Quantité de désastres et de calamités survenus après son exil et sa mort ayant été attribués à la vengeance de son âme « rancuneuse 》 (goryō 御霊), il fut réhabilité puis vénéré comme dieu du Ciel, Tenjin 天神, au sanctuaire Kitano Tenman-gū 北野 天満宮 de Kyōto. Sur les âmes rancuneuses, voir Anne Bouchy, "Du bon usage de la malemort : traitement des "âmes rancuneuses" et rituels oraculaires dans la société japonaise ", dans Brigitte Baptandier (sous la dir.), De la malemort en quelques pays d'Asie, 200I, p. 20I-234. (N.D.T.) 
Dans la ligne de cette tradition locale, c'est le comité des commerçants et artisans de Sasaguri qui a administré ce sanctuaire jusqu'à la fondation du Renshō-ji en I952, après quoi ce temple en a assuré les célébrations. À la suite de l'achat de cette terre en 197I, le Renshō-ji a reconstruit en 1976 un nouveau sanctuaire Beni-hime Inari, où fut transférée l'âme de Beni-hime, et à qui fut décerné le titre de Roi céleste suprême Beni-hime de Yamazaki ${ }^{39}$. Depuis, le sanctuaire de Beni-hime est géré par le Renshō-ji. Ce temple doit sa renommée non seulement à l'histoire de Beni-hime, mais aussi à la fonction de reidan-shi 霊断師 ${ }^{40}$, " conseiller spirituel ", assurée par Takeuchi Taeko 竹内夕工子(妙子) : née en 1934 à Kagoshima 鹿児島, elle est la femme du supérieur aujourd'hui décédé. Nous verrons plus loin les grandes lignes de la vie de Taeko.

Le SANCTUAIRE BeNi-HIME INARI. - En I97I, Taeko et son mari ont acheté, en même temps que le terrain sur lequel il se trouve, ce sanctuaire qui jusque-là avait été géré par le comité des commerçants et artisans de la commune. C'est lors d'une absence de son mari, qui était parti pour la " pratique rude » (aragyō 荒行) du bouddhisme Nichiren, qu'elle a appris que la terre était en vente. Son mari lui a alors écrit de s'en porter acquéreur. Elle a donc fait un emprunt de 5 millions de yens à la banque pour l'acheter et a déclaré le sanctuaire comme un établissement religieux à personnalité juridique. C'est elle qui a ainsi mené à bien toute la procédure à la place de son mari.

LE RENSHō-JI ET LES MOINES de LA FAMILle. -

C'est le père de mon mari, Shōshin 正信, décédé en 1983, qui a fondé le Renshō-ji. Il était originaire de Shikoku et est venu travailler à Kyūshū dans les mines de charbon de Tagawa 田川 (département de Fukuoka). C'est alors qu'il a commencé à faire des pratiques au Myōan-ji 妙安寺, dans le quartier Tōjin-machi 唐人町 de Hakata, sous la direction du maître Ōno Seijun 大野正純. Il a obrenu en r933 sa qualification de moine au dōjō 渞場 (《lieu de pratiques 》) du mont Minobu 身延山 de Yamanashi 山梨41. Ayant entendu dire que Sasaguri était un site de pèlerinage placé sous l'autorité du bouddhisme Shingon, mon beau-père y est venu pour y implanter le bouddhisme Nichiren dont il voulait diffuser l'enseignement. Tout au début, il a utilisé tel quel l'ancien pavillon de quarantaine qui se trouvait ici ; puis,

39. Saijōi Yamazaki Beni-hime tennō 最上位山绮紅姫天王.

40. Le terme reidan, composé de rei 霊 (《âme 》) et dan 断 (《trancher/rompre »), est souvent interprété comme le fait de supprimer les effets néfastes des âmes sur les vivants. Pour s'opposer à cette interprétation décrétée erronée, l'Association Reidan-shi-kai 霊断師会 du Nichiren a donné une définition officielle du terme reidan. Celui-ci serait l'abréviation de la formule bouddhique ryözen jōdo dangi shösbin 霊山倢土断疑生信, c'est-à-dire "trancher le doute pour éveiller en soi la foi en la Terre Pure de la Montagne sacrée " (autrement dit, être certain de l'existence du paradis bouddhique). La " Terre Pure de la Montagne sacrée » désigne le mont de l'Aigle (ou des Aigles), Ryōju-sen 霊第山 (sk. Grdhrakūṭa-parvata), où le bouddha Shakyamuni dispensa son enseignement de divers sūtra, notamment le Sütra du Lotus. Selon cette définition, reidan-shi 霊断師 peut donc être traduit par " maître d'éveil spirituel », et il désigne une fonction de conseiller dans l'Association Reidan-shi-kai du Nichiren. Dans le contexte présent, la compréhension du terme qui est celle de Takeuchi Taeko et de ses consultants reste ambigüe ; aussi avons-nous utilisé dans la traduction soit reidan-sbi, soit conseiller/ère. (N.D.T.)

41. Fondé par Nichiren 日蓮 en 128I, le Kuon-ji du mont Minobu 身延山久遠寺 (Minobu, Yamanashi 山梨県身延町) est le temple principal de l'École bouddhique Nichiren. (N.D.T.) 
chaque année, il a construit de nouveaux bâtiments et il a fini par démolir l'ancien en 1994. Mon mari, Genkō 元幸, est devenu maître des rites (shubō-shi 修法師) au mont Minobu, où il a pratiqué l'ascèse. Moi, je suis née à Kagoshima et je me suis installée à Sasaguri après mon mariage en 1955 . L'année suivante, en 1956 , mon mari a commencé la " pratique rude ", l'aragyō Nichiren, durant ro jours au mont $\mathrm{Minobu}^{42}$, et il est allé jusqu'à la cinquième étape, ce qui était son souhait. Il a continué ensuite à Nakayama 中山 ${ }^{43}$. Au mont Minobu, comme la température tombe en dessous de zéro, l'eau que l'on verse sur soi provoque des gerçures et des crevasses sur tout le corps. Aussi, comme on ne peut pas s'essuyer avec des serviettes, se sèche-t-on en mettant un vêtement blanc, dit "absorbe-eau » (mizutori 水取). Les fidèles, souhaitant les leur voir porter, donnent ces vêtements aux pratiquants qui, une fois la période d'ascèse terminée, les lavent pour y calligraphier le mandala ${ }^{44}$ avant de les rendre aux fidèles. Ces derniers les gardent comme vêtement (kyö-katabira 経帷子) dont on les revêt au moment de leur décès. Mon mari, Genkō, est mort en 1995 à 67 ans, sans voir l'achèvement du bâtiment principal, terminé en 1997.

Le beau-père de Taeko semble avoir été un homme de caractère, et même quelqu'un qui avait l'esprit d'opposition, pour avoir construit un nouveau temple Nichiren au cœur même d'un espace dominé par le Shingon. C'est en travaillant à la mine de Tagawa qu'il a décidé de devenir moine Nichiren, et il a ensuite choisi pour terrain le lieu où se dressait un hôpital pour malades en quarantaine, dont il a d'abord utilisé tel quel le bâtiment. C'était une ancienne léproserie. Or les temples Nichiren ont administré de nombreux établissements pour lépreux, comme le Keifūen 恵楓園 de Kikuchi 菊池 à Kumamoto.

De nombreux moines Nichiren partent pour la «pratique rude » (aragyō) de Ioo jours, en plein hiver, sur le mont Minobu. Durant leur absence, ce sont leurs paroissiens qui assurent les charges financières du temple et les frais de cette retraite. Si le temple n'a pas assez de paroissiens, les moines ne peuvent y participer. C'est ainsi pour des raisons économiques que le fils de Taeko n'a pu aller au-delà de la troisième étape de cette pratique. L'accomplissement de l'aragyō permet aux moines, une fois de retour dans leur temple, de voir affluer les fidèles qui souhaitent faire appel à leurs pouvoirs. Ceux qui ont accompli cette «pratique rude » font ensuite le tour de tous les temples Nichiren de leur département, pour faire une prestation de l'« ascèse de l'eau 》 (mizugyō 水行), consistant à se verser des seaux d'eau sur la tête, comme il l'ont fait pendant l'aragyō. Puis, tous les moines revêtent le vêtement blanc et une étole blanche, et font pour les fidèles les rites de protection avec l'épée en bois qu'ils ont reçue à la fin de l'ascèse. Ayant une barbe de ioo jours, ils ont alors l'air de vrais maîtres des rites correspondant à l'image qu'en ont les fidèles.

42. Cette «pratique rude » du mont Minobu faite dans sa totalité dure 100 jours entre novembre et février (période la plus froide de l'année), et elle consiste en une alternance de séances de versements d'eau sur soi avec un seau ( 7 fois par jour) et de récitations de sütra, associées à des privations de sommeil (limité à 3 heures par jour) et à une alimentation minimale. (N.D.T.)

43. Hokekyō-ji 法華経寺, temple fondé en 1260 par Nichiren et situé à Nakayama d'Ichikawa (Chiba) 千葉県市川市中ll. (N.D.T.)

44. Il s'agit du « mandala du Sūtra du Lotus » de Nichiren, calligraphie des caractères du nom de ce sūtra entouré par ceux des bouddhas, bodhisattvas et nombreuses autres figures mentionnées dans le Sütra du Lotus. (N.D.T.) 
L'aragyō a lieu chaque année au mont Minobu, temple principal du bouddhisme Nichiren, ainsi qu'au Hokekyō-ji 法華経寺 de Nakayama.

TAEKO, « CONSEILlER SPIRITUEL 》 (reidan-shi 霊断師). — Taeko est titulaire du titre de reidan-sbi 霊断師 décerné par l'association des reidan-sbi du Nichiren, qui a son siège au Kōryū-ji 幸龍寺 à Tōkyō $\bar{o}^{45}$ :

Je suis devenue reidan-shi en 1967. Reidan est mentionné dans le dernier écrit de Nichiren. Chaque année depuis 1955, le congrès national des reidan-shi a lieu au mont Minobu. Ce sont les difficultés matérielles qui m'ont conduite à devenir conseiller spirituel. À l'époque, mon mari ne pouvait assumer sa tâche de supérieur à cause d'une pneumonie. Notre fils aîné, le supérieur actuel, venait d'entrer en première année d'école primaire et notre fils cadet n'était pas encore scolarisé. Aussi me suis-je décidée à obtenir le diplôme pour assurer les finances du temple. Maintenant que notre fils Yōryō 曜良, Teruyoshi de son nom profane, est devenu supérieur, et que les aspects matériels de notre existence sont assurés, mon travail est davantage fondé sur les liens avec les visiteurs que sur des nécessités financières. Ils viennent me voir après avoir entendu parler de ce que je fais. Je ne fais aucune publicité. Ce travail, autrefois méprisé, fait maintenant partie du parcours des spécialistes religieux Nichiren. Pour obtenir le diplôme, les hommes font la « pratique rude » au Hokekyō-ji à Nakayama, les femmes suivent un cours de 35 jours, sans « pratique rude », au mont Minobu. J'ai suivi un cours de 8 jours. Je suis affiliée à l'Association des femmes des temples Nichiren, nommée après guerre Jitei-fujin kai 寺庭婦人会. Une fois devenue reidan-shi, j’ai fait des pratiques vers 1975 au mont Minobu. La discipline y est sévère : lever à $4 \mathrm{~h} 30$, office à $5 \mathrm{~h}$, petit déjeuner et étude de la doctrine. Le bain est remplacé par des ablutions d'eau froide ; on doit manger sans rien laisser et ne pas bavarder.

Le reidan, c'est voir (miru 見る) ${ }^{46}$ la maladie, les affaires humaines, la prise d'emploi, le concours d'entrée à l'université, les brouilles. Il est interdit de chercher à voir le moment de la mort de quelqu'un. Même si l'on comprend quand cela va se passer, il ne faut pas en parler. Les consultants viennent de tous les coins du département de Fukuoka. Il arrive qu'on me consulte par téléphone depuis Tōkyō. Autrefois, il y avait chaque jour une vingtaine de visiteurs. Je n'avais pas le temps de manger. Ils ont été nombreux jusqu’à la construction du bâtiment principal du temple. Lors de consultations concernant les âmes, j'ai souvent fait des rites pour les morts. Généralement, je fais un service pour toutes les âmes abandonnées (segaki kuyō 施餓鬼供養). En cas de problèmes liés aux tombes, il peut se produire des cas de possession (byōi 恣依). La source de la santé est la vénération. Chaque matin, je me recueille une heure devant Beni-hime sama. Il m'arrive de recevoir des oracles. Parmi les visiteurs, certains me demandent : "Est-ce que je ne serais pas possédé par quelque chose de mauvais ? 》 Quelqu'un m'a dit un jour : «Quand je suis dans le bain, je vois une mer de sang ", et j'ai alors vu que cette personne était possédée par une femme. Le I3 du mois est le jour de la célébration de la mort de Nichiren ; aussi fais-je, ce jour-là, un service pour toutes les âmes abandonnées (segaki kuyō), et également lors de la fête des morts (o-bon お盆). Pour construire le bâtiment principal du temple, il a fallu trois cents millions de yens. Quand il n'y a plus eu besoin de l'argent, les visiteurs ont diminué. C'est lorsqu'il a fallu assumer plusieurs tâches en même temps que j'ai pensé que ce travail n'était pas quelque chose que l'on peut faire avec les seules forces humaines.

Devenue reidan-shi pour des raisons familiales et pécunières, Taeko, qui a fait des pratiques au mont Minobu, dit qu'elle voit les causes des problèmes de ses

45. Karasuyama, Setagaya-ku 東京都世田谷区鳥山.

46. Ici « voir » désigne une compréhension des situations obtenue par la vision intérieure ou subtile. (N.D.T.) 
consultants et qu'elle fait des rites pour les morts. Lorsque ces problèmes dépendent des « âmes》( $r e i$ 霊), elle parle de «nuisance» (sawari さわり) causée aux personnes concernées par les âmes des ancêtres ou d'autres catégories d'âmes, laquelle se manifeste sous la forme de troubles physiologiques. Dans ce cas, elle propose des rites pour apaiser ces âmes. Comme elle dit parfois « recevoir des oracles », on peut penser qu'elle a la capacité de faire face elle-même à l'influence de ces âmes. C'est pourquoi les visiteurs ont afflué tant et si bien que, durant un temps, elle n'avait pas même le temps de manger.

Selon les informations du site de l'association des reidan-shi de Karasuyama à Tōky $\bar{o}^{47}$, le reidan-sbi donne des conseils de façon à orienter favorablement le destin «en utilisant le rituel secret “kushiki reidan-bö" 九識霊断法, qui est une actualisation concrète de la vénération envers le Sütra du Lotus». Lorsqu'on a obtenu un reidan de la part d'un conseiller, on reçoit l'amulette gushō-reijin-fu 具生霊神符 qu'il faut ensuite acheter chaque mois, car elle est renouvelée mensuellement.

Taeko, née à Kagoshima, s'est installée à Sasaguri à l'occasion de son mariage. Dans ce sens, c'est quelqu'un du debors. Le premier supérieur du Renshō-ji était originaire de Shikoku. Il était venu à Kyūshū à la recherche de "liens (karmiques) » (en 縁), et c'est par ce biais qu'il est devenu moine Nichiren. Il est surprenant qu'il ait établi ce temple Nichiren au cœur même du pèlerinage de Shikoku à Sasaguri, cette zone sous obédience Shingon. Géographiquement et religieusement parlant, lui aussi est donc indéniablement quelqu'un du debors. Pour s'installer, il a pu bénéficier d'un bâtiment qui était un ancien pavillon hospitalier de quarantaine, où étaient notamment isolés les lépreux. Par là également, Taeko et sa famille, bien qu'habitant à l'intérieur de Sasaguri, se trouvaient en fait situés dans ce qui était un debors à l'intérieur même de cette commune.

L'oratoire de Beni-hime Inari, géré à l'heure actuelle par le Renshō-ji, tant pour les aspects rituels qu'administratifs, est lui aussi marqué par l'extériorité. L'entité qui y est vénérée, Beni-hime Tennō, a toutes les caractéristiques de l'âme terrible propitiée et vénérée sous forme de goryō pour être apaisée, puisque, selon l'histoire des origines de l'oratoire, elle était la fille du tragique Sugawara no Michizane, et mourut au cours d'un voyage. Dans la mesure où Beni-hime est une « voyageuse morte accidentellement », il n'y aurait rien d'étonnant à ce que soit associée à son nom une telle tradition néfaste. Car dans la religion populaire, l'entité venue du dehors qui est susceptible d'être de type goryō est souvent considérée comme une source de calamités : c'est pourquoi elle finit souvent par être vénérée comme une divinité protectrice. En l'occurence, c'est tout à fait le cas de Beni-hime, âme malheureuse de l'extérieur, aujourd'hui objet d'un culte local. Quoique je n'aie pu recueillir sur place de traditions orales à ce sujet, cette histoire laisse supposer que c'est en raison de sa mort accidentelle qu'on imputa à son âme la cause de quelque calamité arrivée en ces lieux et, par là, qu'on en vint à la vénérer. Autrement dit, si l'un des aspects du fait religieux coutumier japonais est de transformer en divinité protectrice locale une entité de type terrible venue de l'extérieur, on peut penser que

47. <http://www.reidanshikai.jp/> (dernier accès le 9 juin 20I4). 
Beni-hime est un bon exemple de la façon dont une puissance du debors relevant de cette catégorie est transformée en objet de culte du dedans.

En tant qu'épouse du supérieur d'un temple Nichiren, Taeko se situe au fond du religieux. Elle a d'abord assumé, du dedans, le rôle de soutien séculier pour trois générations de supérieurs : son beau-père, son mari et son fils, qui, eux, assuraient la part du religieux et du sacré. Mais pour subvenir aux besoins de sa famille, elle a choisi de suivre une formation religieuse au mont Minobu, centre du bouddhisme Nichiren, où elle est devenue conseillère spirituelle. Aujourd'hui, même si ce n'est plus par nécessité, elle continue tout de même ses activités de reidan-shi qui l'ont rendue célèbre localement. Comme elle l'indique elle-même en mentionnant qu'elle " reçoit des oracles ", ses activités ont également un contenu qui tend vers celles des religieux détenteurs de pouvoirs. Aussi se situe-t-elle en fait à une position intermédiaire entre le religieux officiel et le profane.

\section{Celles qui se rendent à l'extérieur de Sasaguri}

\section{À la suite d'un maître}

À Wakasugi, où se trouve le temple qui est considéré comme l'Oku-no-in du Nouveau pèlerinage de Shikoku à Sasaguri, il existe une organisation locale appelée l'Association du sommet sacré, Reihō-kai 霊峰会 ${ }^{48}$. Ses membres, qui sont les habitants de ce quartier de Sasaguri, entretiennent les forêts et assurent la gestion matérielle de l'Oku-no-in, où ils tiennent une boutique dont ils gèrent la vente des amulettes et des talismans. Cette boutique est gardée alternativement par les membres de l'Association Wakana (Wakana-kai 若菜会), que composent principalement les femmes au foyer des 48 familles affiliées à l'Association du sommet sacré.

L'une d'entre elles, Yasukōchi Junko 安河内淳子, est née à Wakasugi en 1935 et fait aussi partie du groupe des femmes qui se réunit pour chanter les hymnes du pèlerinage (goei-ka 御詠歌). Sa famille est affiliée de génération en génération au temple paroissial Sonnō-ji 尊能寺 de la Vraie Terre Pure (Jōdoshin-shū 浄土真宗). Néanmoins, elle a pris une voie différente de celle des gens de Wakasugi. L'occasion en fut la rencontre avec une femme de l'extérieur de Sasaguri, pratiquant l'ascèse (gyōja) et qu'elle nomme " le maître de Shime » 志免49.

LE MAÎTRE DE Shime. — Yokota Shinmyō 横田信妙, décédée il y a plus de ro ans, est le maître dont Junko respecte encore aujourd'hui l'enseignement, et dont elle continue à visiter les lieux de pratique, dans la région nord de Kyūshū, où celleci l'emmenait autrefois. Maître Yokota appartenait à la catégorie des spécialistes

48. Sur le Reihō-kai 需峰会, voir dans ce même volume les contributions de Suzuki Masataka, "Continuités et transformations de la société locale : le fait coutumier dans le village de Wakasugi ", P. 27-II4 et celle d'Anne Bouchy, "Les rapports communautaires aux espaces forestiers entre politiques du dehors et stratégies du dedans : les montagnes-forêts de Sasaguri », p. II5-202.

49. Commune proche, située au sud-ouest de Sasaguri, entre Sue 須恵町, Kasuya 粕屋町 et l'arrondissement Hakata de Fukuoka 福岡市博多区. 
religieux qui ont l'expérience de la possession, qui pratiquent régulièrement l'ascèse de la cascade et des ablutions, et qui se rendent périodiquement en pèlerinage sur des lieux saints. Leur culte a pour centre les oracles (kuchiyose 口寄せ) des dieux et des bouddhas, que, dans cette région, l'on désigne par l'expression « le vent de la main sort » (tekaze ga deruテカゼが出る). Ce n'est pas seulement maître Yokota, mais aussi les fidèles rassemblés autour d'elle qui manifestent cette capacité oraculaire. Certains compagnons de Junko partagent avec elle cette même expérience d'avoir suivi maittre Yokota : c'est sans doute une des raisons pour lesquelles elle continue à entretenir ce que cette dernière lui a transmis. Mais l'essentiel est certainement que Junko possède elle-même ces capacités, dont elle parle en ccs tcrmcs.

SUR ELLE-MÊME. -

Quantité de choses viennent sur mon corps. Les morts (botoke sama ホトケ様) se reposent sur $m o^{50}$. Ces morts peuvent être ceux de ma famille ou d'autres. Ils provoquent chez moi de terribles bâillements. Mais c'est tout à fait autre chose que de la fatigue physique. Cela a commencé à se produire quelques années après ma rencontre avec maître Yokota. Mes petits-enfants sont eux aussi souvent sujets à des maux divers : c'est parce que les morts se reposent sur eux. Parfois je me dis qu'il aurait peut-être mieux valu ne rien faire. Maintenant, ils (les morts) ont l'habitude de venir se reposer sur moi.

Du vivant de mon maître, je l'accompagnais chaque année les 4 et 5 octobre au rite du feu (obitaki お火焚き) du Goryū Sonryū-in 五流尊澈院 à Okayama 岡山. J'allais aussi avec elle à la cascade de Ni-no-Taki 二の滝 (Sasaguri). Avant que je n'entre sous la cascade, elle faisait le rite de protection des «Neuf Lettres »(kuji 九字). Aujourd'hui, à la place de l'ascèse de la cascade, chaque mois, durant une semaine, je fais la pratique de l'immobilité durant toute la journée (fudō no ichi nichi gyō 不動の…日行), à compter du jour de la célébration mensuelle de Fudō myōō. C'était donc pénible d'aller alors travailler pour le Reihō-kai 霊峰会.

Lorsque ma divinité protectrice est descendue sur moi pour la première fois, c'est d'abord une entité bouddhique qui est venue. Le dieu protecteur, lui, n'arrivait pas à descendre facilement. Ce bouddha est Namikiri Fudō-son 波切り不動尊 (《Fudō qui coupe les vagues»), et mon dieu protecteur est Hachidai Ryūō 八大竜王, les Huit grands rois dragons. Le temps de cette descente est très bref. Je regrette de ne pas avoir pu poser toutes mes questions à ce moment-là. Ceux qui possèdent la perception subtile (reikan) parlent avec les dieux, mais moi je ne le peux pas. Si l'on veut demander quelque chose, il faut consulter quelqu'un qui a la perception subtile. À la maison, je récite le texte d'Inari Gosha daimyöjin 稲荷五社大明神 (pour mon protecteur), et Jūroku Jigaku 十六自我供 pour Fudō-son. Ma fille (née en 196I) et mes petits-enfants l'un étudiant et l'autre lycéen m'accompagnent.

Je pratique devant Hachidai Ryūō. Les âmes des morts viennent se reposer sur moi. Peutêtre ai-je cette capacité de naissance ; en tout cas elles viennent facilement. Je n'aime pas voir les photos des ancêtres chez les autres. J'essaie d'éviter de les regarder, sinon je me sens mal. Je me demande si ces morts ne souffrent pas dans l'au-delà. Mon maître disait toujours que l'autre monde est plus dur que celui-ci. Si la durée de cette vie n'est que de 50 ans, dans l'autre monde, elle est de 3000 ans. Cela veut dire que, si l'on ne vit pas icibas de façon correcte, il faudra assumer cette part en faisant des pratiques dans l'au-delà.

50. Junko utilise le terme tayoru 頼る, qui signifie " compter sur ", " se reposer sur ", " recourir à ». Il est ici employé dans le double sens, corporel et moral, de " se reposer sur », et désigne l'état de celui sur qui viennent, descendent les âmes, les dieux et les bouddhas. (N.D.T.) 
Pour Junko qui dit subir l'intrusion des âmes des morts comme quelque chose de pénible, seuls ceux qui possèdent réellement des capacités subtiles sont à même de maîtriser leur état et de dialoguer avec les entités descendues sur eux. Or elle reconnaît ne pas en être encore arrivée là. Bien que sa famille soit affiliée à la Vraie Terre Pure (qui réfute particulièrement ces pratiques), elle dispose des instruments cultuels du Shingon qui étaient ceux de sa grand-mère. Il semble ainsi que cette famille soit non seulement particulièrement religieuse, mais qu'en outre, elle se transmette de génération en génération une disposition spécifique à la descente des entités, puisque Junko souligne que ses petits-enfants connaissent des états semblables aux siens. Par ailleurs, comme Junko pratique à sa manière, tout en suivant les enseignements de son maitre, elle ressent comme pénible le fait de devoir participer aux activités religieuses communautaires du Reihō-kai qui lient entre eux les habitants de Wakasugi. C'est en suivant son maître que Junko est allée au Goryū Sonryū-in de Kojima à Kurashiki 倉敨市児島 (Okayama), temple qui est l'un des centres du shugen de Kumano 熊野, et c'est là qu'elle a reçu l'ordination bouddhique.

Née à Wakasugi, elle y vit toujours. À ce titre, c'est bien quelqu'un du dedans. Pourtant, tout en maintenant ses relations à l'intérieur de la communauté locale, elle participe parfois avec quelque réticence aux rites religieux de Wakasugi qui reposent sur le lien local, et donne la priorité à ses pratiques personnelles. Cellesci s'appuient sur la confiance et le respect envers celle qui fut son maître, Yokota Shinmyō, et sur le lien avec les fidèles de celle-ci, qui sont tous des gens du dehors de Wakasugi. C'est parce qu'elle n'a pas trouvé de lien religieux satisfaisant à l'intérieur de Sasaguri, qu'elle s'est orientée vers l'extérieur en prenant appui sur sa propre intériorité.

\section{Les compagnes du pèlerinage au sanctuaire d'Ise (Sangū dōgyō 参宮同行)}

Nous avons vu précédemment que Miyamoto Tsune.ichi parlait du pèlerinage à l'époque Meiji. Or à Sasaguri, il existe des «associations d'amis " (tomodachi no kai 友達の会), amicales réunissant ceux qui vont ensemble en pèlerinage au sanctuaire d'Ise 伊势. On appelle cette pratique « aller ensemble au Sanctuaire (d'Ise) », sang $\bar{u}$ dōgyō 参宮同行, terme qui désigne aussi ceux qui s’y rendent, les « compagnons du chemin de pèlerinage au Sanctuaire ». Cette coutume est intéressante sous l'angle adopté par Miyamoto, qui y voit un voyage permettant aux femmes de « connaître le monde ». Or cette coutume existe encore aujourd'hui à Sasaguri.

À Wada 和田, quartier de Sasaguri que ne traverse pas le chemin du pèlerinage de Sasaguri, un groupe de I9 hommes est allé au sanctuaire d'Ise en février 1955, et a fait tout un périple de 17 jours, qui les a menés d'Ise à différents sites, dont deux des célèbres «Trois paysages du Japon »(Nihon sankei 日本三景) ${ }^{51}$, c'est-̀̀-dire Niigata 新潟, Nikkō 日光 et Matsushima 松島, puis à Tōkyō, au Kansai, au mont Kōya et à Miyajima 宮島. Aujourd'hui, dans ce même Wada, on trouve également

5I. Les «Trois paysages du Japon» sont ceux de Matsushima 松島 (département de Miyagi 宮城県), Ama no hashidate 天橋立 (département urbain de Kyōto 京都府) et Miyajima 宫島 (département de Hiroshima 広島県). La liste de ces sites a été établie à l'époque d'Edo. (N.D.T.) 
une association de femmes pour le pèlerinage d'Ise, les « compagnes de route » (onna dōgyō 女同行). À l'heure actuelle, il est difficile de partir Io jours alors que tout le monde travaille. Pourtant la coutume d'un voyage de quelques jours s'est perpétuée. Sakai Takako 境たか子 (née en 1950), qui habite Wada, a participé à un voyage de 3 jours avec un groupe de 15 personnes. Lorsqu'elle est venue dans cette famille à l'occasion de son mariage, aller en pèlerinage à Ise était pour elle tout à fait normal. Quant à Abe Noriko 阿部教子 (née en 1957), elle est allée à Ise en 2002 avec 6 femmes de sa génération, sur les conseils de ses beaux-parents. Après son mariage en 1955, Yasukōchi Junko 安河内淳子 (née en 1935, citée précédemment), qui habite à Wakasugi, a participé à un pèlerinage à Ise avec le groupe des «compagnes de chemin 》 (tomodachi dōgyō 友達同行), qui fut un voyage de 13 jours les menant à Ise, Miyajima, Kyōto, au temple Zenkō-ji 善光寺 de Nagano 長野, au Kenroku-en 兼六園 de Kanazawa 金沢, à Tōkyō, au mont Kōya et à Sendai 仙台. Dans l'enceinte du sanctuaire de Wakasugi, se dressent ainsi des stèles édifiées par les habitants du village qui ont fait le pèlerinage en groupe à Ise.

Cette pratique du pèlerinage à Ise appelée dōgyō, le « voyage de conserve », par un groupe de femmes, ne date pas d'aujourd'hui dans cette région, où elle semble avoir été très populaire : on trouve par exemple, parmi les noms des donateurs d'une statue du bouddha Ashuku 阿閂如来, installée dans l'oratoire de Ta-no-ura Kannon 田浦 镜音 ( $\mathrm{n}^{\circ} 80$ du pèlerinage de Sasaguri), celui du « groupe des compagnes de chemin de la commune de Kanda » (Kanda machi-shü onna dōgyō ichidō 茂田町集女同行一同) et, parmi ceux des donateurs de la statue du bodhisattva Miroku 弥勒菩薩, celui du " groupe des compagnes de chemin de la commune de Kanda Nanbara » (Kanda machi Nanbara onna dōgyō ichidō 获田町南原女同行一同). De fait, des confréries pour le pèlerinage à Ise, appelées “ confréries d'Ise 》 (Ise kō 伊勢講), 《 pèlerinage à Ise » (O.Ise Mairi お伊勢詣り) ou "compagnes/compagnons du chemin de pèlerinage » (sangū dōgyō 参宮同行), ont été répertoriées dans toute cette région de Kyūshū $\bar{u}^{52}$. La plupart sont des confréries masculines ; certaines sont mixtes. D'autres, appelées dōgyo yori 同行寄り ("groupe de compagnons de route »), sont composées de couples qui se réunissent une fois par an. Pour les femmes de la confrérie d'Ise de la commune de Nijō (Itoshima-gun 系島郡二丈町), il est d'usage de constituer une cagnotte pour permettre à deux d'entre elles de partir en pèlerinage deux fois par an à Mei-no-hama 姪浜 ou à Dazai-fu, et parfois au sanctuaire d'Ise. Cette coutume du voyage des femmes pour " connaître le monde » sous le prétexte d'un " pèlerinage à Ise », relevée par Miyamoto Tsune.ichi, est donc également prégnante ici, dans cette région du nord de Kyūshū. Le circuit de 3 jours permet aux femmes de Sasaguri de partir en pèlerinage et correspond à cette demande féminine.

Un très grand nombre de femmes de Sasaguri sont venues du debors de la commune, à leur mariage, pour résider dans la maison de leur époux. Considérée tout d'abord comme une étrangère (yoso mono $\exists$ y者), comme quelqu'un de l'extérieur (soto monoソト者), chacune d'entre elles met longtemps, au fil de la vie quotidienne,

52. Nishi Nihon bunka kyōkai 西田本文化協会, éd., Fukuokaken-shi. Minzoku sbiryō ben : mura no seikatsu, jō 福同织史——民俗資料編: ムラの生活・上 (Histoire du département Fukuoka. Documents relatifs aux faits coutumiers : la vie du village, volume I), 1985, p. 38, 69, 91, I02, 161, 222, 26 r. 
à devenir quelqu'un du dedans. Or, à Sasaguri comme dans toute cette région du nord de Kyūshū, à l'instar des hommes qui, à un certain moment de leur vie, partent en groupe de la même génération pour un pèlerinage à Ise, les femmes ont adopté cette pratique d'un pèlerinage collectif féminin : celui-ci a lieu un certain temps après le mariage, et les belles-mères elles-mêmes les y encouragent. Ici, sortir du dedans pour aller ailleurs prend la forme de cette séquence de la vie religieuse qu'est le pèlerinage à Ise. Pour ces femmes au cœur de la vie séculière, le temps religieux est une ouverture sur l'extérieur.

\section{L'endroit et le revers du monde profane, les mines de charbon de Sasaguri}

\section{L'exploitation minière au Japon et les mines de Sasaguri}

En I873, la première « loi des mines du Japon » (Nihon kōbō 日本坑法) fut promulguée par le $259^{\mathrm{e}}$ décret gouvernemental ${ }^{53}$. Par là, le gouvernement, qui avait nationalisé les mines en 1869 , imposait l'obligation d'une autorisation administrative pour toute extraction minière et tout creusement préalable, ainsi que pour la location des zones minières par les exploitants autres que l'État. Cette loi stipulait que l'industrie minière devait avoir pour but premier de respecter l'intérêt des mines et que les exploitants devaient payer les impôts miniers. L'exploitation anarchique fut ainsi évitée et le progrès technique, accéléré. Le moteur de l'expansion des mines japonaises fut le développement de la Marine et de la défense nationale. Les deux navires de guerre équipés de chaudières à vapeur de dernier modèle, le Naniwa 難波 et le Takachiho 高千穂, avaient besoin annuellement de 7 millions de kin 斤 de charbon, lequel était importé d'Angleterre ${ }^{54}$. Aussi l'exploitation des mines fut-elle accélérée pour assurer l'autonomie de la défense nationale. En mai 1887, un examen de la mine de Shinbaru du village de Sue 須恵村新原 (limitrophe de Sasaguri) permit d'en certifier le charbon comme étant de qualité supérieure : la gestion de cette mine revint alors à la Marine japonaise. L'année suivante, en $\mathbf{8 8 8}$, les mines tout autour furent également désignées comme houillères de réserve pour la Marine. C'est ainsi qu’à Sasaguri, des mines furent ouvertes à Kanaide 金出, Takata 高田, Sasaguri, Onaka 尾仲 et Tsubakuro 津羽黒 (fig. 4).

Le début de l'exploitation minière à Sasaguri remonte au $\mathrm{XIX}^{\mathrm{e}}$ siècle, lorsque l'extraction du charbon fut entreprise par des groupes de villageois de Tsubakuro ${ }^{55}$. En 1873 , quand fut instauré le système des travaux forcés pour les criminels, ceux-ci furent réquisitionnés pour des travaux miniers à la demande d'entreprises nationales et privées, et ils furent rémunérés. À l'époque la plus prospère de l'industrie minière, les criminels condamnés à plus de to ans de travaux forcés furent engagés dans les mines nationales et dans celles de grandes firmes comme Mitsui 三井 à Miike 三池 (Fukuoka). Quant aux prisonniers ayant une peine de plus courte durée,

53. Sasaguri-chō bunkazai senmon-iinkai, éd., Sasaguri chōshi. Rekisbi-ben, p. 8.

54. I kin équivalait à 450 $; 7$ millions de kin correspondent à 3150 tonnes.

55. Sasaguri-chō bunkazai senmon-iinkai, éd., Sasaguri chōshi. Rekishi-ben, p. 8. 


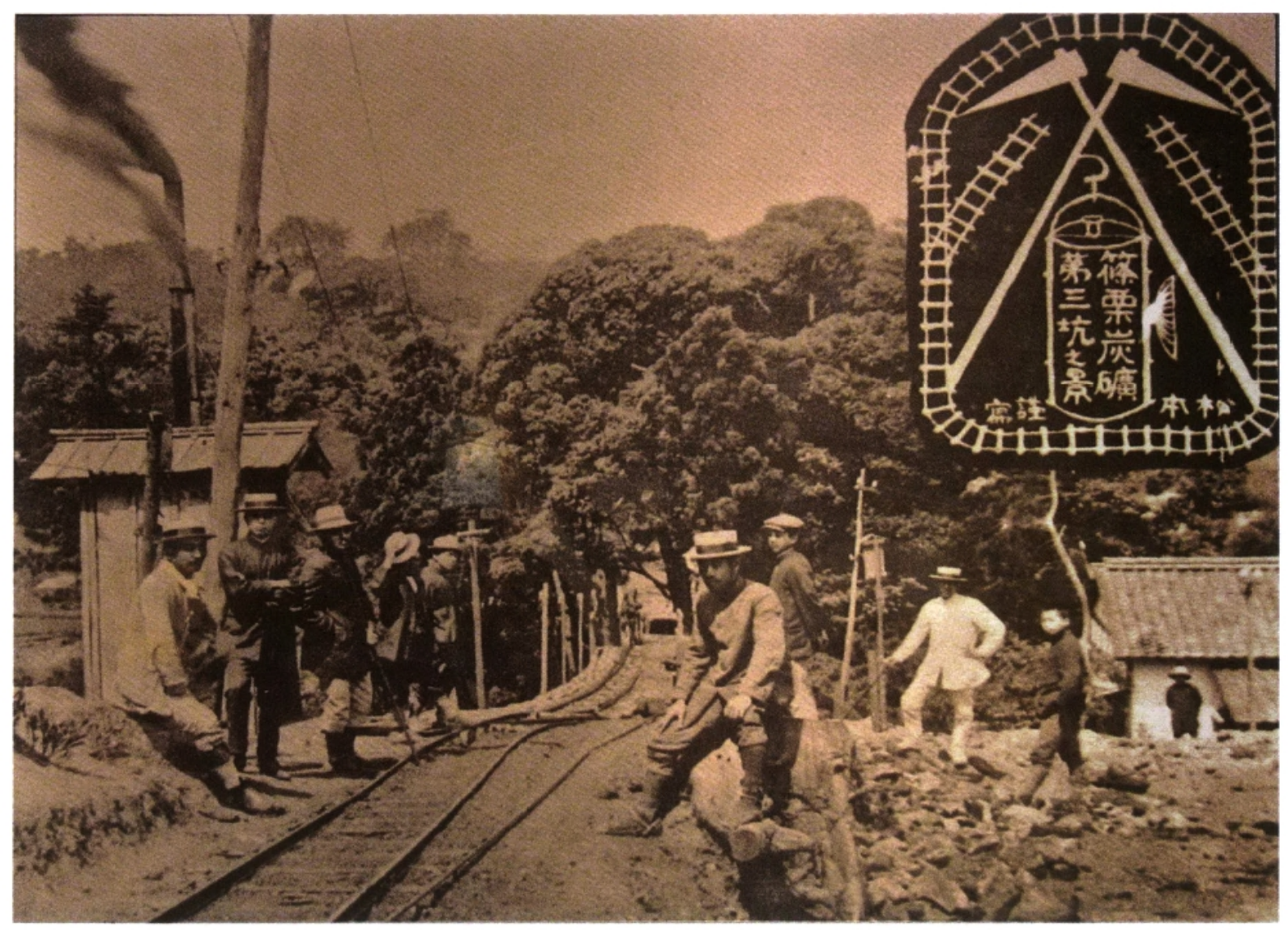

Fig. 4 : Une mine de Sasaguri. (Archives du Centre de documents historiques et de matériaux ethnographiques de Sasaguri)

ils travaillaient dans les mines privées de plus petite envergure. Selon un article de journal de 1885,540 détenus de la prison de Fukuoka travaillaient à Umi 宇美 et à Tsubakuro. Déplacé en I886 dans le village Ōkuma 大隈村 (la commune de Kasuya 粕屋町), le bureau pour la gestion de ces prisonniers, qui jusque-là se trouvait à Tsubakuro, devint le « bureau déplacé d'Ōkuma » (Ōkuma shutsuyaku-sho 大隈出 役所). Située près de la porte principale de l'actuelle école primaire de Kita Seto 北勢門小学校, la prison de Tsubakuro fut utilisée entre 1883 et I886. À cette époque, il y eut de nombreux décès parmi les prisonniers, dont les tombes sans nom subsistent aujourd'hui dans la montagne de Tsubakuro.

En 1892, l'exploitant minier Konomi Takasuke 許斐鷹介 fit fusionner la mine de Takata avec celle de Tsubakuro. Devenue la propriété de Hashimoto Hanjirō 橋本半 次郎 en 1908, celle-ci devint la mine Takata 高田炭鉱. En 1919, elle fut rachetée par la société minière Meiji, et renommée mine Meiji-Takata 明治高田鉱業所. En I924, cette société acheta également la mine voisine de Kubara 久原. La mine Meiji-Takata fut exploitée pendant 44 ans jusqu'à sa fermeture, le 30 avril i960. Aujourd'hui, il n'en reste que des terrils (fig. 5 ). 


\section{La face officielle des mines de Sasaguri}

Nous examinerons tout d'abord quel était le travail dans la mine Meiji-Takata à partir de ce que m'en ont dit deux mineurs qui y ont travaillé : Mita Kikuo 三田 喜久雄, habitant de Shita-machi 下町 à Sasaguri (né en 1927), et Hosokawa Akira 細川暁 (né en 1935).

Mita, qui fut responsable de la mine Meiji, a travaillé to ans dans l'industrie du chrome et 20 ans dans les mines de charbon. Son parcours le mena des mines Hōkoku 豊国鉱業 de Chikuhō 筑豊 à celle de Takata, puis à celles de Shoro 庶路 et de Toyosato 豊里 à Hokkaidō, et à la mine Meiji-Saga 明治佐賀 de 'laku 多久 (département Saga), suivant des mutations tous les 3 ou 4 ans. Ingénieur diplômé de l'université technique de Kyūshū, Hosokawa a participé à l'ouverture des mines Meiji d'Akaike 赤池 et d'Usuki 臼杵 à Tagawa 田川 (Kyūshū), et, pendant la guerre, à celles de Chine, de Corée et de Birmanie. Ces deux hommes ont tous deux travaillé longtemps à la mine Meiji-Takata, comme cadres supérieurs, voici ce qu'ils m'en dirent :

«Entreprise minière de Takata " (Takata kōgyōsho 高田鉱業所) est le nom officiel de la houillère de Sasaguri, dite couramment " mine de Takata » (Takata tankō 高田炭坑). Au sommet de la hiérarchie se tenait le directeur, puis ceux qui s'occupaient de l'extraction, le chef de service et les chefs de sections. Lancées à la fin du XIX ${ }^{e}$ siècle, les entreprises minières Meiji fondèrent la société électrique Yasukawa 安川電機 avec leurs bénéfices. Pour remplacer le charbon, qui était nécessaire au navire de guerre Mikasa était importé d'Angleterre au XIX' siècle, le Japon lança l'exploitation des mines nationales, dont celles de Mitsui et de Shime 志免. Le charbon du bassin houiller de Kasuya avait une haute valeur calorifique et il était utilisable par les navires de guerre. Les prisonniers travaillaient à la mine de Shime, gérée directement par la Marine.

\section{SÉCURITÉ ET ACCIDENTS DANS LA MINE. -}

De l'entrée de la mine jusqu'au chantier, il fallait une heure pour descendre avec le convoyeur sur rails. Entre la galerie de mine et le chantier le plus profond, il y avait $400 \mathrm{~m}$ de profondeur. Les galeries étaient sur plusieurs étages ; c'est là que l'ascenseur déposait les mineurs. Nous y entrions avec des lampes de sécurité pour détecter les fuites de grisou. Ce moyen de détection a été introduit vers 1955. La longueur de la flamme mesurait la densité du gaz. Il y avait des responsables de la sécurité, qui possédaient un diplôme national. À l'intérieur des galeries sort du méthane qui a été comprimé durant plusieurs dizaines de milliers d'années. S'il s'élève entre 3 et $15 \%$, il explose. Dans la mine Mitsui, une explosion a tué 300 personnes en 1955; un autre, 400 personnes dans celle de Hōkoku la même année. Il y a eu de grands accidents dans les mines japonaises. La poussière de charbon s'enflamme, et comme il y a production d'oxyde de carbone, cela provoque une explosion de grande envergure. Il y avait des rites annuels pour demander la sécurité. Dans la mine, il y avait un oratoire qui était consacré au dieu de la montagne (yama no kami 山の神), et affilié au sanctuaire Ōmishima $大$ 島 $^{56}$, où se rendaient chaque année ceux qui travaillaient dans la mine Meiji pour y planter un arbre. Le jour de la grande fête du sanctuaire Ōmishima, les mineurs viennent de tout le pays. À Sasaguri, un sanctuaire se dressait à côté du terril.

56. Île du département Ehime 愛媛 dans la mer intérieure. (N.D.T.) 


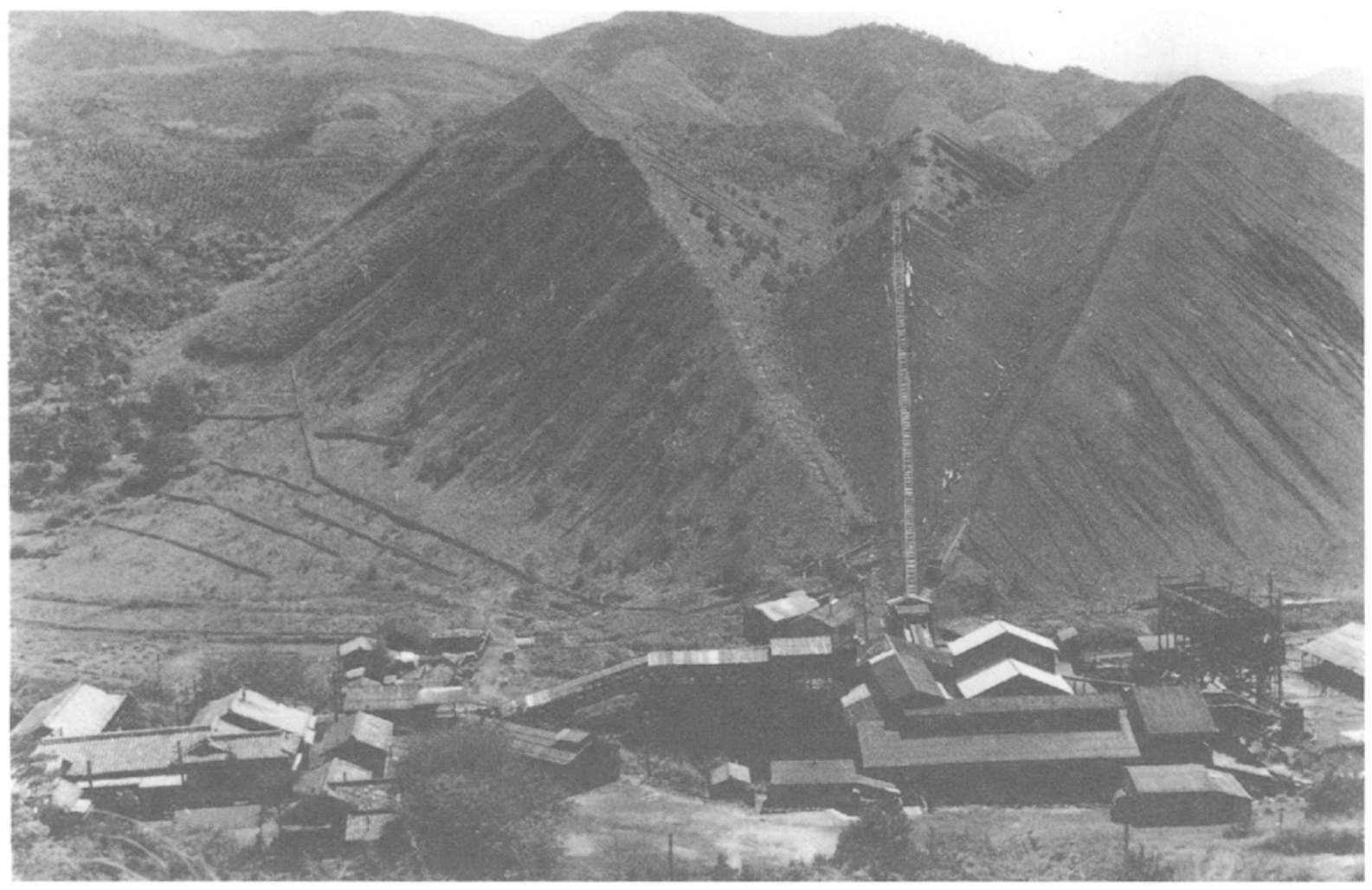

Fig. 5 : Terril de Sasaguri (196r, à la fermeture de la mine). (Archives du Centre de documents historiques et de matériaux ethnographiques de Sasaguri)

Après la guerre, la loi sur la sécuritć minière interdit de travailler nu. Il fallait porter des manches longues, un pantalon et des gants. Après 1955, vinrent s'y ajouter le casque et les chaussures de protection à armature de fer. Avant la guerre, là où il faisait le plus chaud, on ne portait même pas de cache-sexe (fundoshi 神) car, avec la poussière, cela nous irritait la peau. Plus la galerie est profonde, et plus la chaleur est élevée. Tous les 30 mètres, la température monte d'un degré.

Quoique le dimanche soit en principe jour de congé, les mineurs de la première équipe renforçaient les murs et les échafaudages. La loi sur la sécurité minière obligeait à faire des vérifications 3 heures avant le commencement du travail. Aussi deux mineurs vérifiaientils la sécurité le lundi matin avant l'embauche. Nous craignions les endroits où il y avait eu des accident mortels à la suite d'un éboulement, ou les passages les moins fréquentés, car les mineurs les plus anciens nous faisaient peur avec leurs histoires. On y passait en récitant l'invocation au bouddha Amida. Partour dans les mines de petites et moyennes dimensions, il y avait toutes sortes d'histoires terrifiantes; aussi y faisait-on des rites. Lorsqu'il y avait eu une explosion mortelle, aussitôt après avoir transporté les morts, et dès que le gaz avait disparu et que le déblaiement avait été fait, nous recommencions à travailler. Après l'explosion, nous entrions dans les galeries avec des bouteilles d'oxygène pour transporter les morts et les blessés. Avec la pression, le choc de l'explosion réduit le corps en miettes. Monsieur Mita a fait trois fois l'expérience de cette sorte d'accident. On ne peut distinguer de la roche les corps noircis par la poussière de charbon. Ils n'étaient pas montrables aux familles. Comme il y a des risques d'explosions secondaires et tertiaires, c'était extrêmement dangereux. Nous craignions toujours de ne plus revoir 
le jour. Mais comme les familles venaient nous supplier de sortir rapidement les corps, nous descendions malgré tout. Il fallait aussi faire attention à la bouteille d'oxygène qui ne durait qu'une heure et demie.

Les accidents miniers de Sasaguri ont été recensés ${ }^{57}$. Le 29 juin 1920 , s'éleva brusquement un long sifflement. Ce fut le plus grand accident du début du $\mathrm{xx}^{\mathrm{e}}$ siècle dans les mines Meiji. Il y eut un brusque jaillissement d'une importante quantité d'eau qui empêcha toute évacuation. 2I personnes y laissèrent la vie. Il a fallu attendre l'année suivante, en août I92I, pour retrouver tous les morts. La mine Takata n'a connu aucun accident par explosion de grisou et il lui fut décerné en I953 le prix de la meilleure houillère. Mais comme les contrôles de sécurité n'empêchent pas que des accidents se produisent tout de même, parallèlement à la gestion rationalisée, les mineurs continuaient à prier les dieux.

Comme à l'intérieur de la mine, il faisait frais en été et chaud en hiver, on finissait par $s^{\prime} y$ trouver bien ${ }^{58}$. Nos horaires de travail étaient de 8 heures de présence obligatoire et de 5 heures de travail effectif. Le salaire élevé nous procurait une vie agréable. Le travail était organisé selon les trois-huit. De l'entrée jusqu’à la sortie, on restait 8 heures de suite dans la mine. Il fallait une heure pour aller au chantier le plus éloigné, et une autre pour prendre le repas. On travaillait donc effectivement pendant 5 heures. Les mineurs de la première équipe travaillaient de 7 à 15 heures, ceux de la seconde de 15 à 23 heures, et ceux de la troisième de 23 à 7 heures. L'ordre des équipes changeait chaque semaine. La première équipe du samedi pouvait se reposer assez longtemps, du dimanche jusque vers I heure le lundi. Selon les catégories professionnelles, le début du travail pouvait varier d'une heure. On pouvait faire 2 heures supplémentaires lors du changement. Le transport du charbon se faisait pendant les heures de travail effectif, et les heures supplémentaires étaient employées à préparer le chantier pour l'équipe suivante, afin que le relais du travail se passe sans heurt. Chacun faisait à tour de rôle des heures supplémentaires, sur décision des surveillants.

Si ces deux mineurs " finissaient, disent-ils, par se trouver bien » dans la mine, on peut se demander si c'est là ce que tous pensaient. Peut-être parlent-ils ainsi parce qu'ils étaient des cadres supérieurs. Il ne faut pas oublier qu'au début de Meiji, l'extraction minière était ce que l'on imposait aux prisonniers comme travaux forcés, et que les mines étaient des lieux de travail extrêmement pénibles.

LE LOGEMENT ET LA VIE DE TOUS LES JOURS (selon Mita Kikuo). -

Il y avait les « logements des employés » et les « logements des mineurs ", mais habituellement on parlait de "baraquements" (naya 納屋) (fig. 6). Là où l'on utilisait le charbon de qualité inférieure qui n'avait pas été vendu, cela produisait de la fumée ; aussi fallait-il ramoner les tuyaux des poêles toutes les semaines, sinon tout était recouvert de suie. Mais ici, nous consommions des boulets de charbon. Lorsqu'ils étaient grands, les baraquements avaient trois pièces, les autres deux. À la mine Meiji d'Usuki à Saga, la pièce était de $3,6 \mathrm{~m}$ sur $2,7 \mathrm{~m}$. Juste à l'entrée, il y avait une pièce de $10 \mathrm{~m}^{2}$ avec un placard au fond. Sur le côté, une autre de $7,29 \mathrm{~m}^{2}$ et une cuisine de $10 \mathrm{~m}^{2}$ avec un évier et

57. Sasaguri-chō bunkazai senmon-iinkai, éd., Sasaguri chōshi. Rekishi-ben, p. 8.

58. Le locuteur utilise l'expression sumeba miyako 住めば都, littéralement « là où l'on vit, c'est la capitale ", c'est-à-dire : on finit par trouver que le lieu où l'on se trouve par nécessité est le meilleur endroit pour vivre. (N.D.T.) 


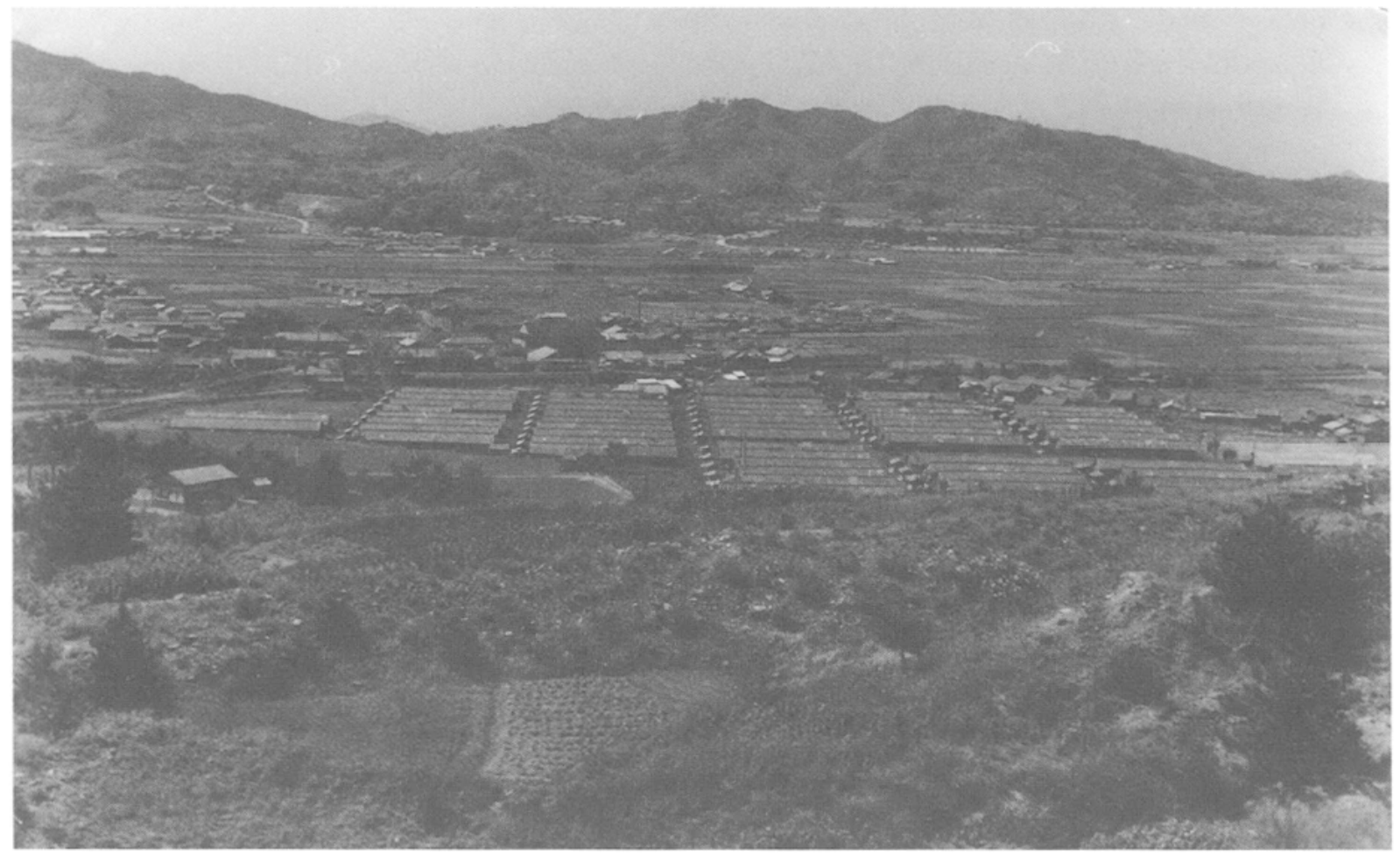

Fig. 6 : Les habitations (« baraquements ») des mineurs à Takata.

(Archives du Centre de documents historiques et de matériaux ethnographiques de Sasaguri)

une porte de service. Des logements de cette taille étaient alignés en rangées de 3 ou 4. À l'extérieur, se trouvaient les toilettes à usage commun.

Il y avait aussi des logements pour les mineurs intérimaires d'autres entreprises. Lorsque ce système fut supprimé, ceux-ci se sont plaints qu'on leur enlevait leur emploi. Les habitants des baraquements, eux, étaient des employés réguliers ; un chef de baraquement gérait l'ensemble. La mine Meiji a aboli en 1906 le système des baraquements. Après la guerre, tous étaient des employés : ceux qui travaillaient dans la mine, ceux qui faisaient le tri du charbon et les employés de bureau. Ceux qui travaillaient à la mine avaient d'abord reçu une formation.

Yamamoto Sakubee 山本作兵衛 (1892-1984) a commencé à travailler à la mine de Kyūshū-Chikuhō à l'âge de 7 ans. À partir de 1952 , il a commencé à tenir un journal qui relate son expérience en l'illustrant de dessins ${ }^{59}$. Il décrit le logement des mineurs vers 1899 . L'habitation mesurait $2,7 \mathrm{~m}$ sur $1,8 \mathrm{~m}$, avec une pièce de $7,29 \mathrm{~m}^{2}$ sans placard. L'entrée-cuisine au sol de terre battue mesurait $90 \mathrm{~cm}$ sur $2,7 \mathrm{~m}$. Il n'y avait qu'une porte-volet à l'entrée, et les fenêtres étaient soit à grilles soit équipées de volets se levant verticalement. Entre chaque logement, il n'y avait qu'un mur

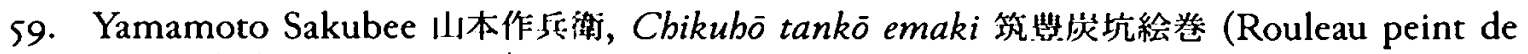
la mine à Chikuhō), 1973, p. 8-1I ("Jūtaku ni tsuite » 住宅について [Sur le logement]), p. 32-34

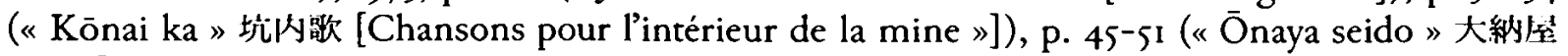
制度 [Sur le système des grands baraquements]). 
de 2,I m, plâtré grossièrement. Un baraquement comportait environ io logements sans plafond. Aussi, lorsque quelqu'un faisait griller du poisson, tout le bâtiment se remplissait-il de la fumée et de l'odeur.

Le système des baraquements cité précédemment, est ici appelé par Yamamoto "système des grands baraquements 》 (önaya seido 大納屋制度). Il avait pour objectif le contrôle des mineurs déplacés d'une mine à une autre. Toutefois, même parmi les mineurs employés directement par l'entreprise, nombreux étaient ceux qui détestaient les surveillants rigides des baraquements, et ce système de contrôle. Le chef du baraquement était appelé nay'a tōryō 納屋頭領 ou naya gashira 納屋頭. Il était aussi responsable des mineurs qu'il avait recrutés et qu'il y avait introduits. Ceux qui avaient une famille bénéficiaient d'un logement appelé " petit baraquement » (ko-naya 小納屋). Les célibataires habitaient dans celui du chef du baraquement, appelé « lieu de repas » (banba 飯場). L'entreprise versait environ 10\% du salaire de chacun d'eux au chef du baraquement. Etre chef nécessitait assez d'autorité, de virilité, de magnanimité et de dignité pour être respecté et influent. Il fallait être quelque peu canaille pour diriger les mineurs d'alors. Sous ses ordres, le chef avait un subalterne, sorte de régisseur appelé kanba 勘場, qui remplissait le rôle de comptable et de secrétaire. Attaché à son chef par des liens de parenté fictive, il pouvait faire n'importe quoi, jusqu'à mourir pour lui. Il était connu pour sa cruauté et sa brutalité. Une chanson satirique des mineurs de l'époque dit ainsi : "Répugnant régisseur, méchant kanba, chef de baraquement sans pitié, gotton, gotton! »

Selon les dires de Mita Kikuo et de Hosokawa Akira :

Les grandes entreprises minières avaient un local communautaire, où les mineurs pouvaient aller jouer au go (igo 囲碁). Mais pendant les jours de congé, les travailleurs préféraient aller à Hakata. Autrefois, il y avait un quartier d'établissements de plaisir (akasen 赤線) ${ }^{60}$, et des baraques de théâtre forain. Au Centre Shinwa 信和会館 (littéralement "Salle de réunion de la confiance et de l'harmonie »), on passait un film une fois par semaine. Tout le monde s'y rendait. Lorsqu'il y avait une projection de film en plein air, cela attirait la foule. Les grandes entreprises géraient aussi un hôpital, une crèche sur chaque site minier, et il y avait des magasins que fréquentaient aussi les habitants de la commune, attirés par les prix peu élevés.

Le salaire variait selon les conditions de travail, à l'intérieur ou à l'extérieur de la mine, ou encore sur les lieux d'extraction ou aux alentours. Il y avait une part fixe et une part variable selon le rendement. Sur les lieux d'extraction, les équipes de mineurs avaient le rendement pour objectif premier. Le salaire fixe concernait le transport et l'assistance. Le salaire du travail d'extraction se composait d'une partie fixe (30\%) et d'une autre partie, dépendant du rendement (70\%).

Le «Centre Shinwa » mentionné ici est lié à l'envers de la mine de Sasaguri, que nous examinerons plus loin. Selon les archives locales ${ }^{61}$, l'entreprise de la mine Meiji avait

6o. Le terme akasen, littéralement $\alpha$ ligne rouge ", désignait l'aire délimitée par un cercle rouge sur le plan de la ville de la police, là où la prostitution privée était tolérée par la police après la guerre. La gouvernement d'occupation (GHQ) a supprimé la prostitution publique, mais la police japonaise a toléré la prostitution privée dans des zones spéciales. Par extension, le terme désigne les quartiers de plaisir dans le Japon moderne.

6I. Sasaguri-chō bunkazai senmon-iinkai, éd., Sasaguri chōshi. Rekishi-ben, p. 8. 


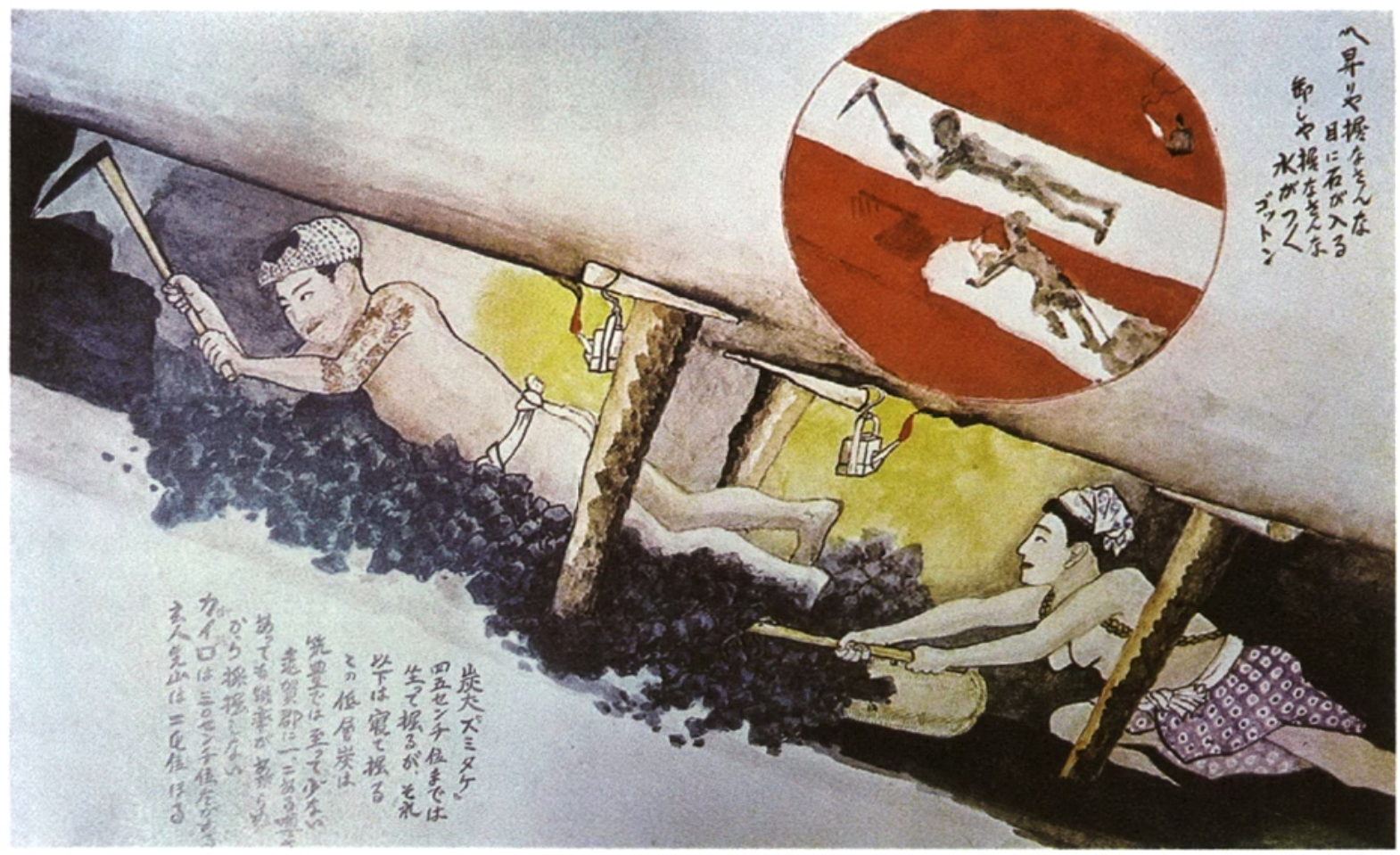

Fig. 7 : Couple de mineurs (Dessin de Yamamoto Sakubee 山本作乓衛, Chikubō tankō emaki 筑豊炭坑絵巻). La collection des quelque 700 dessins de Yamamoto est le premier élément documentaire japonais à avoir été inscrit au registre de la Mémoire.

créé l'Association Shinwa 信和会, dont une branche avait été installée à Takata. Cette association avait pour but, d'une part la médiation entre les travailleurs et le patronat, et d'autre part les échanges amicaux entre tous les employés. Pour cette association fut construit un grand bâtiment nommé le «Centre Shinwa ». Les mineurs pouvaient s'y divertir, s'y cultiver et s'y détendre des tensions de leur vie quotidienne. Bien que les récits précédents aient bien distingué ce Centre du quartier des établissements de plaisir, les deux étaient en réalité gérés par la même organisation.

\section{Le travail et la vie quotidienne des femmes}

Toujours d'après les dires de Mita Kikuo et de Hosokawa Akira :

Les femmes triaient le charbon, car aux plus petits morceaux étaient mêlées de la boue et de la poussière de houille. Après le lavage, le charbon était séparé et expédié comme marchandise. Les morceaux qui flottaient étaient mélangés à du charbon et à de l'argile. Ils étaient séchés et servaient comme combustible pour l'usage domestique des mineurs. Le charbon brûlé et rapidement refroidi se transforme en charbon qui ne dégage pas de fumée, appelé « coke » (garaガラ).

La plupart des travailleuses étaient des épouses et des filles de mineurs. Il y avait aussi des employées qui collectaient dans les logements les boîtes à repas pour les mineurs qui descendaient sur les lieux d'extraction à partir de midi. D'autres employées les leur distribuaient dans la mine. Ils les mangeaient à l'endroit réservé aux employés à l'intérieur la mine. 
Après la guerre, il fut interdit aux femmes de travailler à l'intérieur de la mine, alors qu'elles y avaient jusque-là travaillé avec les hommes. Selon le texte de Yamamoto Sakubee cité précédemment ${ }^{62}$, cet arrêt intervint en 1931. Néanmoins, les femmes continuaient à entrer dans les mines de petite taille. Tous les membres de la famille des mineurs, y compris les femmes, y travaillaient ensemble. Les femmes faisaient généralement équipe avec leurs maris ou leurs frères (fig. 7). Les hommes faisaient l'extraction de la houille à l'avant et, à l'arrière, les femmes transportaient celle-ci jusqu'aux chariots de convoyage. Mais en l'absence d'hommes pour assurer l'extraction, ce sont les femmes qui assuraient celle-ci. En 1946, l'entrée des femmes dans les mines de petite taille fut elle aussi interdite, de même que le système des baraquements (il s'agit là d'un autre système que celui dont il était question auparavant, lequel avait été supprimé en 1906), et que les syndicats ouvriers furent créés.

Les femmes se déshabillaient pour travailler dans les endroits les plus chauds. Mais elles n'ôtaient que leur veste. Leurs habits étaient assez courts, et elles ne portaient pas de sous-vêtements. Elles se couvraient la tête d'un linge essuie-main.

Nombreuses étaient donc les femmes qui travaillaient avec leurs maris mineurs, mais dès la fin du travail, encore noires de suie, elles se mettaient à préparer le repas. Si elles avaient un nourrisson, elles le confiaient à quelqu'un, et il leur arrivait de faire des allers et retours entre la mine et la surface pour aller le nourir au sein. Les enfants commençaient à travailler dans la mine dès l'âge de Io ans, en tant que mineurs de l'arrière. Il y en avait donc beaucoup qui manquaient l'école pendant de longues périodes, ou même qui n'y allaient jamais.

Pour une meilleure compréhension de la vie de ces femmes, nous nous référerons ci-après aux récits faits à Tajima Masami 田嶋雅已, entre 1987 et 1991, par des femmes qui avaient travaillé dans les mines de Matsubara 松原地区 à Tagawa dans le nord de Kyūshū, ville autrefois connue comme l'une des trois cités minières de Chikuhō.

Nōmi Shizuko 能美シズュ (née en 1913) s'exclame : «On me demande souvent, Mémé, après tout, as-tu jamais été vraiment une femme ? Quelle jeunesse as-tu donc eue ? Eh bien, oui, je suis une femme à poigne ! À l'époque, il n'y avait ni assurance, ni protection. Comment faire vivre une famille à une telle époque en faisant la jeune fille! » Alors que son père était malade, à l'âge de 14 ans, elle est descendue dans la mine à la place de sa mère qui, venant d'accoucher, ne pouvait aller travailler. À 17 ans, pour aider ses parents, elle a été vendue et contrainte à travailler comme prostituée.

Inoue Masayo 井上マサヨ (née en 1909) est descendue dans la mine à l'âge de is ans, en tant que mineur de l'arrière. Accablée d'injures par les hommes mineurs de l'avant, elle a travaillé comme un chien dans les profondeurs de la terre. Une fois mariée, elle a continué à y aller avec son mari, mais a arrêté en 1931, à la suite de l'interdiction de l'entrée des femmes dans les mines. En 1942, avec l'intensification de la guerre et l'arrivée massive des Coréens, elle s'est mise à préparer les repas au logement, en alternance 2 fois par jour. Les Coréens, qui n'avaient aucune formation de mineur, étaient forcés de travailler sous une surveillance continuelle. S'ils prenaient la fuite, ils étaient rattrapés, et pour l'exemple ils étaient frappés à tour de bras, et aspergés d'eau. C'était si pénible qu'elle se bouchait les oreilles pour ne plus rien entendre.

62. Yamamoto Sakubee, Cbikubō tankō emaki, p. 22, 28-30 (“Onna kōfu »女坑夫 [Les femmes qui travaillent dans les mines]). 
Kikuchi Uru 菊地ウル (née en 1900) raconte : «Je suis une paysanne d'Ehime; la mine me terrifiait. On dit que les peureux comme moi sont possédés par les âmes de ceux qui sont morts dans la mine. Ça m'est arrivé deux fois. Je n'arrêtais pas de trembler, et n'arrivais pas à manger. » Après son mariage à l'âge de 19 ans, elle est descendue travailler dans la mine avec son mari, et aussi après la naissance de son enfant qu'elle donnait à garder pour so sens 銭 par jour.

Takimoto Yukiko 湆本ユキコ (née en 1927) explique quant à elle : «Autrefois, les femmes qui avaient leurs règles, la “souillure rouge" (aka fujō 赤不浄), n'étaient pas les bienvenues dans la mine, car on disait qu'elles la souillaient et portaient malheur. Pourtant, plus personne ne parla comme ça pendant la guerre, car à l'époque la production du charbon devait augmenter à tout prix. »

Hidaka Emiko 日高エミコ (née en 1925) déclare : «Avec la guerre, tous les hommes disparurent. J'ai donc travaillé comme un homme. Mais à bien y repenser maintenant, c'était horrible. Même si nous avions une grande expérience, que des femmes toutes seules fassent l'extraction de la houille, ça n'était vraiment pas normal. »En 1944, avec l'exclusion des femmes, une fois le charbon extrait sous la direction d'un surveillant, celles-ci creusaient des trous pour y mettre de la dynamite et dégager les veines de charbon, après qu'un homme eut renforcé les supports du plafond pour qu'ils ne s'écroulent pas.

Mori Setsu 森セツ (née en 1910) est descendue dans la mine pour que ses enfants aient de quoi manger, après avoir entendu dire : «Si l'on travaille dans la mine, on bénéficie de riz pour les repas. » Même les grandes exploitations minières, comme Mitsui, ont commencé à embaucher des femmes à partir de 1941-1942. C'est l'insuffisance des rationnements de riz qui les a fait travailler à partir de 1943 .

Une femme anonyme (née en 1923) ajoute : "La mine durant la guerre, c'était une véritable tyrannie. " Elle parle ici des sanctions prises par le patron contre les mineurs. S'ils ne pouvaient pas aller au travail, la direction du personnel les appelait et les faisait mettre à plat ventre pour les frapper. "Les Coréens étaient encore plus mal traités que nous. Ils ne travaillaient que pour manger, sans recevoir aucun salaire. „ $\grave{A}$ cause de ces mauvais traitements infligés dans la mine, un militaire vint d'Ashiya 芦屋. Mais lui-même se révéla également tyrannique. Et lorsqu'elle dit : «Ce fut vraiment un soulagement que le Japon perde la guerre!", ses paroles traduisent bien son état d'esprit.

Hosaka Fumiko 保城つミ子 (née en 1924) est descendue dans la mine après la guerre, entre 1959 et 1965 . Le travail de terrassement en dehors de la mine n'était pas suffisant pour lui permettre de faire vivre ses enfants toute seule. Elle a donc travaillé avec acharnement. Dans les mines des grandes exploitations, comme Mitsui ou Mitsubishi 三菱, la houille n'était pas entièrement extraite à cause du risque d'effondrement des galeries. Elle allait donc extraire en cachette ce qui restait dans ces anciennes galeries. C'était comme un jeu de hasard : s'il restait du charbon, elle gagnait de l'argent ; s'il n'en restait plus, elle ne gagnait rien ${ }^{63}$.

Un grand nombre de ces femmes qui ont œuvré dans les mines étaient venues de l'extérieur. Toutes ont non seulement travaillé à l'arrière pour aider les hommes qui extrayaient le charbon à l'avant, mais elles ont aussi fait l'expérience de tâches extrêmement pénibles pour subvenir aux besoins de la vie quotidienne, soit en faisant

63. Tajima Masami 田嵑雅巳, Tankō-bijin. Yami wo tomosu onna tachi 炭坑美人一一閣を灯 す女たち (Les beautés des mines : les femmes qui illuminent les ténèbres), 2000, p. 4-13 (Nōmi Shizuko 能美シズコ), p. 148-155 (Inoue Masayo 井 ト:マサヨ), p. 204-207 (Kikuchi Uru 㐘池ウル), p. 208-21I (Takimoto Yukiko 滝本ユキコ), p. 220-223 (Hidaka Emiko H占エミコ), p. 224-227 (Mori Setsu 森セツ), p. 228-233 (femme anonyme), p. 234-242 (Hosaka Fumiko 保坂フミ子). 
elles-mêmes ce travail de mineur de l'avant, soit en étant vendues par leurs parents, ou encore en descendant dans la mine pour pouvoir nourrir leurs enfants. Mori Setsu reconnaît que « s'il n'y avait pas eu de mine, [elle] n'aurai[t] pas eu besoin de travailler ainsi au fond de la terre ». À partir de 1942 , avec le départ des hommes pour la guerre, les femmes ont dû aller travailler à leur place dans les mines. Elles ont vu les traitements cruels infligés aux Coréens qui étaient contraints d'y travailler. Aussi, comme le reconnaît cette femme anonyme, la défaite du Japon fut-elle pour elles un soulagement, car cela signifiait l'arrêt de la guerre. Mais même après la guerre, les problèmes matériels les ont obligées à travailler au noir et à pratiquer l'extraction illégale du charbon. Pour elles, les paroles de mineurs comme Mita et Hosokawa, qui finissaient par aimer la vie dans les mines, sont vides de sens. Pour la plupart d'entre elles, le travail dans les mines, comme celle de Takata à Sasaguri, ne fut qu'un moment de leur vie de femme. Néanmoins, on voit par là que ces femmes, tout en assurant de l'intérieur la vie de la famille, entretenaient de forts liens avec l'extérieur sur le plan économique.

Le travail de la mine étant effectué majoritairement par les hommes, on peut considérer que ces derniers constituaient le centre et le dedans de ce cadre. Par rapport à eux, les femmes, qui venaient de l'extérieur de ce monde masculin et travaillaient à l'arrière, étaient donc une existence marginale. Pourtant, en l'absence des hommes enrôlés dans l'armée pendant la seconde guerre mondiale, ce sont les femmes qui durent jouer ce rôle du dedans en assurant le gros des travaux miniers. Quant aux étrangers, amenés de force de Chine et de Corée pour y travailler sous la contrainte, ils se situaient au-dehors du debors.

\section{L'envers des mines de Sasaguri}

Mita Kikuo et Hosokawa Akira ont présenté le Centre Shinwa des mines de Sasaguri comme un lieu culturel distinct du quartier des établissements de plaisir. Pourtant des archives montrent que ces deux espaces étaient en réalité séparés sans l'être, et constituaient tous deux l'envers de cet univers des mines.

Fujita Kototome 藤田少女姫 (1938-1994), spécialiste de la divination fort renommée, qui a souvent fait son apparition à la télévision, a habité durant un certain temps dans le quartier des établissements de plaisir à côté du Centre Shinwa de Sasaguri. Son frère Fujita Yōzō 藤田洋三 (né en 1943) a raconté cette partie de la vie de sa sœur dans une série d'articles parus dans la revue Jiyū 自由 $^{64}$. Au début du premier article, l'auteur explique que son intention est de rechercher les causes de la mort de Kototome : «En février 1995, après une vie mouvementée, Kototome, spécialiste de la divination, a été tuée sauvagement à Hawaï. Les causes véritables de sa mort

64. Fujita Yōzō 藤田洋三, «Fujita Kototome no sei to shi » 藤田少女姫の生と死 (Vie et mort de Fujita Kototome), Jiyū 2003, qui ont été envoyés par l'auteur au Centre de documents historiques ct de matćriaux ethnographiques (Rekishi minzoku shiryō-shitsu 歴史民俗資料公) de Sasaguri. Ces articles ont été réunis dans la publication : Fujita Yōzō 藤田洋三, Tōako to Yōzō. Fujita Kototome no shinjitsu 東亜 子と洋三一一藤田小女姫の其実 (Tōako et Yōzō : la vérité sur Fujita Kototome), 2004. 
n'ont pas encore été découvertes ${ }^{65}$ \%. Laissant de côté l'histoire de ce meurtre, nous suivrons le récit de la vie de Fujita Kototome qui donne un bon aperçu de la situation du quartier de plaisir à Sasaguri dans lequel elle habitait.

Le cadre de vie de Fujita Kototome. - Kototome, de son vrai nom Fujita Tōako 藤田東 亜子, est née en 1937 à Nagasaki, dans une maison de prostitution ${ }^{66}$. Elle est la fille aînée d'un lunetier (86 ans), habitant de la commune d'Ōi 大井町 du département de Fukuoka. L'auteur de cette série d'articles, Yōzō, est son cadet. Elle a été inscrite dans le registre d'état civil en tant que fille aînée de Fujita Tsunekichi 藤田常吉 (fils de Fujita Genza.emon 藤田源左衛門 et de sa femme Riha リ八) et de sa première femme Hisae 久枝, et Yōzō, en tant que fils de Tsunekichi et de sa deuxième femme Kikue キクエ ${ }^{67}$.

Kototome (Tōako) et Yōzō sont nés dans un milieu familial complexe, et ont été élevés par des parents adoptifs avec lesquels ils entretenaient également des relations complexes. Cette complexité tient au système de la vente des femmes dans lequel ils étaient pris. En effet, ceux qui vivaient dans et autour des maisons de prostitution n'avaient pas de liens parents-enfants fondés sur la consanguinité, mais établissaient des liens fictifs de parents et enfants, dits « selon l'état civil » ou "d'adoption »: lorsque les enfants avaient grandi, ces gens les vendaient dans ces mêmes maisons. C'est là l'histoire d'une maison de prostitution, appelée Club de la mine Meiji (Meiji kōgyō kurabu 明治鉱業俱楽部) de Sasaguri, qui était gérée par Kikuhara Ishi 菊原イシ, la mère de Kikue, elle-même mère de Yōzō selon l'état civil.

Yōzō et l'association des anciens élèves. - Après 45 ans d'absence, Yōzō prit part à la réunion annuelle de l'association des anciens élèves de première année de l'école primaire communale de Sasaguri à Seto 勢門小学校. Le professeur Fuji 藤先生, responsable de cette classe, s'y trouvait aussi. Tous les autres participants (Morinaka 㷊中, Arayama 荒山, Nogaku 野角, Hirashima 平島, Okayama 岡山), qui étaient des enfants des employés de la mine Meiji, savaient que Yōzō n'était pas le vrai fils de Kikue. C'est à cette occasion qu'il apprit que Kikuhara Ishi, mère de Kikue et ancienne gérante du Club de la mine Meiji, vivait à Sasaguri. Il lui rendit alors visite. Elle avait 96 ans $^{68}$.

C'est ici que s'est noué le lien de Sasaguri et des enfants Fujita, par l'intermédiaire de l' « établissement récréatif » qu'était le Club de la mine Meiji-Takata. On note que les camarades de Yōzō, habitants de Sasaguri, connaissaient mieux que lui-même ses vraies origines et le fait que ce club était un lieu spécial.

L'Association Shinwa. - Les mines Meiji fondèrent en 1919 l'Association Shinwa 信和会 pour la détente des mineurs. La mine de Takata confia l'administration de l'établissement où elle fut installée à des " gens des bords de rivière " (kawasuji mono 川筋もの) ${ }^{69}$. Le service administratif qui en était chargé était la section des affaires générales de l'entreprise, là où travaillait Tsunekichi, père de Yōzō. En 194I, Tsunekichi vint à Sasaguri. Son but était de recruter des mineurs pour ouvrir une nouvelle mine, mais aussi de préparer l'ouverture d'un centre de femmes de réconfort (ianjo 想安所) ${ }^{70}$, dit « lieu récréatif »

65. Fujita Yōzō, Jiyū, juin 2002, p. 136.

66. Le prénom Tōako (littéralement « fille de l'Asie orientale ») est caractéristique de cette époque, où prévalait l'idéologie selon laquelle le Japon étendait sa domination sur la « Sphère de coprospérité de la grande Asie orientale 》 (Dai-Tōa kyōei-ken 大東亜共栄圈). (N.D.T.)

67. Fujita Yōzō, Jiyū, juin 2002, p. 136-148.

68. Fujita Yōzō, Jiyū, juin 2002, p. $145^{-148 .}$

69. Nom utilisé pour désigner les malfrats dans cette région. (N.D.T.)

70. Appellation des lieux de prostitution à cette époque. (N.D.T.) 
(boyōsho 保陮), dans le cadre des œuvres sociales effectuées par l'Association Shinwa. Après le recrutement des femmes qui devaient y travailler, la mine Meiji confia la gestion de cet endroit à l'Association Shinwa, qui elle-même la transféra aux yakuza locaux. Ceux-ci déléguèrent cette gestion à Kikuhara Ishi, la femme de leur patron. C'est ainsi que la maison d'Ishi fut louée comme lieu récréatif réservé à la mine Meiji. Ishi débuta son affaire en réunissant des femmes qu'elle connaissait. En 1943, une nouvelle mine fut ouverte à Sasaguri. Mais à cause de l'absence des mineurs japonais mobilisés par l'armée, il y avait alors Io travailleurs coréens ou chinois pour un Japonais. Aussi la maison étaitelle très peu fréquentée. Après la guerre, les femmes qui en étaient parties pratiquèrent la prostitution à Kokura avec les soldats américains. Mais dès qu'elles surent que le Club de la mine Meiji était ouvert, elles revinrent à Sasaguri ${ }^{71}$.

La guerre et l'après-guerre. - En 1945, Hisae et Tōako gagnèrent Tōkyō. Après son entrée à l'école nationale Koiwa 小岩国民学校, Tōako fut conduite par un intermédiaire de la prostitution, appelé " gentil monsieur ", au lac Tazawa 田沢湖 d'Akita 秋田 d'où il était originaire. C'est là que Tōako devait être formée pour devenir geisha. Mais à la fín de la guerre, la vente des femmes ayant été interdite, Tōako aurait dû être libérée. Or à cette époque, il existait un grand nombre de petites filles comme elle dans l'entourage de "gentilles dames " du quartier chaud de Yoshiwara 吉原 à Tōkyō. Elles avaient été kidnappées, adoptées, ou étaient nées dans une maison de prostitution ; elles étaient ainsi dépourvues d'état civil et n'avaient nulle part où aller. Un grand nombre d'entre elles, comme Tōako, furent donc livrées à la prostitution, notamment à Tone 利根 (département Gunma 群馬県) ${ }^{72}$.

Naissance de la spécialiste de la divination Fujita Kototome. - Tōako prit d'abord le nom de Fujita Kotodo-hime 滕田小乙姫; elle devint spécialiste de la divination et fonda une nouvelle religion dite " enseignement Kotodo-hime " 小乙姫教. Elle passait sa vie à voyager avec un groupe de femmes qui, pour vivre, pratiquaient la divination et aussi la prostitution ${ }^{73}$. La mine Meiji et la prostitution. - En 1949, Tsunekichi fut muté à la mine de Takata à Sasaguri. Il transforma alors le lieu récréatif peu fréquenté en un club privé de cette entreprise où se pratiquait la prostitution. À la différence de la petite maison gérée par Kikuhara Ishi avant guerre, le bâtiment fut agrandi et transféré à côté de l'cnccintc d'un sanctuaire, éloigné des maisons particulières. Il comportait 16 pièces de $17 \mathrm{~m}^{2}$ et était entouré d'une véranda. L'Association Shinwa en était propriétaire, mais sa gestion était assurée par la section des affaires générales de la mine, et la direction en était confiée à Ishi. Ishi hébergeait chez elle les femmes qui allaient travailler au club, situé à 300 mètres de là. En 1950, Yōzō entra à l'école primaire communale de Seto à Sasaguri. Il habitait au "logement minier» (tanjū 炭住), appelé par ceux qui y résidaient « logement pour les employés»(shataku 社宅). Les résidents étaient tous des gens venant de l'extérieur de Sasaguri ${ }^{74}$.

Le Club de la mine Meiji et les femmes. - Vers 1952, il n'y avait là que des logements pour les employés de la mine Meiji. À cette époque, les films ayant pour sujet la mère et la maternité étaient à la mode et passaient souvent au Centre Shinwa. Au cours de l'hiver 1954, Fujita Kototome, devenue célèbre, arriva à Sasaguri. Aussitôt, un message fut diffusé dans toute la mine Takata par haut-parleur : « Fujita Kototome est ici, rassemblement chez Fujita Tsunekichi. »Vinrent alors tous les hommes et une partie des femmes employés à la section des affaires générales, des femmes de la section du tri de charbon, ainsi que les femmes qui habitaient chez Ishi et travaillaient au club, lesquelles arrivèrent avec leurs

71. Fujita Yōzō, Jiyū, juillet 2002, p. 149-1૬ı.

72. Fujita Yōzō, Jiyū, août 2002, p. 131-140; septembre 2002, p. 144-145.

73. Fujita Yōzō, Jiyū, octobre 2002, p. 135-137; novembre 2002, p. 141-143.

74. Fujita Yōzō, Jiyū, novembre 2002, p. 143-150. 
enfants. Après la prise d'une photo souvenir, les femmes se rendirent au club pour écouter les récits de Tōako, qui fut ainsi mise à contribution pour le recrutement de femmes. Les femmes du club savaient bien ce qu'elles devraient faire à la capitale, tandis que les employées du tri de charbon et leurs amies crurent qu'il s'agissait d'emplois de femmes de ménage ; certaines d'entre elles partirent ainsi pour Tōkyō, pensant que là-bas elles auraient une vie comme Tōako. Bref, à Sasaguri, Tōako servit de publicité pour recruter les prostituées. En septembre 1955, Tsunekichi, Kikue, Yōzō et ses demi-sœurs quittèrent leur logement de Sasaguri pour aller à Tōkyō ${ }^{75}$.

Fujita Kototome et son père adoptif Tsunekichi eurent une vie hors norme, et dont une partie se déroula à Sasaguri. Les habitants de ce qui était appelé les " logements miniers », qui avaient été jadis placés sous le système des baraquements, étaient tous originaires de l'extérieur de Sasaguri et étaient venus là pour travailler. Le «club » fut créé pour leur détente, comme une mesure conciliatoire. De petites filles kidnappées ou nées dans une maison de prostitution y étaient élevées pour ensuite s'y prostituer. Ce cas concret permet de faire apparaître comment un tel système, une fois mis en place par une entreprise, était géré sans que les employés de celle-ci aient à s'y salir les mains. Parmi les gens de la mine, il y en avait donc qui n'étaient ni des mineurs, ni des femmes travaillant avec eux pour les soutenir, à l'arrière dans les galeries et au foyer. Ces gens-là n'apparaissaient jamais sur le devant de la scène, mais soutenaient également les travailleurs. Personne n'en parlait ouvertement, mais tout le monde connaissait leur existence, comme l'évoque Yōzō lorsqu'il parle de son enfance, alors que lui-même n'en savait rien. Tōako, sœur aînée de Yōzō, tout en étant mise à contribution par les gens de ce monde de l'ubac, a vécu dans le monde extérieur sous le nom de Fujita Kototome, en tant que célèbre spécialiste de la divination. Mais pour les gens de Sasaguri, elle n'était que l'une de ces prostituées venues de l'extérieur, vivant au-dehors sans jamais s'intégrer à la vie locale, et, à ce titre, elle était doublement quelqu'un du debors.

Par le biais de la parole de toutes ces femmes, nous avons appréhendé ce que celles-ci pensent du site religieux de Sasaguri et ce qu'elles y font : les unes sont venues de l'extérieur dans le cadre du nouveau pèlerinage de Shikoku à Sasaguri soit pour pratiquer l'ascèse, soit pour s'y marier ; d'autres y sont nées de mères venues d'ailleurs. Les femmes des mines nous ont ainsi donné un aperçu de ce que fut localement l'intrication des mesures internes et externes de la modernisation à partir de la deuxième moitié du XIX $x^{e}$ siècle.

Le pèlerinage de Sasaguri fut ouvert en 1835 , juste avant la modernisation japonaise, qui fut entreprise par Jinin, nonne venue du dehors. Avec la législation religieuse autoritaire du gouvernement de Meiji qui cherchait à faire du shintō une religion d'État, il connut une situation critique dont il put sortir grâce à un homme du dehors, Hayashi Kaku.un, venu du mont Kōya en I899. Kaku.un, premier supérieur

75. Fujita Yōzō, Jiyū, décembre 2002, p. 145-146; janvier 2003, p. 139-145; février 2003 , p. $157-165$. 
du Nanzō-in à Sasaguri, ouvrit le temple à tout le monde et se tourna plus particulièrement vers les travailleurs de la mine et les entraîneuses. Grâce à leur talent oratoire et administratif, tous les supérieurs de ce temple ont su se distinguer et se faire accepter par la société locale du nord de Kyūshū. Et tout au long de leur activité de prédication à l'extérieur, dans un mouvement de retour vers l'intérieur, ils ont su attirer les pèlerins vers le circuit de pèlerinage.

Facile d'accès, Sasaguri est un lieu de pèlerinage commode pour les habitants du nord du Kyūshū. Les cascades en constituent des pôles religieux d'attraction, non seulement pour tous ceux qui pratiquent, mais aussi pour les pèlerins des étapes du pèlerinage, ou encore pour les fidèles de tous les autres espaces religieux comme les temples surnuméraires. Les religieux ayant des pouvoirs non ordinaires, comme Shōzaki Ryōsei, Shichijō Kinue et ses parents ou Yamamoto Seien, font partie de ceux qui, venus du dehors, n'ont cessé de travailler au-dedans et ont ainsi contribué à affermir le rayonnement de Sasaguri comme champ d'attraction religieux. Par ailleurs, leurs déplacements avec leurs fidèles vers d'autres lieux saints extérieurs, tels que le mont Raizan dans Fukuoka ou le mont Ishizuchi à Shikoku, font émerger à la fois les caractéristiques religieuses de Sasaguri et les liens que les gens de cette localité entretiennent avec le debors.

L'installation du Renshō-ji, temple Nichiren, à l'emplacement d'un établissement de quarantaine pour les lépreux, au cœur même de ce monde sous obédience Shingon, témoigne de l'action produite par un lieu tel que Sasaguri sur les différents courants religieux. En raison des modalités agressives de l'activité de son fondateur Nichiren, cette école bouddhique a tendance à recourir à une propagation combative, à des pratiques extrêmes ainsi qu'à l'intimidation d'autrui. Dans le même temps, elle n'a cessé de soutenir les hôpitaux et les dispensaires pour les lépreux. Les supérieurs du Rcnshō-ji n'ont pas craint la marginalité du lieu où ils s'étaient implantés. Mais ils n'ont pas dérogé à la règle de la pratique extrême, et l'activité de reidan-shi que déploie, pour vivre, Taeko, épouse du supérieur de ce temple, la rapproche des autres spécialistes religieux reconnus comme ayant des pouvoirs. La force d'attraction du pèlerinage de Sasaguri est sans doute ce qui permet de dépasser les frontières et les clivages existant entre les différentes branches religieuses.

Quant au cas de Yasukōchi Junko qui, originaire de Wakasugi, est partie à la recherche d'un lien religieux extérieur, sans s'arrêter à ceux offerts par Sasaguri, il montre que ce sont les pouvoirs de certains religieux qui agissent ici comme force d'attraction vers le debors. Ceci ne va pas sans générer certains conflits personnels dans les rapports avec le dedans. Mais les lieux où Junko se rend à l'extérieur sont aussi des pôles attractifs liés au shugendō qui s'inscrivent dans le cadre plus large des pratiques dans les montagnes. Ainsi, quoiqu'apparemment elle semble faire des va-et-vient qui la mènent au-delà des limites des lieux saints de Sasaguri, extériorité et intériorité fusionnent ici en réalité, par le fondement religieux commun que partagent tous ces lieux.

L'époque de la Restauration de Meiji fut celle de l'ouverture à ce nouveau dehors que constituaient les pays étrangers. La défaite de la Chine voisine, face à l'Angleterre dans la guerre de l'Opium, qui par là avait dû céder une partie de son territoire aux puissances étrangères, suscita une prise de conscience de ce qu'était l'intérieur de 
la Nation et conduisit l'État à renforcer la défense nationale. C'est dans le cadre de mesures de renforcement énergétique que les mines de charbon du nord de Kyūshū furent choisies comme lieu d'exploitation des mines nationales et de construction d'usines sidérurgiques. Ce fut une période de grande prospérité et d'innovation technique, que relatent avec fierté des employés des mines comme Mita Kikuo et Hosokawa Akira, lesquels travaillèrent longtemps à la mine de Takata à Sasaguri. Mais parallèlement à cette élite de travailleurs qui en retiraient de la fierté à une certaine époque, il en existait d'autres, venus du dehors, qui se trouvaient au plus bas de l'échelle dans ces exploitations minières : il s'agissait des grands criminels qui purgeaient leur peine en travaillant dans les mines nationales et gouvernementales, ou des prisonniers de courte durée qui devaient ouvrer dans les mines de petite et moyenne envergure. Par la suite, l'industrie minière se développa au point de devenir l'un des pôles majeurs de l'industrie énergique japonaise, et ce travail, qui était dur, était aussi bien payé. Néanmoins, des femmes se trouvèrent contraintes de le choisir. Pour assister les pères, les maris et les frères qui extrayaient la houille à l'avant, les filles, les femmes et les sœurs en assuraient le transport à l'arrière, tout en continuant à assumer l'ensemble des tâches domestiques. Certaines durent également travailler à l'avant comme les hommes. Quant à ceux qui avaient été amenés de Corée pour travailler au fond des mines, ils subirent les pires traitements. Enfin, il y avait aussi ces femmes qui travaillaient comme prostituées dans le « centre de réconfort » mis en place par les entreprises pour permettre à leurs mineurs de se détendre. La vie de Fujita Kototome (Tōako) racontée par son frère Fujita Yōzō fait partie de l'histoire de cet envers ou ubac de Sasaguri, qui avec celle des mines, a disparu de l'autre côté du temps. Toutes ces narrations sont autant de témoignages de la vie de ces gens qui ne cessèrent de traverser, du debors vers le dedans, et du dedans vers le debors, ce champ d'attraction qu'est Sasaguri.

Pour répondre à notre questionnement central sur la position qu'occupent les femmes par rapport au dedans et au dehors de la vie locale de Sasaguri, dans les relations qu'elles entretiennent avec le religieux et le profane, nous avons tenté de faire apparaître ce qui différencie les personnes venues de l'extérieur de Sasaguri et devenues des gens de l'intérieur ; celles qui, nées au-dedans, sont parties vivre audehors ; les gens du dedans qui, temporairement, sortent au-dehors avant de revenir au-dedans ; enfin, les gens de l'extérieur qui ne font que passer par Sasaguri pour repartir à l'extérieur. On a ainsi pu voir que, dans ce périmètre dont les temples et les oratoires du pèlerinage de ce nouveau Shikoku local constituent le centre, il existe différentes dimensions du sacré et du profane faisant s'entrecroiser intériorité et extériorité. Nos exemples ont été pris en tenant compte du double contexte de Sasaguri : lieu saint du circuit de pèlerinage, et type même du centre industriel moderne avec ses exploitations minières.

Dans un tel environnement religieux, c'est en gagnant la confiance des fidèles et des pèlerins, par l'entremise qu'ils assurent entre eux et les entités cultuelles, que les supérieurs en viennent à occuper une position sacrée de premier plan. Ils ne sauraient néanmoins assurer leurs activités religicuscs sans lc soutien de leurs épouses, qui, toutes laïques qu'elles soient, vivent quant à elles au fond du sacré. Face à eux, il existe aussi celles (et ceux) qui cumulent, d'un côté, la fonction religieuse 
de premier plan de supérieur du temple et, de l'autre côté, au fond du sacré, celle de spécialiste doté de pouvoirs, amené à soulager par ses conseils et ses rituels les afflictions des consultants.

Les quatre générations de femmes des supérieurs du Nanzō-in, temple central du pèlerinage, qui sont toutes venues de l'extérieur de Sasaguri pour épouser le supérieur, constituent le paradigme même du premier cas. Ces épouses, «personnes du fond " $(o k u-s a n)$, dans leur position séculière et cachée, n'ont cessé d'être le support interne de leur époux agissant au premier plan du religieux. Toutefois, les épouses des deux dernières générations different des deux premières, en ce qu'elles assurent non seulement ce rôle de support interne de leur époux, mais apparaissent aussi au premier plan des affaires séculières du temple, dont elles sont la " figure ».

Shōzaki Ryōsei, qui a acquis la position de supérieure du Dainichi-ji, fudasbo du pèlerinage, par l'intermédiaire du Nanzō-in, est emblématique du second cas. Venue du dehors, elle est devenue une personnalité du dedans de Sasaguri. Mais contrairement aux épouses du Nanzō-in, c'est elle qui assure le rôle sacré de premier plan. Elle attire en outre les fidèles par ses pouvoirs charismatiques et, en cela, se différencie des supérieurs du Nanzō-in en se situant aussi au fond du religieux. Occupant à ce titre une position interne à Sasaguri, elle cumule les fonctions de premier plan et de fond du religieux à l'intérieur de ce dedans.

Quant à Shichijō Kinue, née à Sasaguri comme fille du supérieur du Chizuru-ji, puis devenue épouse de son successeur, elle soutient ce dernier, à l'instar des femmes du Nanzō-in, en occupant une position profane à l'intérieur du religieux. Mais elle s'est aussi engagée dans un parcours religieux à la suite de ses parents, dont l'un, son père, était réputé pour la puissance de ses pouvoirs acquis par l'ascèse, et l'autre, sa mère, devint charismatique après la mort de son mari qu'elle remplaça à la tête du temple. C'est ce modèle et la volonté de l'imiter qui l'a conduite à pratiquer sur le long terme l'ascèse de la cascade. Consultée aujourd'hui pour ses conseils, elle cumule, au-dedans, une double fonction sacrée et profane.

Les femmes des temples surnuméraires (bangai) se trouvent institutionnellement à l'extérieur du circuit de pèlerinage de Sasaguri. Certaines, comme Yamamoto Seien, supérieure du Jimyōhō-in, en tant que personne originaire de la ville de Fukuoka, est quelqu'un de l'extérieur qui a fondé son temple à Sasaguri. Mais elle a en même temps le titre de supérieure du temple, reconnue par le Daikaku-ji de Kyōto, et, par là, elle occupe une position religieuse de premier plan. En outre, par ses pouvoirs charismatiques, elle s'inscrit dans le fond du sacré. C'est son époux qui dès le début de son parcours, a assuré le rôle de soutien pour son travail de supérieure et de spécialiste charismatique. Ici, les positions sont inversées. C'est l'époux qui occupe la position du dedans et la femme, la fonction de spécialiste religieux qui se tient à la fois au premier plan et au fond du religieux, en tant que supérieure et charismatique.

Par ailleurs, le cas de Takeuchi Taeko représente une position d'extériorité : en tant qu'épouse du supérieur du Renshō-ji, cet homme du dehors qui fonda ce temple Nichiren au beau milieu de ce périmètre du pèlerinage sous obédience Shingon, dont il n'est même pas une étape surnuméraire, Taeko occupe une position profane et interne au fond du religieux, d'où elle assure le soutien de son mari. Mais s'étant 
ensuite engagée, pour des raisons pécuniaires, dans le système proposé par le bouddhisme Nichiren pour acquérir le titre de conseiller spirituel (reidan-shi), elle a fini par déployer des compétences quasi charismatiques qui l'ont fait connaître. Aussi se situe-t-elle entre le sacré et le profane, dans une position qui, d'extérieure, est devenue aujourd'hui intérieure par rapport à ceux qui viennent la consulter à Sasaguri.

D'autre part, les femmes quittant le dedans de Sasaguri pour aller chercher le religieux au-debors sont ici doublement représentées : d'abord par Yasukōchi Junko, femme lä̈que du dedans, dont une femme charismatique est devenue le soutien intérieur et l'a conduite vers des lieux saints extérieurs à Sasaguri, où elle a finalement reçu l'ordination bouddhique ; et ensuite par ces femmes de Wada, de Wakasugi et plus largement de toute cette région nord de Kyūshū, réunies dans des associations traditionnelles de compagnes pour le pèlerinage au sanctuaire d'Ise (sangū dógyō). Tout en remplissant une fonction ludique, la démarche collective de ces dernières permettait d'associer pèlerinage religieux et «tour du pays » formateur qui, à une certaine époque, pouvait durer jusqu'à deux semaines. Dans les deux cas, le religieux du dehors a constitué pour ces femmes le moyen de sortir du séculier du dedans.

Enfin, le dernier cas de figure est entièrement séculier : il est représenté par les femmes travaillant à l'intérieur et à l'arrière-plan des mines. Celles qui extrayaient le charbon au fond des galeries étaient dans une position d'extériorité par rapport hommes accomplissant la même tâche, mais occupaient une place intérieure centrale dans leurs foyers, où elles assuraient le déroulement de la vie quotidienne pour leurs maris et leurs familles. Quant aux prostituées, amenées sur place depuis l'extérieur pour le délassement des mineurs, elles n'avaient aucune visibilité ; c'étaient des femmes « au-dehors du dehors », qui se tenaient à l'ubac du séculier.

Ce panorama permet d'apercevoir le très large éventail des extériorités et intériorités sociales qui, autour de l'axe religieux-séculier, forment des catégories mouvantes, s'entrecroisant chez une même personne ou un même groupe selon le moment, le lieu de l'observation, le type d'action et le moment de la vie envisagés. 


\section{Bibliographie}

Bouchy, Anne

2001 "Du bon usage de la malemort : traitement des "âmes rancuneuses" et rituels oraculaires dans la société japonaise », dans Brigitte Baptandier (sous la dir.), De la malemort en quelques pays d'Asie, Paris, éditions Karthala, p. $20 \mathrm{I}-234$.

KōNo Nobuko 测野信 $\zeta^{*}$ et al., éd.

1995-2001 Onna to otoko no jikū. Nibon joseisbi saiko 女と桨の時空——月术女性史 再考 (L'espace-temps des femmes et des hommes. Repenser l'histoire des femmes au Japon), I3 vol., Tōkyō, Fujiwara shoten 滕原草外。

KuRA.ISHI Atsuko 伶们あつ\}.

2009 Josei minzoku shiron 女性线俗試論 (Essai d'ethnologie des femmes), Tōkyō, Iwata shoin 光时背院.

LEuPP, Gary P. ゲイリー・P・ループ

1994 «I543 nen kara I868 nen no Nihon ni okeru ijinshukan kankei ni tsuite » ・立四:年加らー八分八年のH本における異人䅦間関係について (Les relations inter-raciales au Japon entre I543 et I868), dans Wakita Haruko 脇H 春子· et S. B. Hanley S・B・ハンレー, éd., Jendā no Nibon shi, jō. Sbükyō

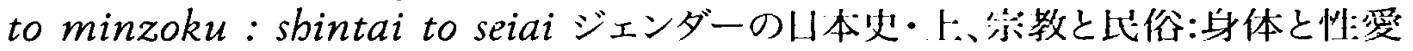
(Histoire du genre au Japon, vol. I, Religion et fait coutumier : corps et

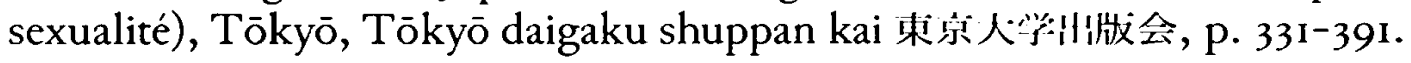

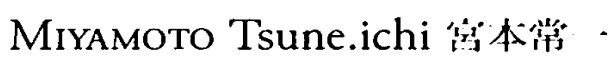

2001 Onna no minzokusbi 女の民俗誌 (Ethnographie des femmes), Tōkyō, Iwanami shoten 若波㥜店。

MORIKURI Shigekazu 森慗茂.

1994 «Baibaishun rōdōsha no hassei. Amakusa mono no furusato kara 》 売賀 央第働者の発生:——菅者のふるさとから (L'émergence des travailleurs de la prostitution : du pays d'Amakusa), dans Wakita Haruko 脇田晴子 et S. B. Hanley S・B・ハンレー, éd., Jendā no Nibon shi, jō. Shükyō to minzoku : shintai to seiai ジェンダーの日本史・上、宗教と氏俗:身体と怆曼 (Histoire du genre au Japon, vol. I, Religion et fait coutumier : corps et sexualité), Tōkyō, Tōkyō daigaku shuppan kai 東宗人学出版会, p. 493-521.

Wakita Haruko 脇四晴了' et S. B. Hanley, éd.

1994-1995 Jendā no Nibon shi, jō. Shūkyō to minzoku : sbintai to seiai ジェンダーの日] 本史 (Histoire du genre au Japon), 2 vol., Tōkyō, Tōkyō daigaku shuppan kai 東家人学计版会. 
Monographies, historiographies locales et documents

Fujita Yōzō 滕四洋: :

2002-2003 «Fujita Kototome no sei to shi » 藤H少姑姑の尘と死 (Vie et mort de Fujita Kototome), Jiyū 自由, juin 2002-juillet 2003, Tökyō, Jiyū-sha 自由社.

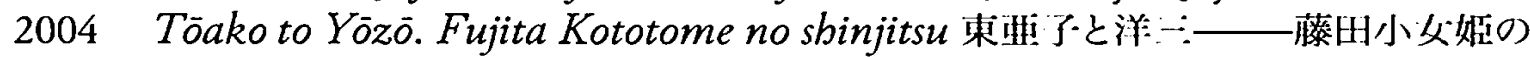
悬実 (Tōako et Yōzō : la vérité sur Fujita Kototome), Tōkyō, Shuppanken iti版硎.

KaWAzoe Shōji 川添榻: : et al., éd.

1997 Fukuoka ken no rekishi 福岡県の歴史 (Histoire du département de Fukuoka), Tōkyō, Yamakawa shuppansha 山川出版社.

Kumamoto daigaku bungaku-bu chiikikagaku-ka minzoku kenkyūshitsu 熊本大学: 文学部地域科学科上俗研究空, éd.

1988 Sasaguri Sbikoku Hacbijü bakkasho. Reijö to fudasho no genzai 篠案四国八 十八力䜣——篦埸と札所の現在: (Les 88 lieux saints de nouveau Shikoku de Sasaguri : la situation actuelle des lieux saints et des stations de pèlerinage), Kumamoto 熊本, Kumamoto daigaku bungakubu Sasaguri kenkyū-kai 熊本大学文学部策案研究会.

Nishi Nihon bunka kyōkai 西日本文化協会, éd.

1984 Fukuokaken-shi. Minzoku sbiryō ben: mura no seikatsu, jō 福岡県史——E俗 資料編: ムラの牛活・上 (Histoire du département de Fukuoka. Documents relatifs aux faits coutumiers : la vie du village, volume r), Fukuoka, Nishi Nihon bunka kyōkai.

Sasaguri-chō bunkazai senmon-iinkai 篠染町文化剘等忺委是会, éd.

1982 Sasaguri chōshi. Rekisbi-ben 篠坚町誌:歴义編 (Historiographie de Sasaguri. Histoire), Sasaguri, Sasaguri-chō yakuba 啋紧町役埸.

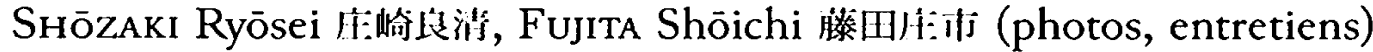

1993 Omikuji. Shinbutsu no utsuwa to narite おみくじ——神仏の器となりて (Les oracles : en devenant le réceptacle des dieux et des bouddhas), Koshigaya

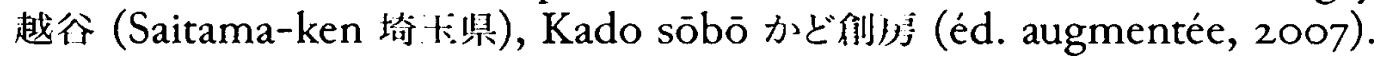

TAJiMa Masami 田鸠雅し

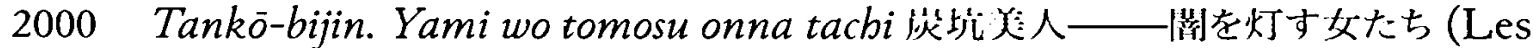
beautés des mines : les femmes qui illuminent les ténèbres), Tōkyō, Tsukiji shokan 築地皆館.

YAMAMOTO Sakubee ॥本作兵衛

1973 Chikubō tankō emaki 筑贯器坑絵巻 (Rouleau peint de la mine à Chikuhō),

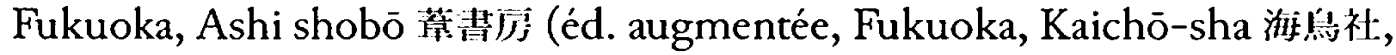
2OII).

YокотA Toyoji 横击量次

1982 Zange no Kuwa. Hayashi Shinkō-ni den 傤恬O)鍬——林真光尼伝 (La houe de repentance : biographie de la nonne Hayashi Shinkō), Fukuoka, Ashi

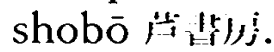


Yomiuri shinbun-sha 讜告新䦌社, éd.

1986 Kyūsbū Sasaguri reijō no tabi. Kōbō daisbi no sekai 九州·策慗需場の旅一 弘法 大師の世界 (Kyūshū. Voyage aux lieux saints de Sasaguri : le monde du Grand Maître Kōbō), Tōkyō, Yomiuri shinbun-sha. 


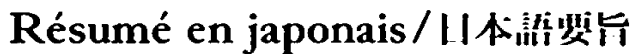

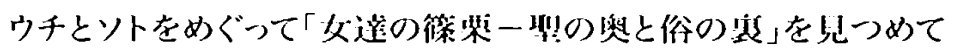

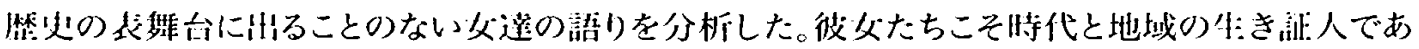
り、文期録には光えてこない佁瓜を文えている。

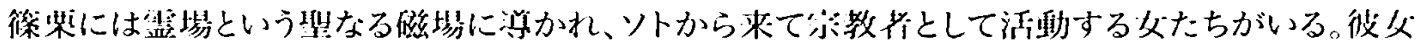

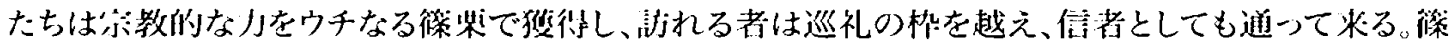

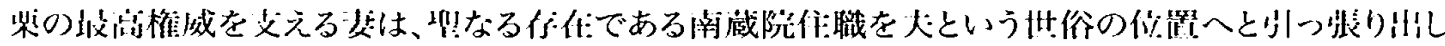

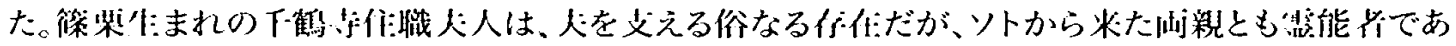

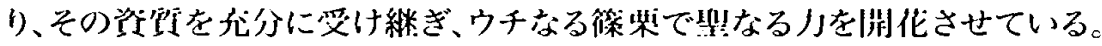

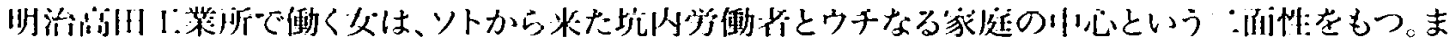

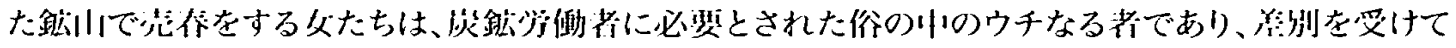
きたソトのソトの存隹でもあった。

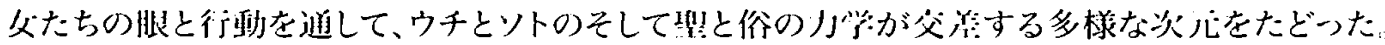

